LUIZ FLÁVIO CORDEIRO FERNANDES

\title{
Caracterização morfológica da endometriose
}

\section{ovariana}

Tese apresentada à Faculdade de Medicina da Universidade de São Paulo para a obtenção do título de Doutor em Ciências

Programa de Obstetrícia e Ginecologia Orientador: Professor Associado Maurício Simões Abrão

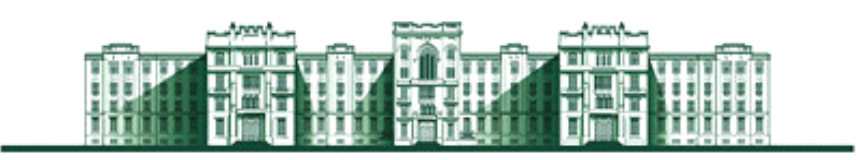

São Paulo

2015 
Dados Internacionais de Catalogação na Publicação (CIP)

Preparada pela Biblioteca da

Faculdade de Medicina da Universidade de São Paulo

Creprodução autorizada pelo autor

Fernandes, Luiz Flávio Cordeiro

Caracterização morfológica da endometriose ovariana / Luiz Flávio Cordeiro Fernandes. -- São Paulo, 2015.

Tese(doutorado)--Faculdade de Medicina da Universidade de São Paulo.

Programa de Obstetrícia e Ginecologia.

Orientador: Maurício Simões Abrão.

Descritores: 1.Ovário 2.Endometriose 3.Proteína supressora de tumor p53 4.Marcadores biológicos 5.Proteínas proto-oncogênicas c-bcl-2 6.Antígeno Ki-67 7.Receptores estrogênicos

USP/FM/DBD-358/15 
"É preciso amor para poder pulsar,

É preciso paz para poder sorrir,

É preciso a chuva para florir."

Renato Teixeira 


\section{DEDICATÓRIA}

Ao meus pais, Edson Luiz e Rosângela, que me ensinaram os valores que regem minha vida, norteiam meus caminhos, que me deixaram voar, mostrando que se pode estar muito perto, mesmo estando longe e, que se pode ganhar mesmo quando imaginamos estar perdendo.

Ao meu irmão, João Ricardo, que também teve o privilégio de receber os ensinamentos de meus pais e pautados por eles torna-se meu maior companheiro, com quem sempre posso contar, que vive minha vida muitas vezes mais intensamente do que eu mesmo. Muito obrigado!

Aos meus tios-pais Itagyba, Marcos e Frederico, que todos os dias exemplificam o termo companheirismo e doação. Meu maior patrimônio. Vocês são responsáveis por cada passo que dou e cada vitória conquistada. Isso aqui não é só meu!

À Ana Paula por todos os anos que vivemos juntos e por ter me dado os meus maiores tesouros.

Aos meus filhos, Maria e Antonio, minhas maiores obras, razões de minha vida, de todos os sacrifícios, escola de amor! Toda poesia é insuficiente para explicá-los e agradecê-los! 


\section{AGRADECIMENTOS}

Um agradecimento especial ao meu orientador Professor Doutor Maurício Simões Abrão, inspirando-me na escolha da especialidade e, posteriormente, ensinando-me a como praticar uma medicina de cuidado, científica, correta, não se contentando com nada menos do que a perfeição. Obrigado pelas oportunidades, pela amizade e por reforçar o gosto pelo academicismo;

Ao Professor Doutor José Mendes Aldrighi, meu pai afetivo, exemplo de conduta e correção, por todo exemplo de esmero na produção do conhecimento e na transmissão deste;

Ao Professor Doutor Sérgio Podgaec, grande amigo, a quem devo inúmeros ensinamentos e oportunidades;

À Professora Doutora Filomena Marino de Carvalho por todas as idéias, pela disponibilidade, pelo exemplo de genialidade e de excelência;

À Dra. Kátia Pincerato pela paciência na leitura e releitura das lâminas, pelas dúvidas tiradas e por todo tempo dispendido;

Ao Professor Doutor Edmund Chada Baracat pela oportunidade de frequentar e vivenciar a Disciplina de Ginecologia da Faculdade de Medicina da Universidade de São Paulo, pelas orientações, pelo carinho desde o final de minha formação;

Ao Professor Doutor Marcelo Zugaib, que juntamente ao Prof. Baracat, acreditaram em mim e me proporcionaram a oportunidade de realizar a pósgraduação no Departamento de Ginecologia e Obstetrícia da Faculdade de Medicina da Universidade de São Paulo;

Aos colegas e amigos João Antonio Dias Júnior, Patrick Bellelis, Lidia Myung, Daniel Bier Caraça, Luciano Gibran, Rogério Gomes, Igor Padovesi, Tatiana Yamashiro, Giuliano Borrelli, Marta Privato e todos os outros membros do setor de endometriose pelo incentivo, apoio e parceria;

Às pacientes, a quem assistimos, estudamos e pesquisamos, a fim de que possamos melhorar toda a assistência com os conhecimentos adquiridos. 


\section{NORMATIZAÇÃO ADOTADA}

Esta tese está de acordo com as seguintes normas, em vigor no momento desta publicação:

Referências: adaptado de International Committee of Medical Journals Editors (Vancouver);

Universidade de São Paulo. Faculdade de Medicina. Serviço de Biblioteca e Documentação. Guia de apresentação de dissertações, teses e monografias. Elaborado por Anneliese Carneiro da Cunha, Maria Julia de A. L. Freddi, Maria F. Crestana, Marinalva de Souza Aragão, Suely Campos Cardoso, Valéria Vilhena. 3a ed. São Paulo: Serviço de Biblioteca e Documentação; 2011.

Abreviaturas dos títulos dos periódicos de acordo com List of Journals Indexed in Index Medicus. 


\section{SUMÁRIO}

Lista de abreviaturas

Lista de tabelas

Lista de figuras

Lista de gráficos

Resumo

Summary

1. Introdução …...................................................................... 1

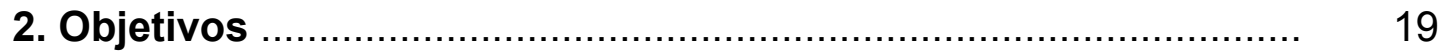

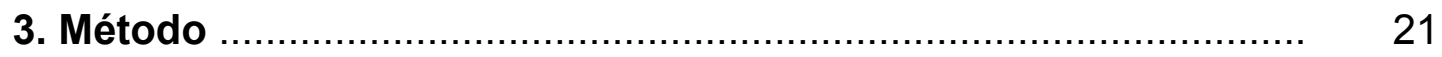

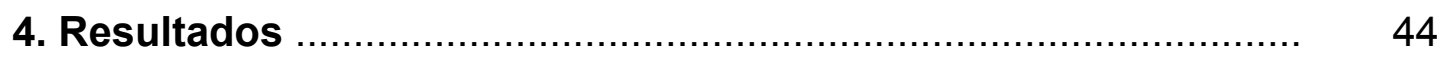

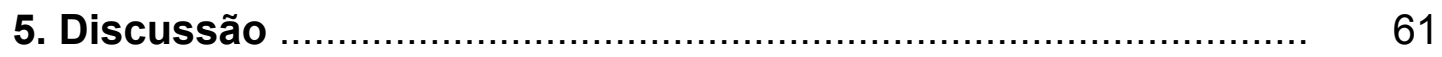

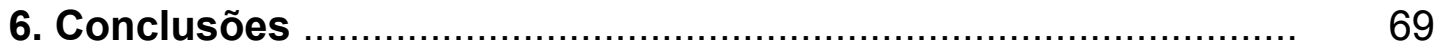

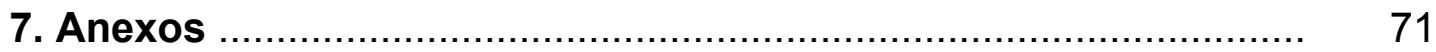

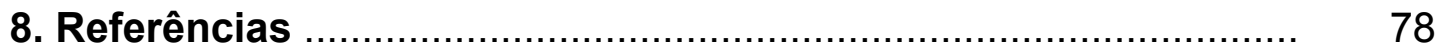




\title{
LISTA DE ABREVIATURAS
}

\author{
RE Receptores de estrogênio \\ REa Receptores de estrogênio alfa \\ p53 Proteína 53 \\ Bcl-2 B-cell lymphoma/leucemia 2 \\ cm centímetros \\ EVA Escala Visual Analógica de dor \\ MO Microscopia ótica \\ EIH Escore imuno-histoquímico \\ HE Hematoxilina-eosina
}




\section{LISTA DE TABELAS}

Tabela 1 Especificação dos marcadores utilizados

Tabela 2 Características clínicas, cirúrgicas e histopatológicas das pacientes estudadas

Tabela 3 Características clínicas das pacientes estudadas de acordo com o tipo histológico da endometriose ovariana

Tabela 4 Características clínicas das pacientes estudadas de acordo com a forma de apresentação da endometriose ovariana

Tabela 5 Características cirúrgicas das pacientes estudadas de acordo com o tipo histológico da endometriose ovariana

Tabela 6 Características cirúrgicas das pacientes estudadas de acordo com a forma de apresentação da endometriose ovariana

Tabela 7 Análise da associação da endometriose ovariana infiltrativa com sintomas

Tabela 8 Análise da associação da endometriose ovariana infiltrativa com a distribuição anatômica das lesões ...

Tabela 9 Correlação entre os marcadores no epitélio do endometrioma ovariano

Tabela 10 Correlação entre os marcadores no estroma do endometrioma ovariano 


\section{LISTA DE FIGURAS}

Figura 1

Figura 2 Fluxograma do estudo

Figura 3 Escala visual analógica de dor.

Figura 4

Figura 5

Figura 6

Figura 7

Figura 8

Figura 9

Figura 10

Figura 11 (1957) extraída do texto original íleo 20x) 40x) (HE - 40x) infiltrativa (HE - 20x)
Esquema da histologia do endometrioma ovariano proposto e adaptado de Hughesdon

Classificação da American Society for

Reproductive Medicine revisada em 1996,

Fotos de laparoscopia de pacientes com endometriose: a) lesão peritoneal; b) lesão retrocervical; c) lesão de reto-sigmóide; d) lesão de bexiga; e) lesão de ureter esquerdo; f) lesão de apêndice; g) lesão de vagina; h) lesões de

Fotomicrografias ópticas de espécimes de endometriose ovariana tipo estromal puro (HE -

Fotomicrografias ópticas de espécimes de endometriose ovariana tipo endometrioide (HE -

Fotomicrografias ópticas de espécimes de endometriose ovariana tipo tuboendometrioide

Fotomicrografias ópticas de espécimes de endometriose ovariana tipo indiferente (HE - 40x)

Fotomicrografia óptica de espécimes de endometriose ovariana forma cística não

Fotomicrografia óptica de espécimes de endometriose ovariana forma cística infiltrativa (HE - 40x) 
Figura 12

Figura 13

Figura 14

Figura 15

Figura 16

Figura 17

Figura 18

Figura 19
Fotomicrografia óptica de espécimes de

endometriose ovariana forma

intraparenquimatosa (HE - 10x)

Fotomicrografia óptica de espécimes de

endometriose ovariana forma

intraparenquimatosa (HE - 40x)

Fotomicrografia óptica de espécimes de

endometriose ovariana forma peritoneal

infiltrativa (HE - 20x)

Fotomicrografia óptica de espécimes de

endometriose ovariana forma peritoneal não

infiltrativa (HE - 10x)

Esquema ilustrativo da endometriose ovariana infiltrativa

Fotografia do PTLink (Dako®), sistema usado para deparafinização das lâminas e recuperação antigênica

Fotografia do Coverslippler (Dako®), sistema usado para montagem das lâminas

Fotomicrografias ópticas da imuno-histoquímica de espécimes de endometriose ovariana: a) Bcl2; b) p53; c) Ki-67; d) REa 


\section{LISTA DE GRÁFICOS}

Gráfico 1 Expressão do Bcl-2 no epitélio da endometriose ovariana de acordo com as formas de apresentação .....

Gráfico 2

Expressão do $\mathrm{Bcl}-2$ no estroma da endometriose ovariana de acordo com as formas de apresentação

Gráfico 3 Expressão do Ki-67 no epitélio da endometriose ovariana de acordo com as formas de apresentação .....

Gráfico 4 Expressão do Ki-67 no estroma da endometriose ovariana de acordo com as formas de apresentação .....

Gráfico 5 Expressão do REa no epitélio da endometriose ovariana de acordo com as formas de apresentação

Gráfico 6 Expressão do REa no estroma da endometriose ovariana de acordo com as formas de apresentação .....

Gráfico 7 Expressão do p53 no epitélio da endometriose ovariana de acordo com as formas de apresentação

Gráfico 8 Expressão do p53 no estroma da endometriose ovariana de acordo com as formas de apresentação

Expressão do $\mathrm{Bcl}-2$ no epitélio da endometriose

Gráfico 9 ovariana de acordo com a infiltração do parênquima adjacente

Expressão do $\mathrm{Bcl}-2$ no estroma da endometriose

Gráfico 10 ovariana de acordo com a infiltração do parênquima adjacente

Gráfico 11 ovariana de acordo com a infiltração do parênquima adjacente 
Expressão do Ki-67 no estroma da endometriose

Gráfico 12 ovariana de acordo com a infiltração do parênquima adjacente

Gráfico 13 Expressão do p53 no epitélio da endometriose ovariana de acordo com a infiltração do parênquima adjacente 56

Gráfico 14 Expressão do p53 no estroma da endometriose ovariana de acordo com a infiltração do parênquima adjacente ...

Gráfico 15 Expressão do REa no epitélio da endometriose ovariana de acordo com a infiltração do parênquima adjacente

Expressão do REa no estroma da endometriose

Gráfico 16 ovariana de acordo com a infiltração do parênquima adjacente 


\section{RESUMO}

Fernandes, LFC. Caracterização morfológica da endometriose ovariana [tese]. São Paulo: Faculdade de Medicina, Universidade de São Paulo; 2015

Introdução: De origem controversa e repercussões imprevisíveis, o acometimento ovariano pela endometriose é considerado importante marcador de extensão da doença, pois pode se associar a endometriose profunda. Inúmeras teorias etiopatogênicas tentam explicar a gênese da endometriose ovariana e, duas delas recentemente tem sido reativadas, como a da metaplasia celômica que justificaria o conceito atual de endometriose intra-ovariana profunda e a da menstruação retrógrada, que explica a origem tubárea dos endometriomas. Estima-se em $5 \%$ a $10 \%$ de câncer ovariano em lesões de endometriose de ovário; enquanto, a frequência total de transformação maligna foi estimada entre 0,3 a $2,5 \%$. Objetivo: Avaliar as formas de apresentação da endometriose ovariana e possíveis associações com o quadro clínico, com outros locais de doença, com os marcadores de atividade proliferativa (Ki-67), com a expressão de alterações moleculares dos mecanismos apoptóticos consideradas importantes no processo de carcinogênese das lesões de endometriose (p53 e Bcl-2) e com os receptores de estrogênio (dependência hormonal). Métodos: Estudo de coorte retrospectivo exploratório, com 63 pacientes operadas entre 2002 a 2012, com diagnóstico de endometriose ovariana preenchendo os critérios de inclusão e exclusão. Os preparados histológicos foram reavaliados e reclassificados de acordo com o tipo histológico, com a forma de apresentação e com a presença de infiltração do parênquima ovariano, sendo divididas em endometriose ovariana peritoneal, cistica e intraparenquimatosa. Foram avaliados a expressão do Ki-67, do p53, do Bcl2 e dos receptores de estrogênio no epitélio e no estroma tecidual. As pacientes ainda foram avaliadas de acordo com os sintomas clínicos e locais concomitantes de doença. Resultados: A forma de apresentação da endometriose ovariana mais frequente foi a cística $(72,2 \%)$, seguida pela intraparenquimatosa $(22,2 \%)$ e pela forma peritoneal $(5,6 \%)$. Todas podem apresentar componente infiltrativo. A endometriose ovariana infiltrativa esteve presente em $30,5 \%$ dos casos. Não se evidenciou associação entre sintomas, distribuição anatômica do doença e expressão dos marcadores com as diferentes formas de apresentação ou com a infiltração do parênquima adjacente. Conclusão: $A$ endometriose ovariana apresenta três formas distintas de apresentação, cística, intraparenquimatosa e peritoneal. Todas podem apresentar componente infiltrativo. Apesar da clara diferenciação histológica, ainda se deve identificar o significado clínico destes achados.

Descritores: Ovário; Endometriose; Proteína supressora de tumor p53; Marcadores biológicos; Proteínas Proto-Oncogênicas c-bcl-2; Antígeno Ki67; Receptores Estrogênicos 


\section{SUMMARY}

Fernandes, LFC. Morphologic characterization of ovarian endometriosis [thesis]. São Paulo: Faculdade de Medicina, Universidade de São Paulo; 2015

Introduction: Of controversial origin and unpredictable repercussions, ovarian endometriosis is an important marker of disease extensiveness, as it may be related to deep infiltrating endometriosis. Numerous theories try to explain its origin, but two of them have been recently reactivated, such as celomic metaplasia, which would justify the concept of deep ovarian endometriosis, and retrograde menstruation, which can explain the tubal origin of ovarian endometriosis. It is estimated $5 \%$ to $10 \%$ of ovarian cancer in ovarian endometriosis, but malignant transformation may occur in 0.3 to $2.5 \%$ of the cases. Objective: Identify the presenting forms of ovarian endometrisosis and its possible relations to clinical symptoms, to other sites of disease, to proliferative activity markers (Ki-67), to the molecular expression of apoptotic mechanisms, considered important to the process of malignant transformation ( $\mathrm{p} 53$ and $\mathrm{Bcl}-2$ ) and to estrogen receptors (hormonal dependency). Methods: This is a retrospective exploratory cohort study, done between 2002 and 2012, including 63 women with laparoscopic diagnosis of ovarian endometriosis which fullfilled inclusion and exclusion criteria. The histologic specimens were reanalysed and reclassified according to the histologic pattern, to its presenting form and to the presence of parenchyma infiltration. The expression of Ki-67, p53, Bcl-2 and estrogen receptors were evaluated in the tissue epithelium and stroma. Clinical symptoms and concomitant sites of disease were also evaluated. Results: The most frequent form of ovarian endometriosis was cystic $(72.2 \%)$, followed by intra-parenchymatous $(22.2 \%)$ and peritoneal (5.6\%). All of them can be infiltrative. The prevalence of infiltrative ovarian endometriosis was $30.5 \%$. No association were found between symptoms, anatomical distribution of disease, markers expression and the presenting forms of ovarian endometriosis as well as adjacent parenchymal infiltration. Conclusion: Ovarian endometriosis has three distinct presenting forms, cystic, intra-parenchymatous and peritoneal. All of them can be infiltrative. Even though there is a clear histologic differentiation, its clinical significance is still to be determined.

Descriptors: Ovary; Endometriosis; Tumor supressor protein p53; Biological Markers; Proto-Oncogene Proteins c-bcl-2; Ki-67 Antigen; Receptors, Estrogen 


\section{INTRODUÇÃO}

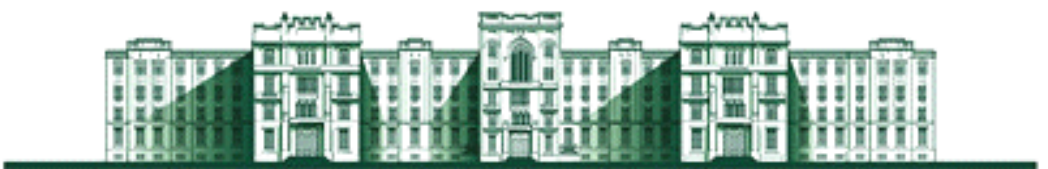


“Em uma tarde de outubro de 1882, enquanto fazia um exame de rotina de um material proveniente do centro-cirúrgico, encontrei um útero uniformemente aumentado em cerca de quatro vezes do seu tamanho natural. Ao abri-lo identifiquei que o causador de seu aumento era um espessamento difuso da parede anterior. $\mathrm{O}$ exame histológico destes cortes mostrou que o aumento de sua espessura devia-se à presença de um tumor adenomiomatoso difuso ocupando a porção interna da parede uterina, e a mucosa uterina, em vários pontos, penetrava este tecido miomatoso difuso."

Assim, Thomas Cullen descreveu, em 1908, no prefácio de seu livro, o que hoje conhecemos como endometriose e que naquela época era chamado "adenomioma uterino" 1.

A endometriose é uma doença crônica, inflamatória e estrógenodependente. Caracteriza-se pela presença de tecido endometrial, glândula e/ou estroma, em localização ectópica, ou seja, fora da cavidade uterina, principalmente no peritônio pélvico e ovários, mas pode acometer outros sítios, como a região retrocervical, o sigmóide, o reto, os ureteres, a bexiga, o íleo, o apêndice e raramente a pleura e o pericárdio ${ }^{2}$.

Estima-se que a endometriose acometa 5 a $10 \%$ da população feminina em idade reprodutiva e 3 a $5 \%$ das mulheres após a menopausa ${ }^{2-4}$. Face aos seus sintomas pode impactar negativamente a qualidade de vida e entre eles, destacam-se a dismenorréia, muitas vezes incapacitante, que ocorre em $62,2 \%$ das afetadas, a dispareunia de profundidade, a dor pélvica 
acíclica, as alterações intestinais e/ou urinárias cíclicas e a infertilidade ${ }^{5,6}$. Os sintomas álgicos podem causar desconforto por anos, justificando os constantes atendimentos de emergência e a alta taxa de absentismo profissional $^{7,8}$.

A etiopatogenia da endometriose é incerta e por isso muitas são as teorias postuladas, como a da metaplasia celômica e a da menstruação retrógrada, ambas aliadas à predisposição genética e imunológica ${ }^{9-13}$.

Sampson (1927), em seu clássico estudo sobre endometriose peritoneal e ovariana, propôs a primeira teoria etiopatogênica, a da menstruação retrógrada, fundamentado no achado peritoneal de fragmentos de endométrio advindos da cavidade uterina através das tubas ${ }^{9}$. A depender do ambiente imunológico local e de fatores genéticos, estas células endometriais ao sofrerem adesão, fixação, neovascularização, proliferação, poderiam justificar a eclosão da doença ${ }^{11,13,14}$, porém não explicaria a endometriose em locais fora da cavidade abdomino-pélvica.

A teoria da metaplasia celômica, proposta por Meyer em 1919, propugna que o epitélio celomático de origem embrionária pode sofrer metaplasia por estímulos ambientais e/ou hormonais e se transformar em glândulas e estroma endometriais ${ }^{12,15}$.

Apesar dessas duas teorias serem as mais divulgadas, várias outras foram descritas tais como a da disseminação linfática, a hematogênica, a genética, a imunológica e a composta, entretanto nenhuma explica a totalidade das possíveis manifestações da doença ${ }^{10,16-20}$. 
Entre as várias classificações, a mais citada é a de 1978, proposta pela antiga American Fertility Society (AFS) e expressa um enfoque cirúrgico para a endometriose, visando duas vertentes: a padronização universal da doença e a caracterização do seu prognóstico reprodutivo. Revisada em 1985 e 1996, classifica a doença em quatro estágios, a partir de um escore decorrente da somatória de valores que são atribuídos a algumas características das lesões, como localização, extensão e associação com aderências ${ }^{21}$. Contudo, essa revisão é considerada incompleta pois não inclui de forma adequada as lesões infiltrativas profundas, nem cumpre o propósito clínico inicial de correlacionar seus diferentes estágios com o prognóstico reprodutivo $^{22}$.

Em 1990, Cornillie et al. (1990) passaram a valorizar a profundidade das lesões na classificação da endometriose, caracterizando-a em dois tipos: profunda ou infiltrativa, quando a invasão peritoneal é maior ou igual a $5 \mathrm{~mm}$, e superficial, quando não excede $5 \mathrm{~mm}$. Esta classificação apresenta uma representação clínica importante, uma vez que a doença profunda associa-se a sintomas mais exuberantes ${ }^{23}$.

Nisolle e Donnez (1997) em outra classificação caracterizaram três tipos de endometriose: peritoneal, ovariana e do septo reto-vaginal. Em análises morfológicas, morfométricas e histoquímicas notaram que nas lesões do tipo peritoneal, as células se assemelham ao endométrio tópico, achado que se associa a teoria da menstruação retrógrada; nas lesões do septo reto-vaginal (atualmente conceito estendido para a doença profunda) observaram que as características das lesões se relacionam com a teoria 
mesodérmica mulleriana; e, na gênese das lesões do tipo ovariana relataram a importância da invaginação cortical de implantes endometriais localizados na superfície do ovário ou peritônio adjacente, bem como o envolvimento secundário de cistos de inclusão ${ }^{15}$.

Abrão et al. (2003) avaliaram uma classificação histológica da endometriose envolvendo quatro padrões: estromal, glandular bemdiferenciado, indiferenciado e misto. No estromal, a morfologia do estroma se assemelha ao endométrio tópico, sem a presença de epitélio glandular; no glandular bem-diferenciado, o epitélio exibe glândulas ou formações císticas indistinguíveis do endométrio tópico em qualquer fase do ciclo menstrual; no indiferenciado, o epitélio apresenta glândulas ou formações císticas com células achatadas ou cuboides baixas, sem correspondência com o endométrio tópico, mas que se assemelham ao mesotélio peritoneal; e, no glandular de diferenciação mista, áreas bem-diferenciadas e indiferenciadas são identificadas concomitantemente e, algumas vezes, células com outras características morfológicas mullerianas, como serosas ou mucinosas. Os padrões indiferenciados e mistos se associaram a quadros álgicos mais intensos e a um pior prognóstico e, por isso, esta classificação assume importante instrumento para prever o comportamento da doença e predizer a resposta ao tratamento ${ }^{24}$. 


\section{ENDOMETRIOSE OVARIANA}

A endometriose ovariana denominada também de endometrioma, acomete 17 a $44 \%$ das portadoras de endometriose ${ }^{25}$.

De origem controversa e repercussões imprevisíveis ${ }^{25}$, a endometriose ovariana é considerada importante marcador de extensão de doença pélvica e intestinal, pois se associa concomitantemente a lesões nestes locais ${ }^{26}$. Por isso, a abordagem da endometriose ovariana nunca pode ser direcionada exclusivamente ao anexo, pois pode redundar em tratamento incompleto em $98,9 \%$ das afetadas, com consequente persistência da doença; ademais, $40 \%$ das portadoras de endometriose ovariana necessitam de abordagem intestinal ${ }^{27}$.

A endometriose ovariana também relaciona-se a um maior número de lesões, especialmente quando bilateral e a um maior risco de comprometimento vaginal, intestinal e ureteral, sem aumento do risco de envolvimento vesical ou de ligamentos útero-sacros. Endometriomas acima de $4 \mathrm{~cm}$ também se associam à endometriose infiltrativa intestinal ${ }^{28} \mathrm{e}$ quando cursam com dismenorréia e dispareunia de profundidade severas, apresentam maior risco de doença profunda ${ }^{26}$.

No tocante a etiopatogenia da endometriose ovariana está consagrada a justificativa clássica de que fragmentos superficiais de endométrio migrem ao parênquima ovariano e, lá, por estímulo hormonal, crescem, sangram, e se acumulam, daí a denominação de menstruações 
cíclicas "enclausuradas", que explica a formação de grandes "cistos de chocolate" exclusivos dos ovários ${ }^{29-32}$.

Entretanto, Brosens et al. (1994), reavivando teoria proposta por Hughesdon em 1957, consideram a endometriose ovariana resultante de um pseudo-cisto com estruturas essenciais similares. Postulam sua formação a partir da sequência: adesão do ovário ao folheto posterior do ligamento largo, facilitação de contato entre os implantes de endométrio e o ovário e favorecimento de adesão a sua supeficie. Com a descamação "menstrual" e sangramento destes pequenos implantes, ocorre progressivo processo de invaginação no córtex ovariano, que resulta em um pseudo-cisto arciforme, constituído, histologicamente, por quatro camadas ${ }^{29,33}$ (Figura 1): cavidade do cisto, revestido por tufos de células endometriais; córtex ovariano interno, margeando a cavidade e composto, por sua vez, de três subcamadas (a mais interna em continuidade com a camada de revestimento da cavidade cística e chamada de zona juncional; uma área central esbranquiçada, formada por uma expansão da túnica albugínea; e a mais externa que representa o córtex propriamente dito); a medula do ovário, deslocada perifericamente, e com formato de "taça de vinho" (espremida entre o córtex ovariano interno e a próxima camada mais externa); e, por fim, o córtex ovariano externo.

Segundo esta teoria, a parte interna do cisto é a superfície externa do ovário e os depósitos de células endometrioides nunca teriam acesso ao parênquima ovariano $29,33,34$. 


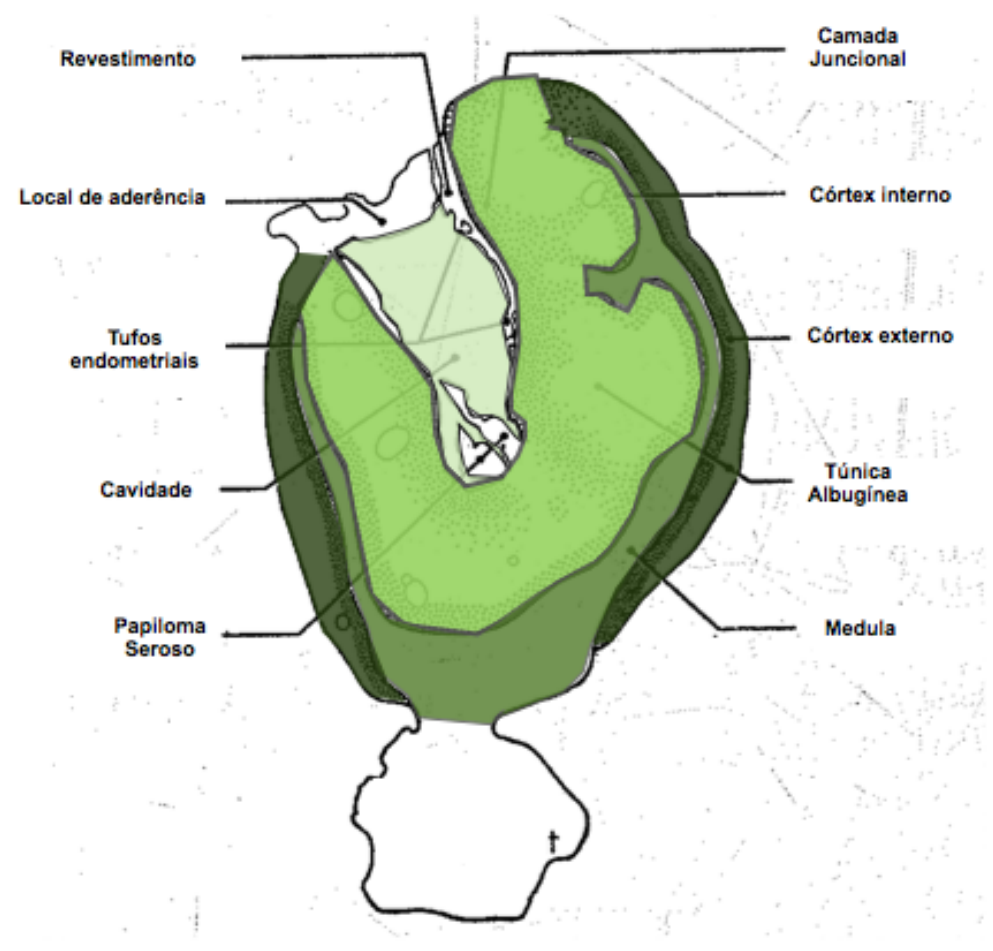

Cavidade do cisto

Córtex ovariano interno

Medula do ovário

Córtex ovariano externo

Figura 1 - Esquema da histologia do endometrioma ovariano proposto e adaptado de Hughesdon (1957) ${ }^{33}$

Estudos mais apurados confirmam que a face interna do cisto é recoberta por tecido endometrial, em $10 \%$ a $98 \%$ da sua superfície, e que o tecido endometriótico penetra na cápsula cística por 0,1 a $2,0 \mathrm{~mm}$, favorecendo sua aderência com a superfície peritoneal e justificando, na maioria dos casos, a rotura do cisto durante a mobilização do ovário na cirurgia. ${ }^{35}$.

Contudo, deve ser ressaltado que $12 \%$ dos endometriomas não se encontram fixos ao ligamento largo e que, eventualmente, nos cistos multiloculados de endometriose ovariana podem ser identificadas invaginações epiteliais continuamente com o tecido endometrial. Frente a esse achados, Donnez et al. (1996) sugeriram que os endometriomas possam ser oriundos da metaplasia do mesotélio que recobre os cistos de 
inclusão ovarianos, caracterizando a chamada endometriose intra-ovariana profunda ${ }^{31,34}$.

Estas inclusões epiteliais encontradas nos ovários em aproximadamente $30 \%$ dos casos ${ }^{36}$ derivam de um processo conhecido como endosalpingiose - presença de células epiteliais tubáreas viáveis na superfície ovariana. As cicatrizes na superfície ovariana causadas pela ovulação, adicionadas à inflamação pélvica e à proliferação estromal ovariana garantem as condições para que estas células epiteliais tubáreas atinjam o córtex ovariano. A transformação da endosalpingiose em endometriose, pode ser explicada pela metaplasia destas células, processo comumente observado no sistema mulleriano, mas também visualizado no lúmen tubáreo após ligadura tubárea. Estes eventos sugerem uma provável origem tubárea de alguns fenótipos da endometriose ovariana ${ }^{16}$.

Consoante com esta teoria, Zheng et al. relataram evidências dessa metaplasia, pois notaram na superfície ovariana, uma transição morfológica, que inclui o epitélio ovariano normal seguido por áreas focais de inclusões epitetiais com características iniciais de endometriose ${ }^{32}$.

\section{Endometriose ovariana e risco de câncer}

Sampson, em 1925, foi o primeiro a descrever a transformação maligna, a partir de um foco de endometriose. Entretanto, propôs que para ser confirmada uma relação causal, deveriam ser incluidos alguns critérios, como presença de tecido endometrial benigno e maligno no mesmo ovário; 
demonstração de o câncer se originar da endometriose ovariana e não de outro local e achado de tecido semelhante ao estroma endometrial circundando glândulas epiteliais características ${ }^{37}$. Em complementação, Scott, em 1953, adicionou um outro critério ainda mais rígido: a necessidade de demonstrar a transição entre endometriose benigna e epitélio maligno ${ }^{38}$.

Grande séries de casos relataram $5 \%$ a $10 \%$ de câncer ovariano em lesões de endometriose de ovário, enquanto que a frequência total de transformação maligna foi estimada entre 0,3 a $2,5 \%{ }^{39,40}$. Consoante com outros estudos, Kobayashi et al., em artigo de revisão realizado em 2009, mostraram que os subtipos histológicos mais associados à endometriose são o carcinoma de células claras (39\%) seguido pelo endometrioide (35\%); identificaram ainda que endometriomas com diâmetro acima de $9 \mathrm{~cm}$ e após a pós-menopausa são fatores de risco independentes para o desenvolvimento de câncer de ovário ${ }^{41}$, sendo que a endometriose ovariana apresenta maior risco de transformação maligna ${ }^{42}$. Pearce et al. (2012), em estudo caso-controle multicêntrico, comparando 7911 mulheres com câncer de ovário invasivo com 13226 controles, identificaram que a endometriose estava associada com um aumento significativo no risco de tumores de células claras, carcinoma seroso de baixo grau e endometrioide invasivo, porém sem qualquer associação de risco com carcinomas mucinosos, invasivos serosos de alto grau ou tumores borderline ${ }^{43}$.

Apesar de muitas especulações, ainda pouco se sabe sobre os eventos genéticos envolvidos no processo de transformação da endometriose em carcinoma de células claras e endometrióide. Wiegand et 
al. (2010) identificaram uma mutação no gene ARID1A com perda da expressão do BAF250 em 46\% dos carcinomas de células claras, em $30 \%$ dos endometrioides e em nenhum dos serosos de alto grau, sendo que em dois casos evidenciaram estas alterações no tumor e na endometriose atípica contígua, mas não nas lesões de endometriose mais distantes, sugerindo que este processo é um evento precoce em lesões préneoplásicas ${ }^{44}$. Kurman e Shih, em 2010, ao estudarem a patogênese do câncer epitelial de ovário admitiram que o epitélio tubáreo exerce um papel precursor nos carcinomas serosos de alto grau, enquanto que os carcinomas endometrioide e de células claras se originam do endométrio, via menstruação retrógrada. ${ }^{45}$.

Do ponto de vista oncológico, Sainz de la Cuesta et al. (1996) ao analisarem pacientes com carcinoma ovariano epitelial estágio I, encontraram endometriose em $28 \%$ delas. Nos casos de mulheres com histologia endometrioide, $39 \%$ estavam associados a endometriose e naqueles com carcinoma de células claras, $41 \%$ apresentavam esta mesma associação. Entre todas as pacientes com a associação câncer ovariano e endometriose, verificaram que em $32 \%$ o carcinoma se originava do tecido endometrioide, preenchendo os critérios propostos por Sampson e complementados por Scott ${ }^{46}$.

Fukunaga et al. (1997) observaram em 1,7\% das endometrioses ovarianas a presença de alterações glandulares atípicas - atipia estrutural e/ou celular do epitélio endometrioide 47,48 - sendo que, destas, $25 \%$ evoluiram para carcinoma endometrioide subsequente. Por outro lado, 
24,1\% dos cânceres de ovário estavam associados a endometriose ovariana e 5,8\% apresentavam endometriose atípica em contiguidade com o tumor. Por isso, alerta-se para o rastreamento e seguimento cuidadoso de pacientes com endometriose ovariana ${ }^{48-50}$.

Entretanto, Kobayashi et al. (2009) notaram que os cânceres associados à endometriose apresentam um prognóstico mais favorável, com longo intervalo de latência antes do desenvolvimento da doença maligna [média: 4,5 anos (1-16 anos)] e são mais propensos ao diagnóstico precoce 41. Cânceres associados a endometriose parecem acometer pacientes mais jovens, são diagnosticados em estágios menos avançados, apresentam menor grau de diferenciação e maior sobrevida ${ }^{51-55}$.

Vários estudos demonstram alterações genéticas nas células endometriais ectópicas conferindo-as uma natureza neoplásica, como perda da heterozigose dos cromossomos 1p, 9p, 11q, 17p e 22q, assim como amplificação do $17 q$, sugerindo uma evolução monoclonal da doença ${ }^{56-60}$. Alterações moleculares também foram descritas e podem estar envolvidas na transformação maligna da endometriose ${ }^{44}$.

\section{Endometriose ovariana e relação com receptores de estrogênios, marcadores de atividade proliferativa e reguladores de apoptose $-\mathrm{Bcl}-2$ e p53}

Juhasz-Böss et al. (2011) evidenciaram que a expressão dos RE na endometriose não varia com as fases do ciclo menstrual ${ }^{61}$. Entretanto, pode 
ocorrer redução gradual da expressão do REa com a progressão da endometriose para a forma atípica e, desta para o carcinoma ovariano de células claras ${ }^{62}$. Del Carmen et al. (2003) já tinham constatado redução gradual da expressão dos RE, quando comparados carcinomas ovarianos associados à endometriose com a endometriose atípica ${ }^{63}$. Mas, como Akahane et al. (2005) observaram aumento progressivo da expressão do REa da endometriose para a endometriose atípica e desta para o carcinoma endometrioide, postularam uma independência hormonal na transformação maligna da endometriose para o carcinoma de células claras, ressaltando que os mecanismos envolvidos diferem entre o carcinoma de células claras e o endometrioide ${ }^{62}$. Estes resultados coincidem com os obtidos por Fujimura et al. que também não encontraram expressão de REa nos carcinomas ovarianos de células claras, mas identificaram sua expressão nos carcinomas endometrioides, adenocarcinomas serosos e mucinosos, reforçando os achados de que tais tumores apresentam características biológicas distintas ${ }^{64}$.

Entre os marcadores de atividade proliferativa o Ki-67 é mais estudado. O Ki-67 é um antígeno nuclear presente apenas em células proliferativas, exceto na fase G0 do ciclo celular e sua expressão relacionase com a condição proliferativa das linhagens celulares. Sua mensuração é rápida e simples e é usada para predizer prognóstico, sobrevida e recorrências de neoplasias ${ }^{65,66}$. Um alto índice proliferativo (alta expressão de Ki-67) está associado a um comportamento tumoral agressivo e 
metástases ${ }^{67}$. Além de situações de malignidade, a mensuração do Ki-67 permite avaliar a atividade proliferativa de várias outras condições ${ }^{68}$.

Em 2009, Park et al. relataram aumento de $30 \%$ na expressão do Ki67 no endométrio de pacientes com endometriose, quando comparadas com o grupo controle ${ }^{69,70}$. Contudo, observaram menor expressão nas células endometriais ectópicas do que nas do endométrio tópico em sua fase proliferativa, assim como uma menor expressão na endometriose ovariana quando comparada com endometriose não ovariana ${ }^{71}$. De forma contrária, Kim et al. mostraram que as células de endometriose profunda apresentam menor expressão do Ki-67 quando comparadas com as de endometriose ovariana e peritoneal ${ }^{72}$. Kahyaoglu et al. (2012) verificaram aumento na atividade proliferativa, pelo índice de Ki-67, em estágios mais avançados da doença ${ }^{73}$, enquanto Khan et al. (1999), por sua vez, evidenciaram maior atividade proliferativa em células da endometriose ovariana quando comparada com células da rete ovarii, onde a expressão do Ki-67 não varia nas diferentes fases do ciclo menstrual ${ }^{74}$.

No tocante aos reguladores de apoptose - Bcl-2 e p53 inicialmente deve ser considerado que a apoptose, ou morte celular programada, é um fenômeno fisiológico necessário para o crescimento, diferenciação e renovação dos tecidos. No endométrio tópico, a apoptose elimina células disfuncionais ou senescentes, permitindo a reparação tecidual do ciclo menstrual. As células apoptóticas se localizam, preferencialmente, no epitélio glandular, mas podem ser encontradas em menor proporção no estroma. Apresentam aumento do número na fase secretória tardia e 
atingem seu pico no período menstrual. Este processo é seguido pela proliferação de novas células, a partir da camada basal, durante a fase proliferativa subsequente e é controlado, principalmente, pela expressão de genes reguladores, incluindo o TP53 que codifica a proteína p53 e membros da família B-cell lymphoma/leucemia 2 - Bcl-2 ${ }^{75-77}$.

O Bcl-2 é um representante de uma classe de proteínas regulatórias que, em sua maioria, exibem função anti-apoptótica ${ }^{78,79}$. Modula o transporte de membrana por meio da formação de canais iônicos, proteicos ou ambos, apresentando efeitos no fluxo de $\mathrm{Ca}^{2+}$ e/ou na translocação de proteínas ${ }^{80}$. O p53 é uma proteína regulatória, pró-apoptótica, que permite o reparo de pequenos danos ocorridos na replicação do DNA, mantendo, com isso, a integridade genômica ${ }^{79}$.

O índice de apoptose nas células endometriais em pacientes com endometriose é menor do que os controles, o que sugere que o número de células que atingem a cavidade peritoneal com a capacidade de escapar da vigilância imunológica é muito maior nas portadoras da doença ${ }^{81}$. Este comportamento diferenciado provavelmente é mantido pelo tecido ectópico, explicando em parte a proliferação excessiva e a apoptose insuficiente destas células ${ }^{76}$. Nesse sentido Dmowski et al. (2001) verificaram redução do índice apoptótico de acordo com o avanço do estágio da doença ${ }^{82}$. No entanto, estas mulheres não apresentam uma variedade cíclica destes índices ${ }^{78}$.

A expressão de Bcl-2 está aumentada nas lesões de endometriose. Abdalla-Ribeiro et al. (2014) constataram alta expressão do Bcl-2 na 
endometriose de ligamento útero-sacro e de reto-sigmóide ${ }^{83}$, assim como Wang et al. (2015) identificaram seu aumento nas células endometrioides ovarianas ${ }^{84}$. Porém sua expressão é ainda maior no carcinoma ovariano, de fato, Nezhat et al. (2002), confirmaram que em áreas histológicas de carcinoma ocorre uma maior expressão de $\mathrm{Bcl}-2$ quando comparadas a áreas benignas da mesma amostra, sugerindo uma relação direta entre o incremento de sua expressão com a transformação maligna deste tecido ${ }^{85}$. Entretanto, Korkmaz et al. (2013) identificaram que sua expressão é reduzida em lesões císticas quando comparada com células endometriais da mesma paciente, reforçando o achado de Nezhat que o aumento de sua expressão pode se relacionar com a transformação maligna do tecido ${ }^{86}$.

Em estudo de Watanabe et al. (1997) não foram identificadas mudanças cíclicas na expressão do Bcl-2 nas lesões de endometriose, inferindo mecanismos diferentes de proliferação e diferenciação entre endométrio tópico e ectópico ${ }^{87}$. Goumenou et al. (2004) também não notaram influência da fase do ciclo menstrual na expressão do $\mathrm{Bcl}-2$ de endometriomas ovarianos ${ }^{88}$.

Ao avaliarem o balanço entre a expressão de genes anti-apoptóticos e pró-apoptóticos no endométrio tópico de mulheres com endometriose, Zubor et al. (2009) verificaram maior expressão da p53 (pró-apoptose) ${ }^{89}$. Por outro lado, em outros estudos foi relatada uma menor expressão endometrial de proteínas pró-apoptóticas, incluindo o p53, e uma maior expressão de proteínas anti-apoptóticas, Bcl-2 ${ }^{90-92}$. 
Fauvet et al. (2003) mostraram ausência de regulação cíclica da p53 e que o padrão de expressão nos endometriomas se assemelha mais com o padrão de doenças malignas do que benignas ${ }^{93}$. Expressão aumentada na lesão atípica e no câncer associados a endometriose são achados comuns e podem ser usados para identificar lesões com potencial pré-maligno ${ }^{85,94-96}$.

Por outro lado, Prefumo et al. (2003), ao compararem a expressão da p53 nos carcinomas ovarianos endometrioides associados ou não a endometrioses, encontraram uma maior porcentagem de células positivas em casos de tumor associado com a doença. Nestes casos, a expressão da p53 no epitélio maligno apresentou alta concordância com a do tecido endometrioide adjacente ${ }^{97}$.

A formação de cistos de endometriose no ovário continua sendo um processo intrigante, uma vez que não ocorre em nenhuma outra localização da doença. Tal constatação sinaliza que se trata de uma forma especial da doença, com importantes diferenças sobre as demais, seja na etiopatogênese ou na constituição do seu tecido endometrioide. Por outro lado, nem toda forma de acometimento ovariano se apresenta como cistos. Assim, uma parte dele aparentemente é superficial e se associa ao mesotélio da superfície, enquanto outra tem caráter infiltrativo no parênquima. Todavia, ainda, não há estudos que definam ou caracterizem suas diferentes formas de comprometimento.

Assim, frente ao exposto, considerando a relevância do acometimento ovariano pela endometriose, suas repercussões clínicas, sua relação com a transformação maligna da doença e a evidente escassez de 
estudos pertinentes ao tema motivamo-nos avaliar as formas histológicas de endometriose ovariana e possíveis associações com o quadro clínico, com outros locais de doença e com os marcadores de atividade proliferativa (Ki67), com a expressão de alterações moleculares do mecanismo apoptótico consideradas importantes no processo de carcinogênese das lesões de endometriose (p53 e Bcl-2) e com os RE (dependência hormonal). 
2. OBJETIVOS 


\subsection{GERAL}

Caracterizar as formas histológicas da endometriose ovariana.

\subsection{ESPECÍFICOS}

a) Estimar a frequência relativa das formas histológicas da endometriose ovariana (superficial, cística e intra-parenquimatosa, com e sem componente infiltrativo);

b) Avaliar a associação entre as diferentes formas histológicas de endometriose ovariana com os sintomas clínicos e o comprometimento extra-ovariano da doença;

c) Avaliar a expressão imunoistoquímica dos receptores de estrogênio a e das proteínas Ki-67, Bcl-2 e p53 na endometriose ovariana, associandoa às diferentes formas histológicas. 
3. MÉTODOS 


\subsection{TIPO E LOCAL DO ESTUDO}

Em estudo de coorte retrospectivo exploratório envolvendo 892 pacientes operadas no período entre 2002 a 2012, no Setor de Endometriose da Divisão de Clínica Ginecológica do Hospital das Clínicas da Faculdade de Medicina da Universidade de São Paulo (HC-FMUSP), 322 apresentaram diagnóstico de endometriose ovariana. Destas, 128 tinham informações clínico-cirúrgicas completas, sendo que 63 preencheram os critérios de inclusão e exclusão (Figura 2). As indicações cirúrgicas incluíam a presença de sintomas álgicos intratáveis clinicamente ou de cistos ovarianos com diâmetro superior a $4 \mathrm{~cm}$.

O termo de consentimento livre e esclarecido (TCLE) não se aplicou no presente estudo, por se tratar de análise retrospectiva, garantindo-se contudo a confidencialidade dos dados de todas as pacientes. O projeto de pesquisa foi aprovado pelo Comitê de Ética em Pesquisa do HCFMUSP, conforme Protocolo 0525/11. 


\section{2 pacientes operadas entre 2002 - 2012}

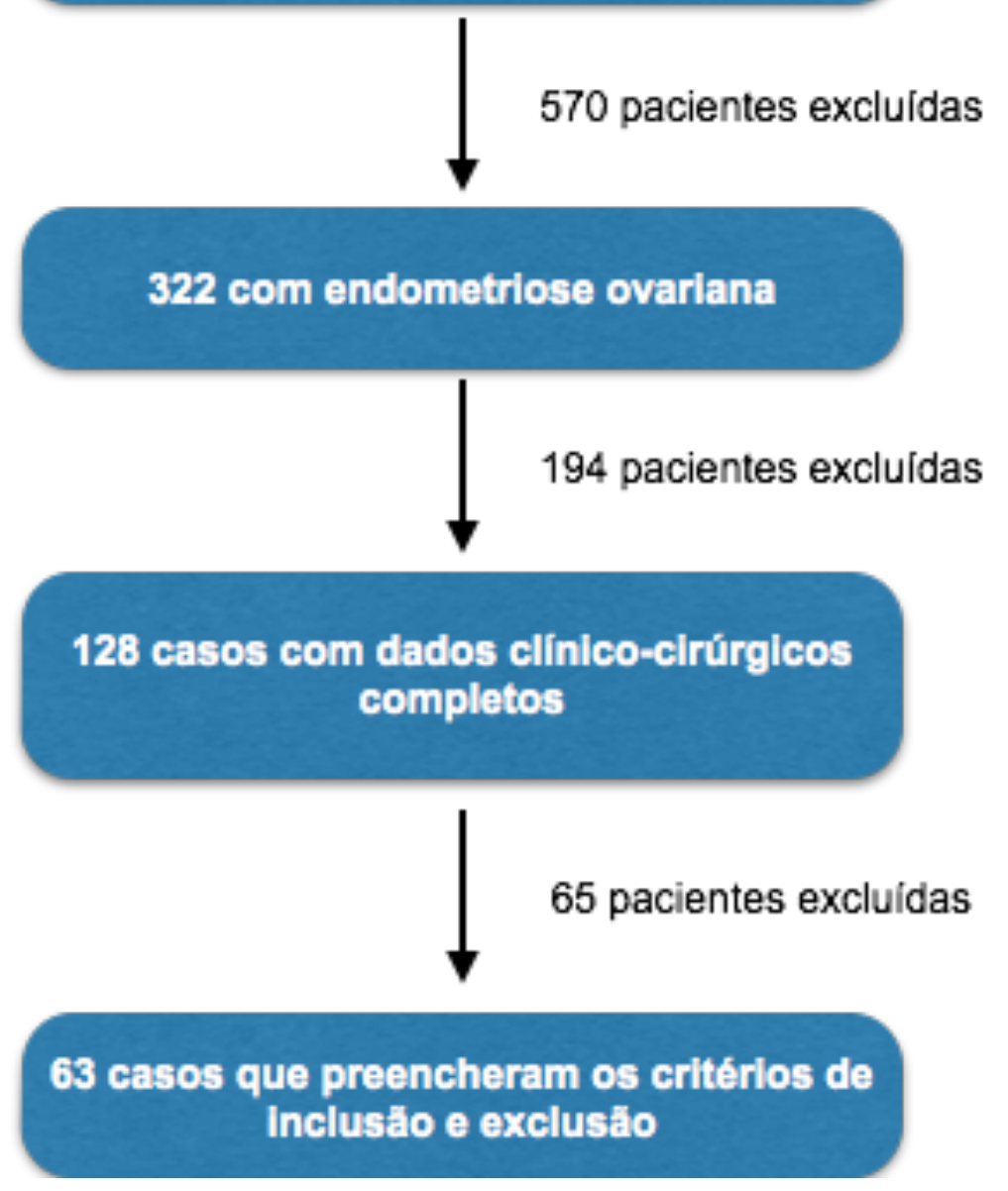

Figura 2 - Fluxograma do estudo

\subsection{CRITÉRIOS DE INCLUSÃO E EXCLUSÃO}

Foram incluídas mulheres submetidas a videolaparoscopia, sem uso de medicação hormonal nos três meses prévios ao procedimento e com diagnóstico histopatológico confirmando a presença de endometriose ovariana. Todas as pacientes com sinais clínicos e/ou laboratoriais de falência ovariana foram excluídas tais como amenorréia e níveis de FSH sérico superiores a $20 \mathrm{Ul} / \mathrm{ml}$. 


\subsection{AVALIAÇÃO CLÍNICA}

Os dados clínicos e demográficos de todas as participantes foram obtidas pela análise do prontuário médico e do banco de dados do Setor de Endometriose da Divisão de Clínica Ginecológica do HC-FMUSP (Access, 2008).

Quanto aos sintomas, o estudo utilizou a seguinte sistematização:

a) Dismenorréia: dor em cólica no período menstrual.

b) Dispareunia de profundidade: dor pélvica e/ou localizada no fundo da vagina durante a relação sexual.

c) Dor pélvica acíclica: dor pélvica sem relação com o ciclo menstrual por pelo menos seis meses, sem melhora com a utilização de analgésicos.

d) Infertilidade: tentativa de engravidar em casal com vida sexual ativa sem utilização prévia de método contraceptivo por pelo menos um ano. Pacientes sem parceiros sexuais no momento do estudo ou que nunca haviam tentado engravidar, ou que porventura estivessem usando métodos contraceptivos naturais ou de barreira foram classificadas como "sem tentativa".

e) Sintomas intestinais cíclicos: dor à evacuação, incluindo puxo e/ou tenesmo, ou ainda hematoquezia durante o período menstrual.

f) Sintomas urinários cíclicos: sintomas urinários durante o período menstrual incluindo disúria, hematúria, polaciúria e/ou urgência miccional, 
associados a resultado de cultura de urina negativa para processos infecciosos.

Os sintomas álgicos foram quantificados de acordo com a Escala Visual Analógica de dor (EVA), onde a nota "0" corresponde à ausência de dor, enquanto que a "10" à máxima dor sentida pela paciente (Figura 3).

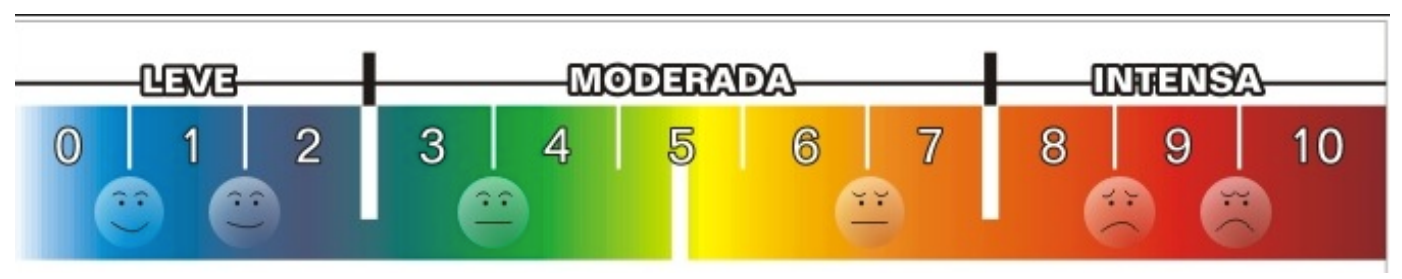

Figura 3 - Escala visual analógica de dor. O "0" corresponde à ausência de dor e o "10" à pior dor sentida pela paciente

\subsection{ESTADIAMENTO E ACHADOS CIRÚRGICOS}

As pacientes foram estadiadas durante o procedimento cirúrgico pelo critério da American Society for Reproductive Medicine revisado em estádios de I a IV (Figura 4) ${ }^{21}$ 
Estádio I (mínima): $\quad 1-5$

Estádio II (leve):

$6-15$

Estádio III (moderada): 16-40

Estádio IV (severa): $\quad>40$

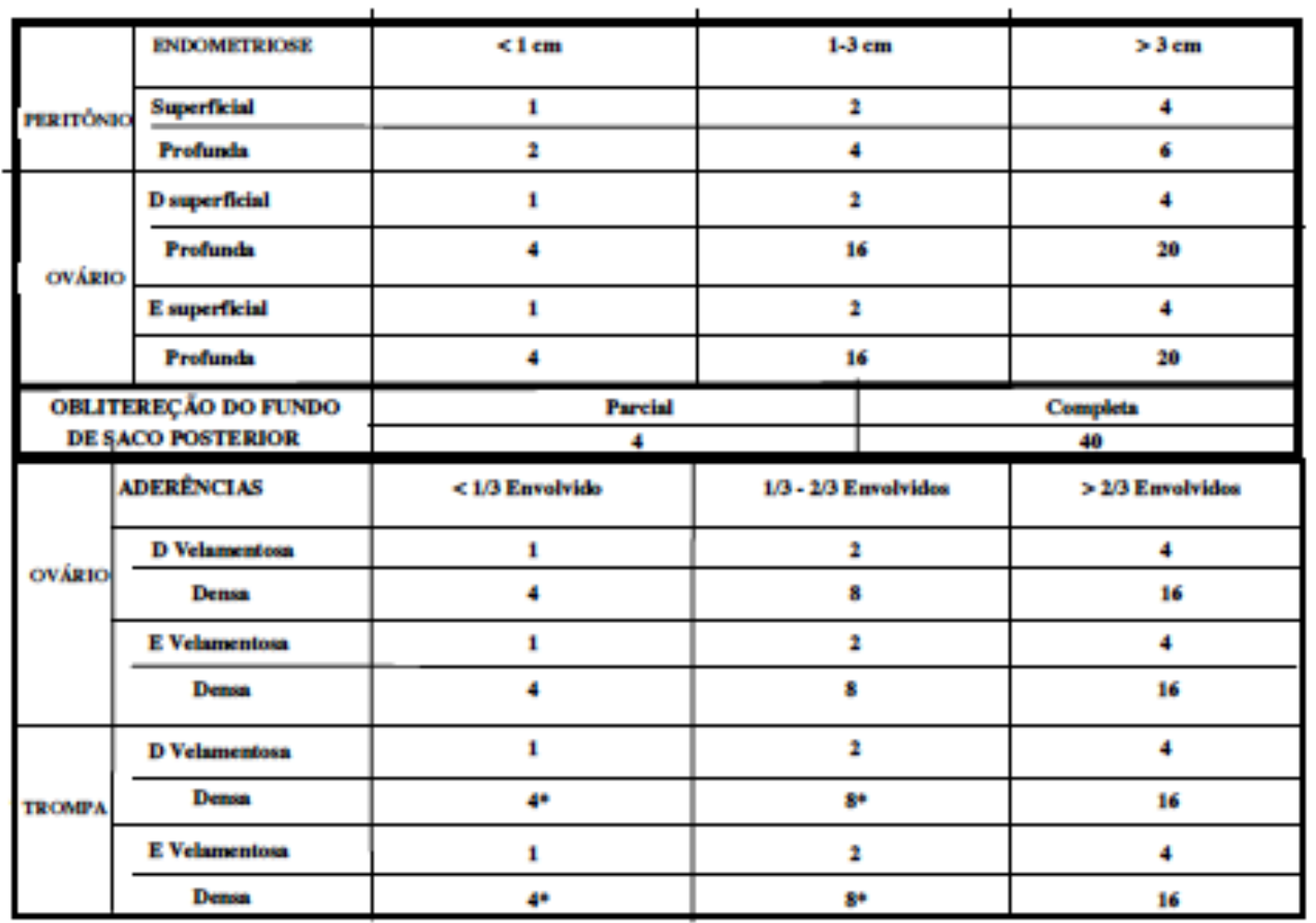

* Se as fímbrias tubárias estiverem totalmente envolvidas por aderéncias, mude o escore para 16.
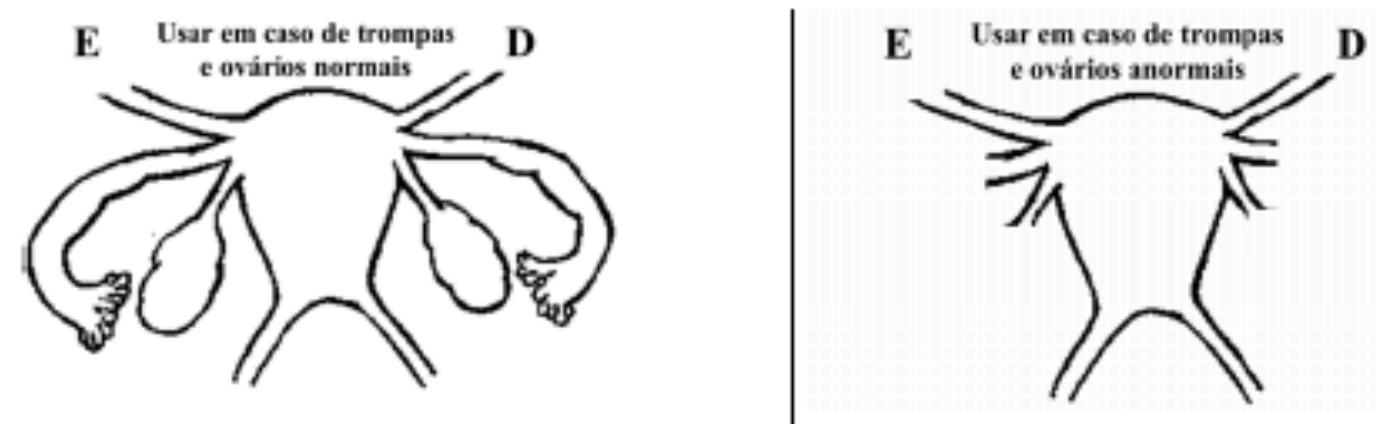

Figura 4 - Classificação da American Society for Reproductive Medicine revisada em 1996, extraída do texto original ${ }^{21}$

Foi avaliado a presença de focos de endometriose em outros locais extra-ovarianos, como lesões superficiais peritoneais e lesões profundas 
retrocervicais, de bexiga, ureter, apêndice, íleo, reto-sigmóide e vagina (Figura 5).
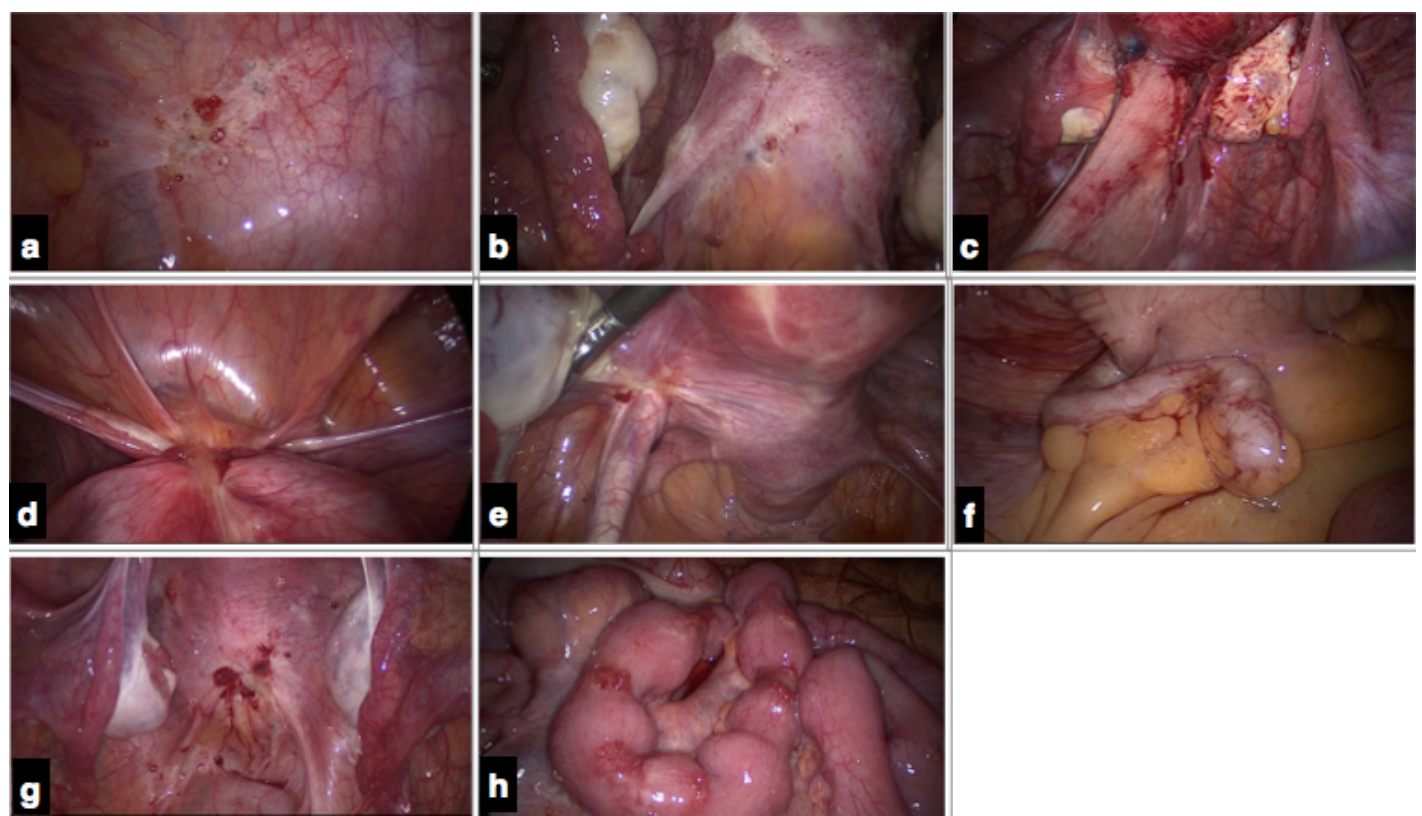

Figura 5 - Fotos de laparoscopia de pacientes com endometriose: a) lesão peritoneal; b) lesão retrocervical; c) lesão de reto-sigmóide; d) lesão de bexiga; e) lesão de ureter esquerdo; f) lesão de apêndice; g) lesão de vagina; h) lesões de íleo

\subsection{AVALIAÇÃO ANATOMOPATOLÓGICA}

Os espécimes histológicos coletados durante a cirurgia foram fixados em solução de formalina a $10 \%$ e incluídos em parafina, segundo processamento padrão da Divisão de Anatomia Patológica, com cortes histológicos de $4 \mu \mathrm{m}$ de espessura e corados pela técnica da hematoxilinaeosina (HE). Os preparados histológicos foram reavaliados pela mesma patologista com o objetivo de confirmar o diagnóstico, proceder à 
classificação histológica e à categorização da forma de apresentação da endometriose ovariana.

A classificação histológica da endometriose foi realizada pelos critérios de Abrao et al. (2003) modificado e consistiu em padrões ${ }^{24}$ :

- Estromal puro - presença de estroma morfologicamente similar ao do endométrio tópico em qualquer fase do ciclo (Figura 6);

- Glandular do tipo endometrioide - previamente denominado "bem diferenciado", caracteriza-se pela presença de epitélio, superficial ou constituindo espaços glandulares ou císticos, composto por células epiteliais com morfologia indistinguível do endométrio tópico nas diferentes fases do ciclo menstrual (Figura 7);

- Glandular do tipo tubo-endometrioide - previamente denominado padrão misto de diferenciação com componentes endometrioide e tubáreo, caracterizado por epitélio endometrioide com células ciliadas e pré-ciliadas do tipo tubáreo (Figura 8);

- Glandular mülleriano não endometrioide - previamente denominado "indiferenciado", caracteriza-se pela presença de epitélio com padrões müllerianos não endometrioides como tubáreo puro, mucinoso e células claras; 
- Glandular indiferente - previamente alocado entre os indiferenciados, caracterizado por epitélio aplainado, do tipo atrófico, sem sinais de diferenciação mülleriana (Figura 9);

- Glandular indeterminado - presença de epitélio, superficial ou constituindo espaços glandulares ou císticos, não característicos de nenhum dos tipos müllerianos ou atrófico;

- Glandular misto de diferenciação - presença na mesma localização de epitélios de padrão endometrioide/tuboendometrioide com outros tipos müllerianos ou atrófico.

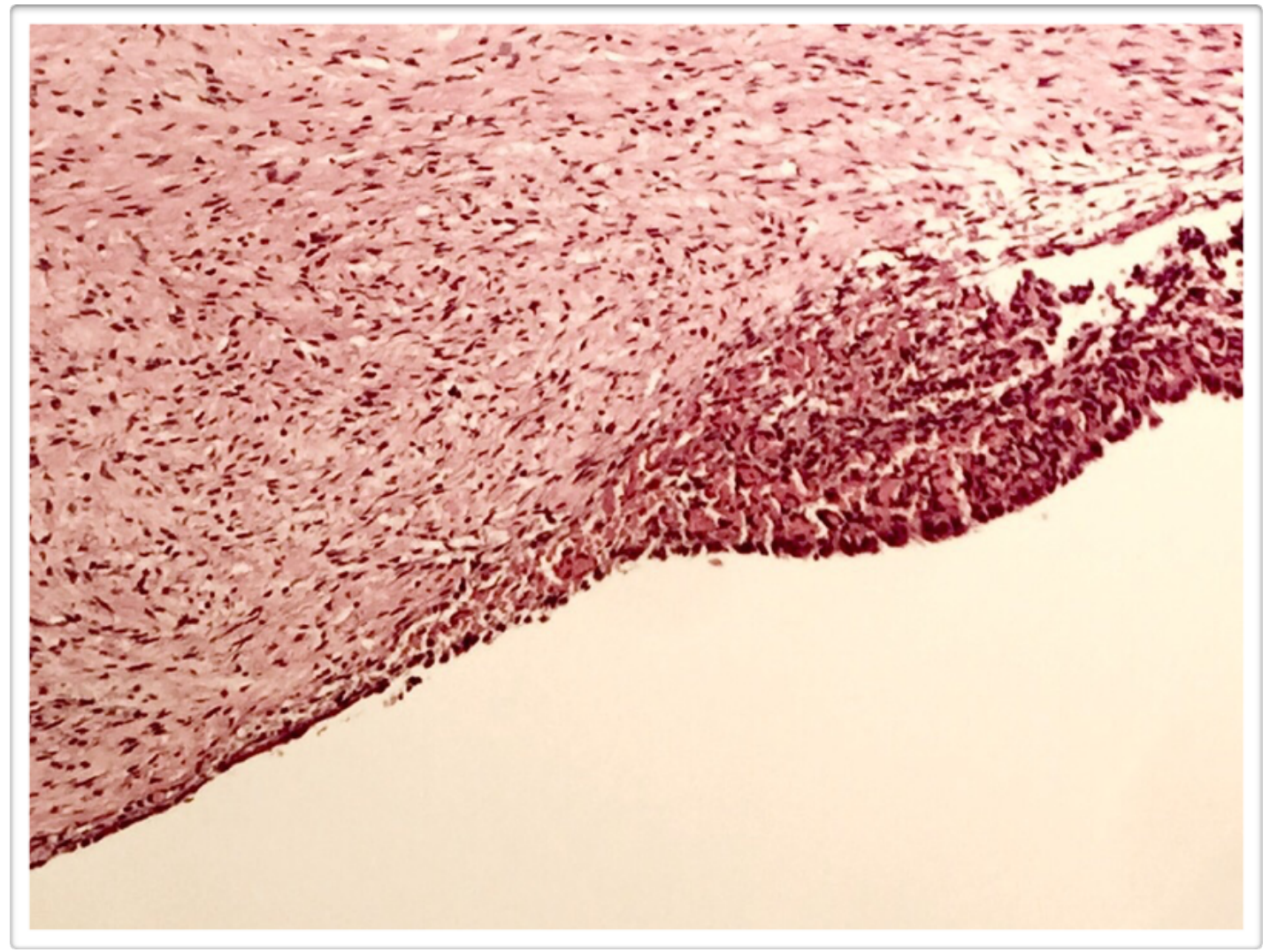

Figura 6 - Fotomicrografias ópticas de espécimes de endometriose ovariana tipo estromal puro (HE - 20x) 


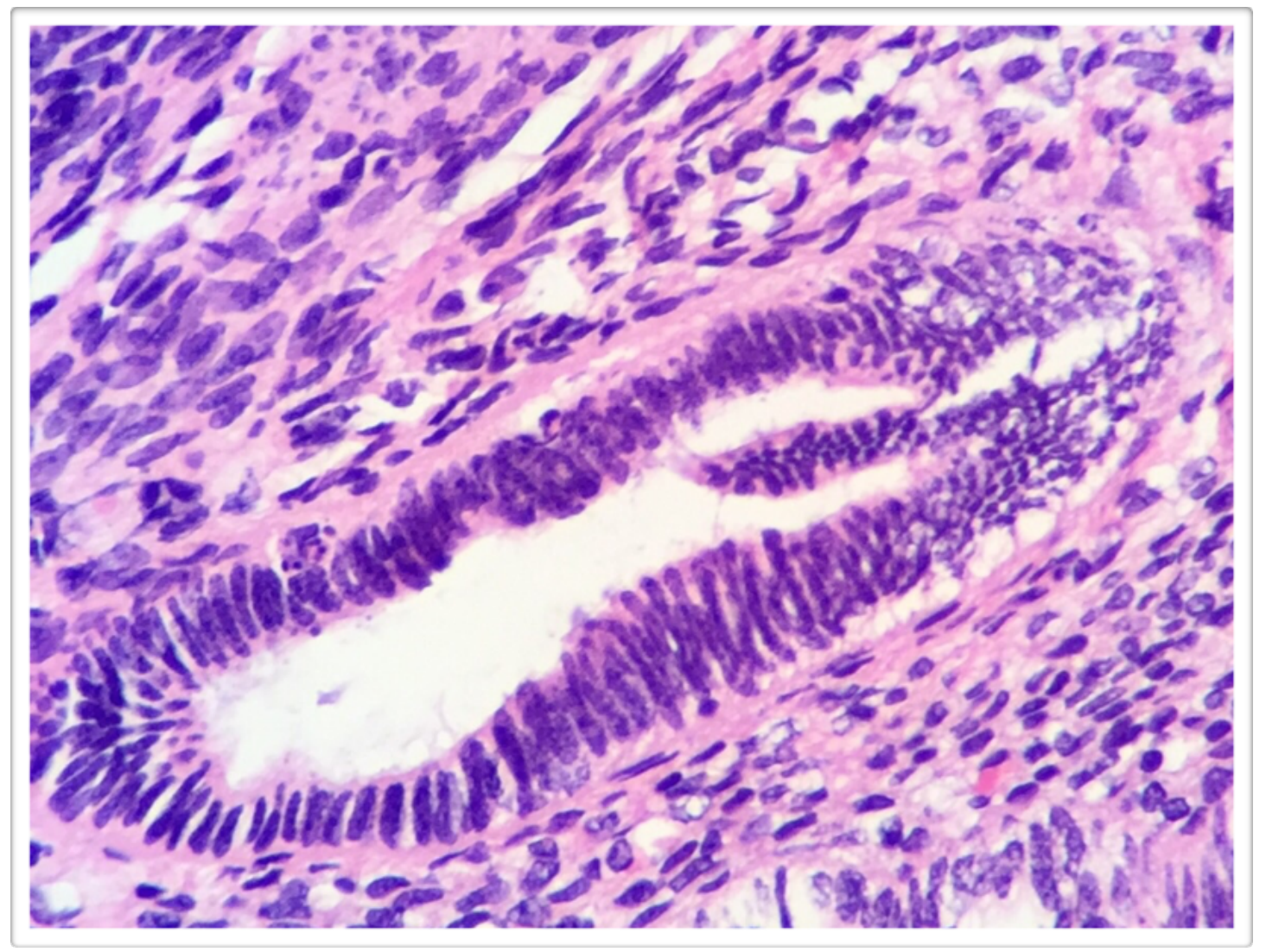

Figura 7 - Fotomicrografias ópticas de espécimes de endometriose ovariana tipo endometrioide (HE - 40x) 


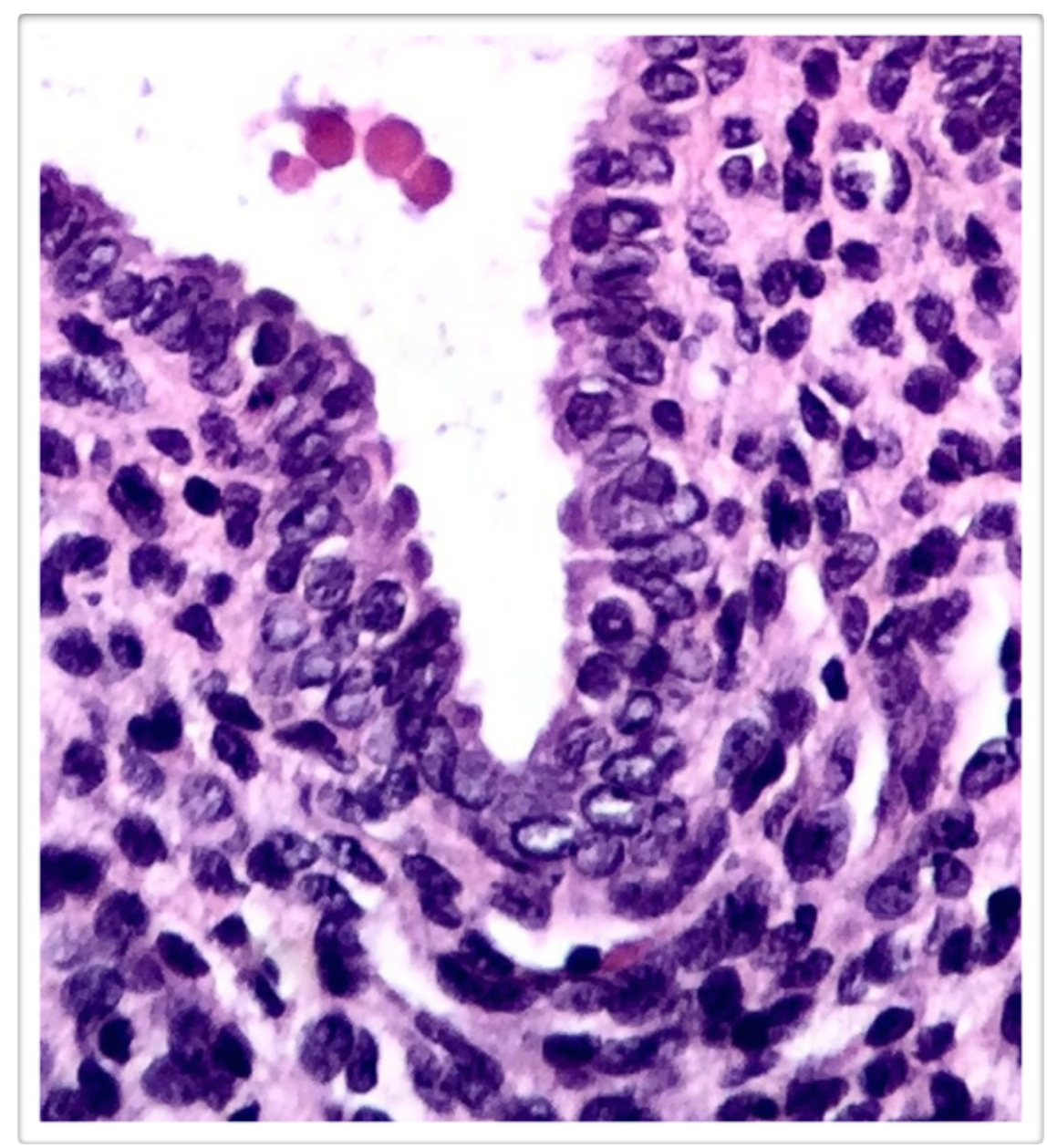

Figura 8 - Fotomicrografias ópticas de espécimes de endometriose ovariana tipo tuboendometrioide ( $\mathrm{HE}-40 \mathrm{x})$ 


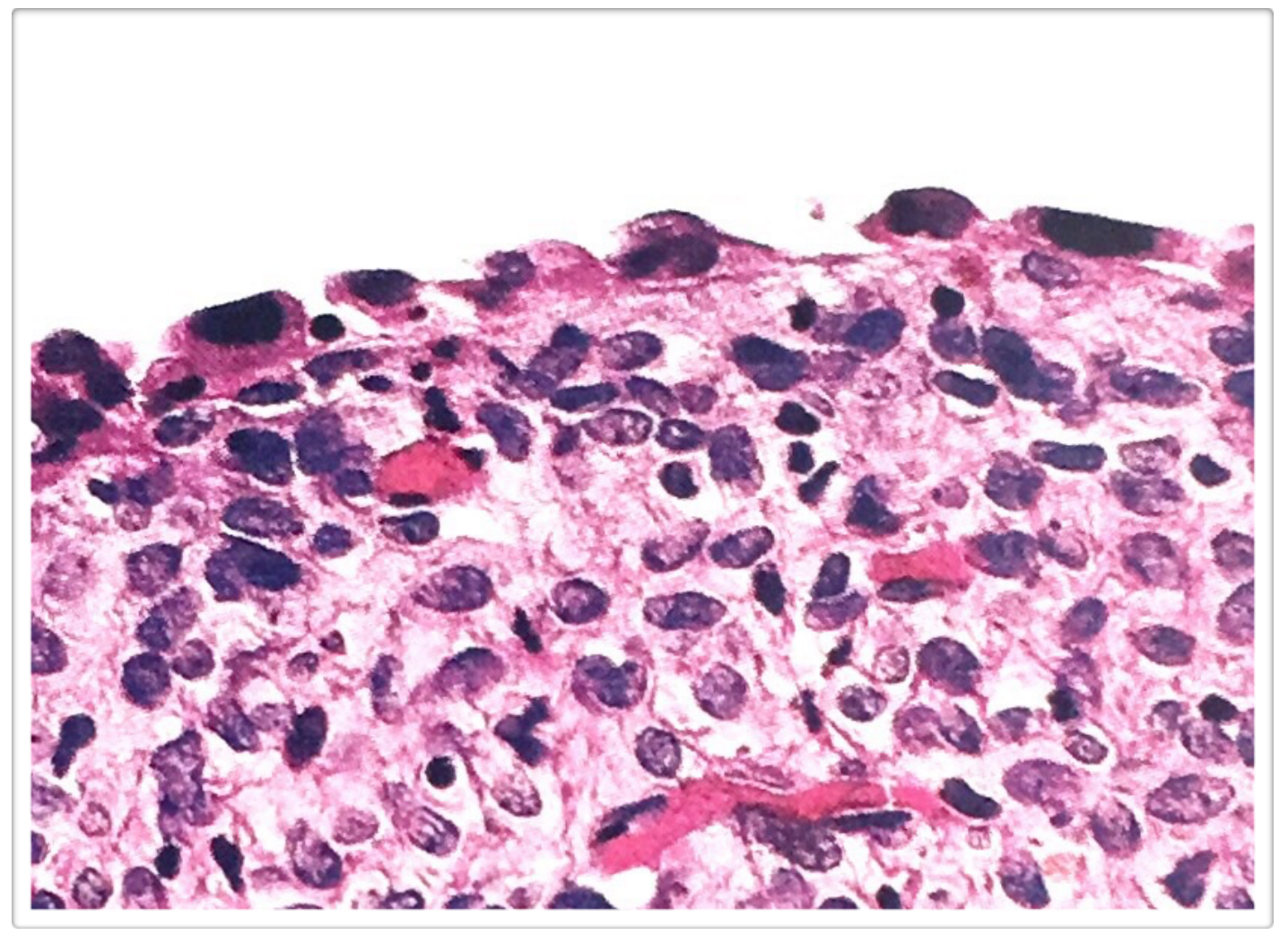

Figura 9 - Fotomicrografias ópticas de espécimes de endometriose ovariana tipo indiferente (HE - 40x)

Para fins estatísticos, considerou-se os tipos estromal, glandular endometrioide e tubo-endometrioide, por apresentarem uma correlação histológica mais próxima ao endométrio tópico, como subtipos endometrioides, enquanto que os tipos misto, indiferente e não endometrióide foram considerados como subtipos não endometrioides.

As formas de apresentação da endometriose ovariana (grupos de estudo) foram assim classificadas:

- Cística - caracterizada pela presença de cisto macroscópico com parede fibrosa de tipo cicatricial e revestimento da superfície interna, focal ou difuso, por tecido endometrioide, estromal e/ou glandular, com ou sem 
infiltração da parede ou extensão extracística (Figuras 10 e 11);

- Intra-parenquimatosa - caracterizada pela presença de tecido endometrioide, estromal e/ou glandular, na intimidade do estroma ovariano (Figuras 12 e 13);

- Peritoneal - envolvimento do peritônio da superfície ou região hilar ovariana, com ou sem infiltração do parênquima ovariano (Figuras 14 e 15).

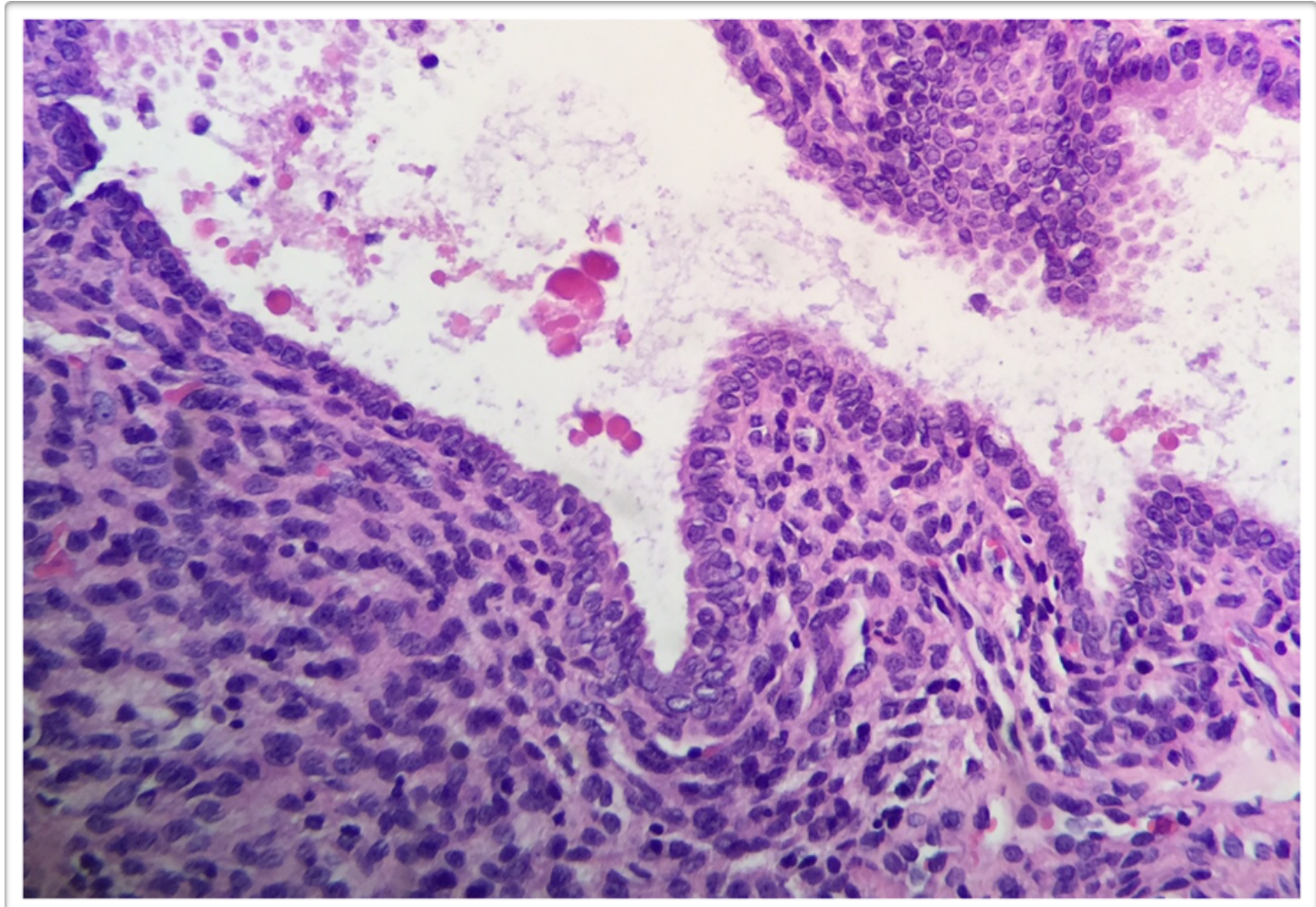

Figura 10 - Fotomicrografia óptica de espécimes de endometriose ovariana forma cística não infiltrativa (HE - 20x) 


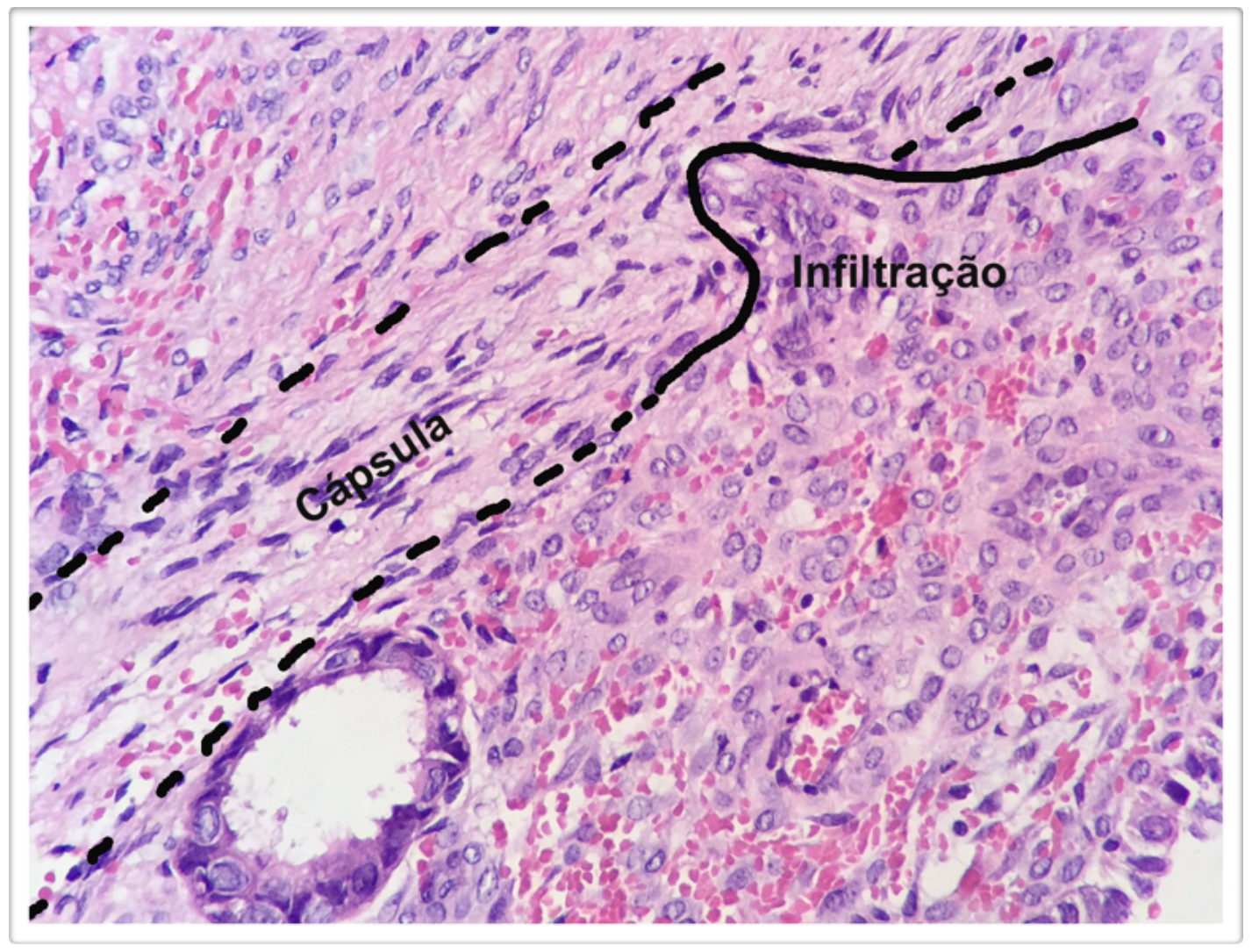

Figura 11 - Fotomicrografia óptica de espécimes de endometriose ovariana forma cística infiltrativa (HE - 40x) 


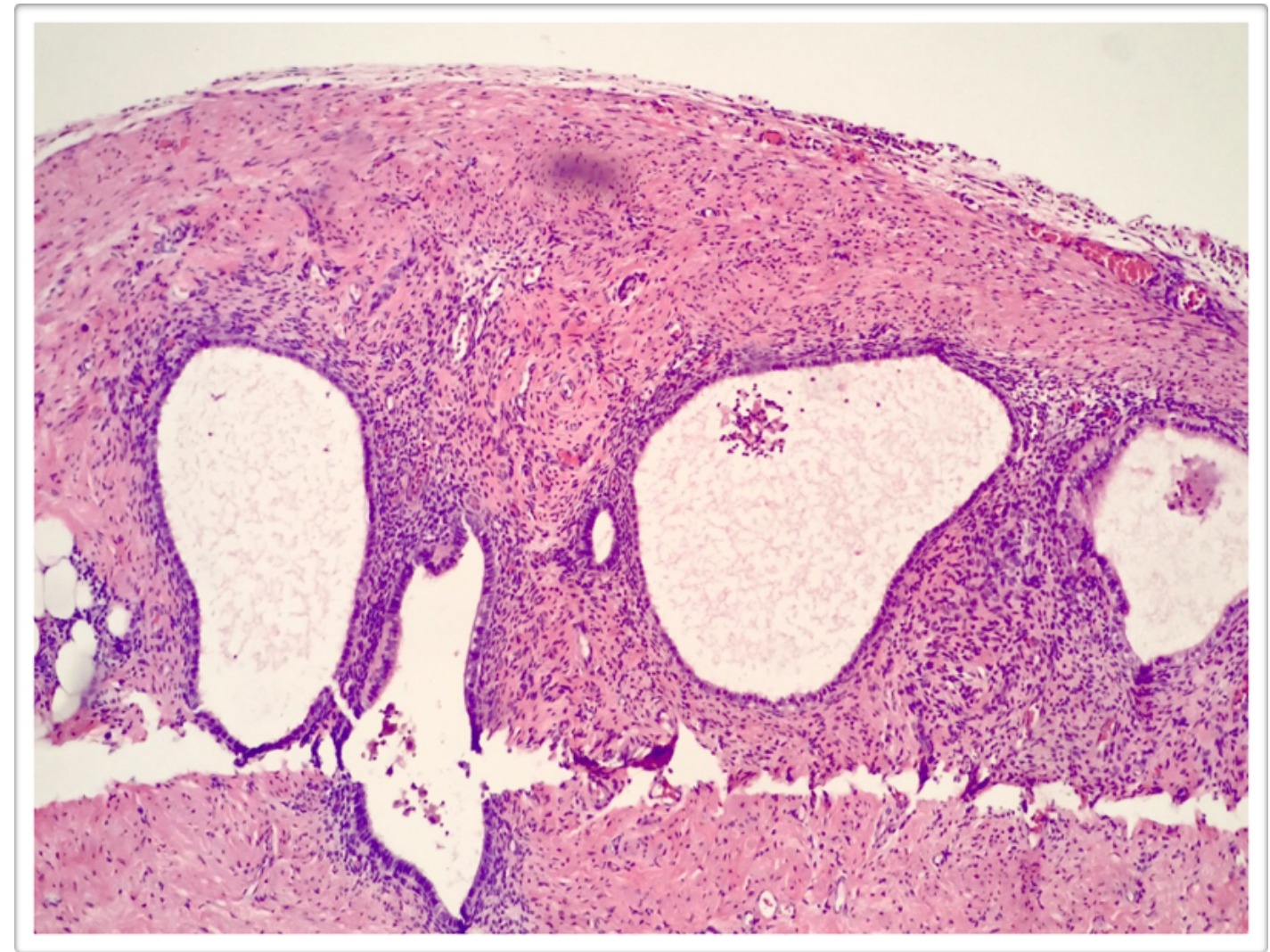

Figura 12 - Fotomicrografia óptica de espécimes de endometriose ovariana forma intraparenquimatosa (HE - 10x) 


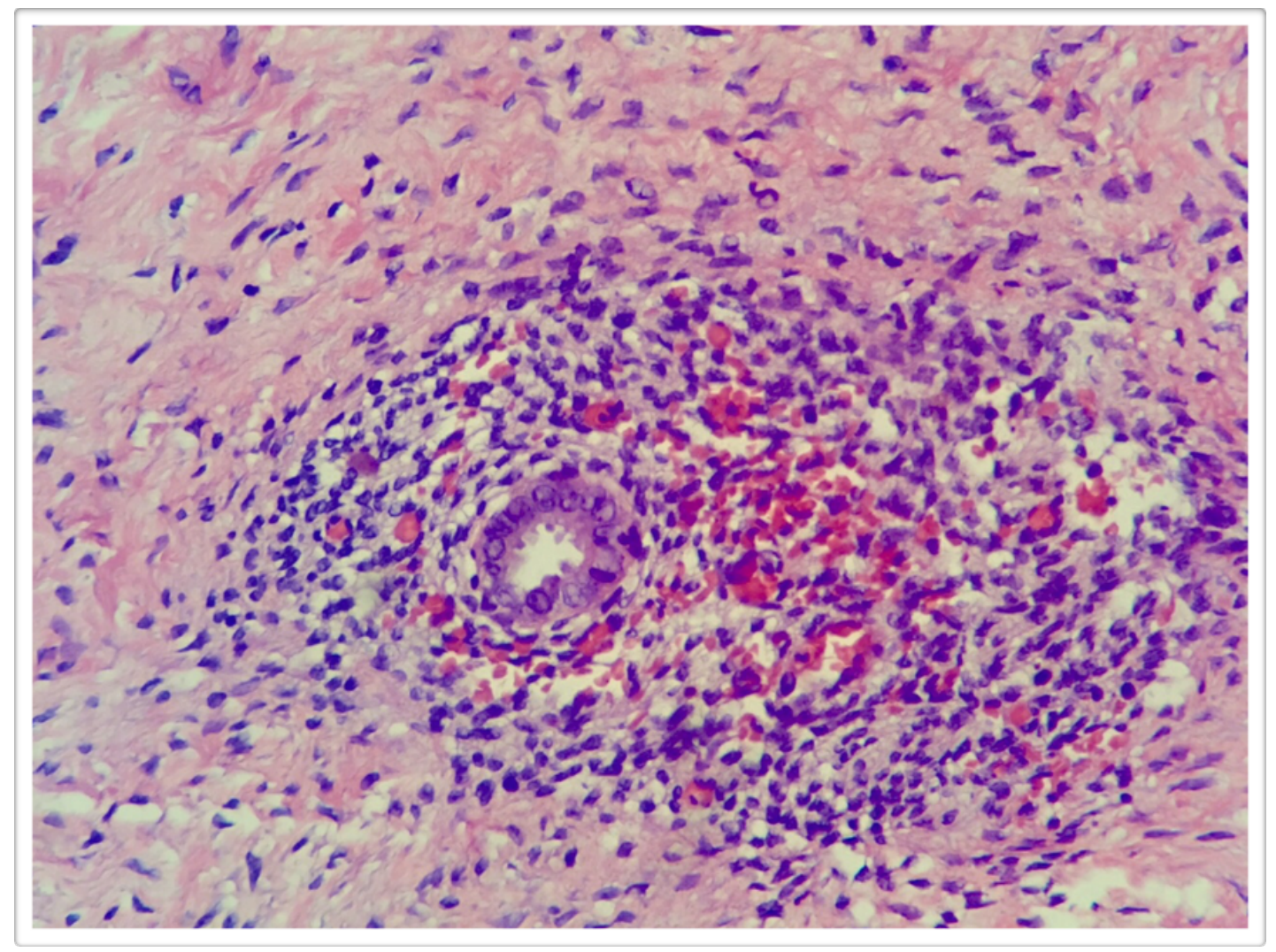

Figura 13 - Fotomicrografia óptica de espécimes de endometriose ovariana forma intraparenquimatosa (HE - 40x) 


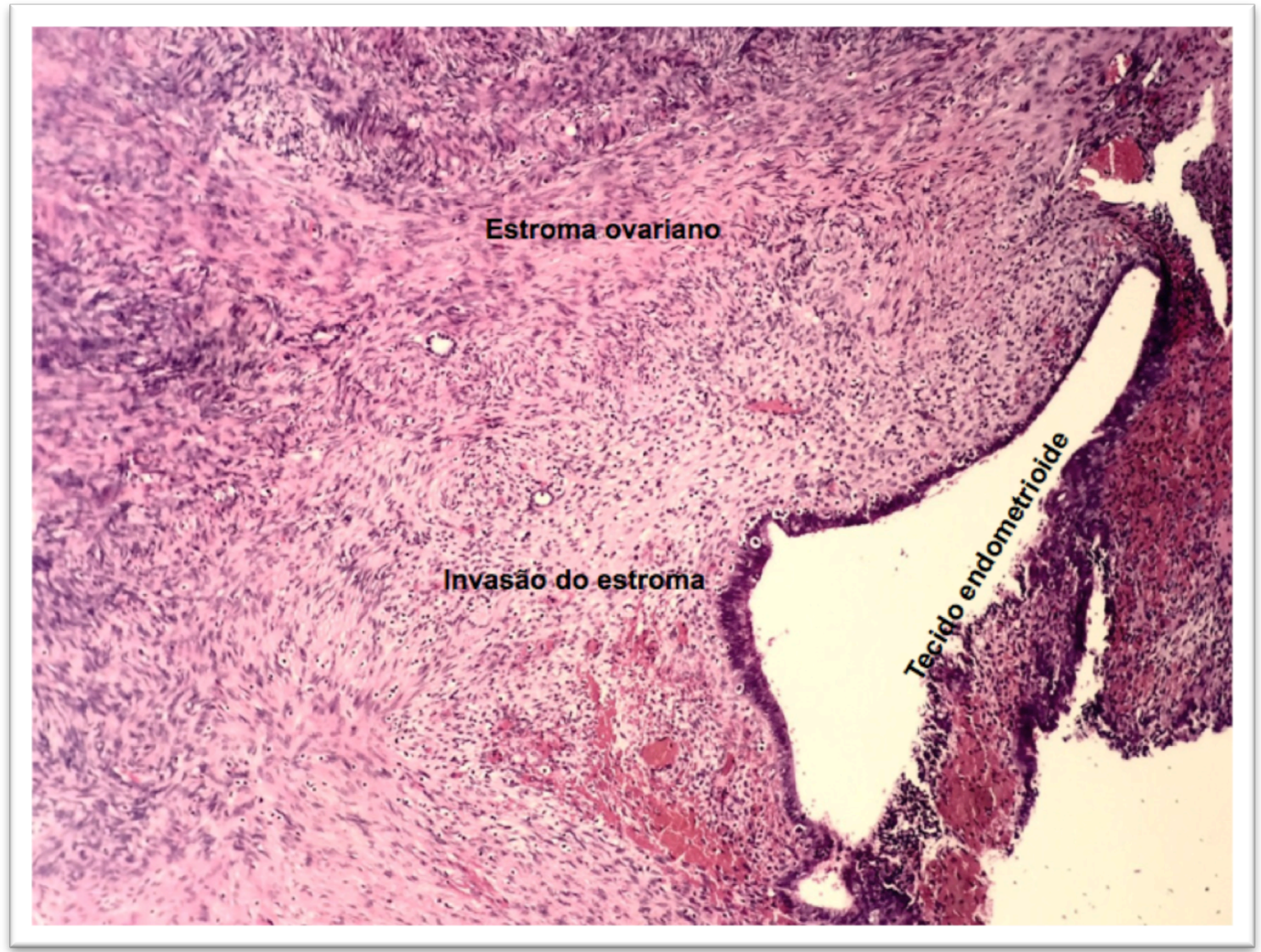

Figura 14 - Fotomicrografia óptica de espécimes de endometriose ovariana forma peritoneal infiltrativa (HE - 20x) 


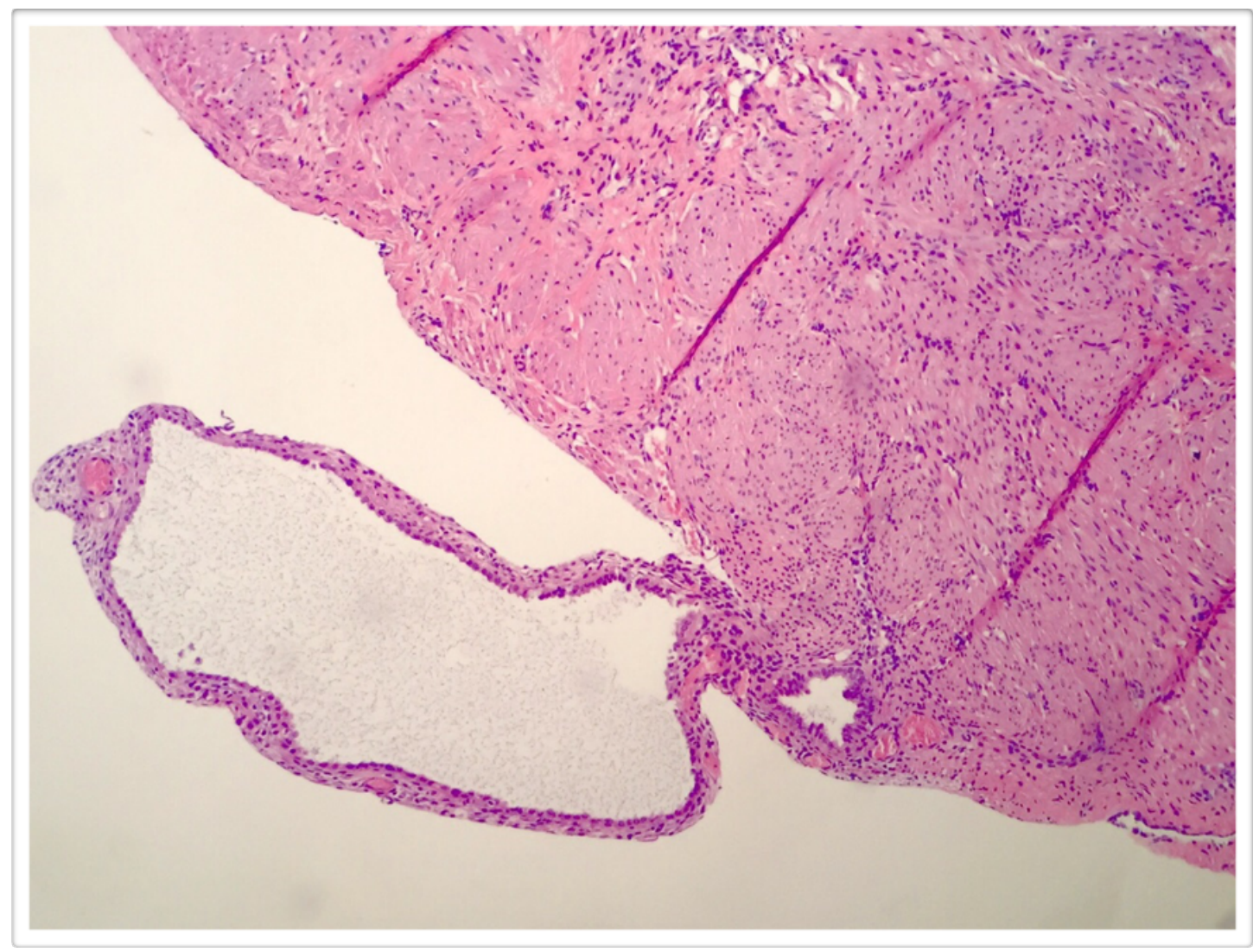

Figura 15 - Fotomicrografia óptica de espécimes de endometriose ovariana forma peritoneal não infiltrativa (HE - 10x)

Em caso de associação entre as três formas de apresentação, as análises estatísticas foram realizadas considerando critérios de severidade do processo, ou seja, a forma intraparenquimatosa mais severa que a cística, que, por sua vez, seria mais severa do que a peritoneal.

Naquelas pacientes com endometriose ovariana da forma cística e peritoneal, avaliou-se a infiltração do parênquima adjacente por tecido endometrioide.

Caracterizou-se ainda a endometriose ovariana infiltrativa (composta pelas formas intraparenquimatosa, cística e/ou peritoneal com infiltração do parênquima adjacente), comparando-a com a não infiltrativa (composta 
pelas formas cística e/ou peritoneal sem infiltração do parênquima adjacente) (Figura 16).

\section{Formas de apresentação histológica}

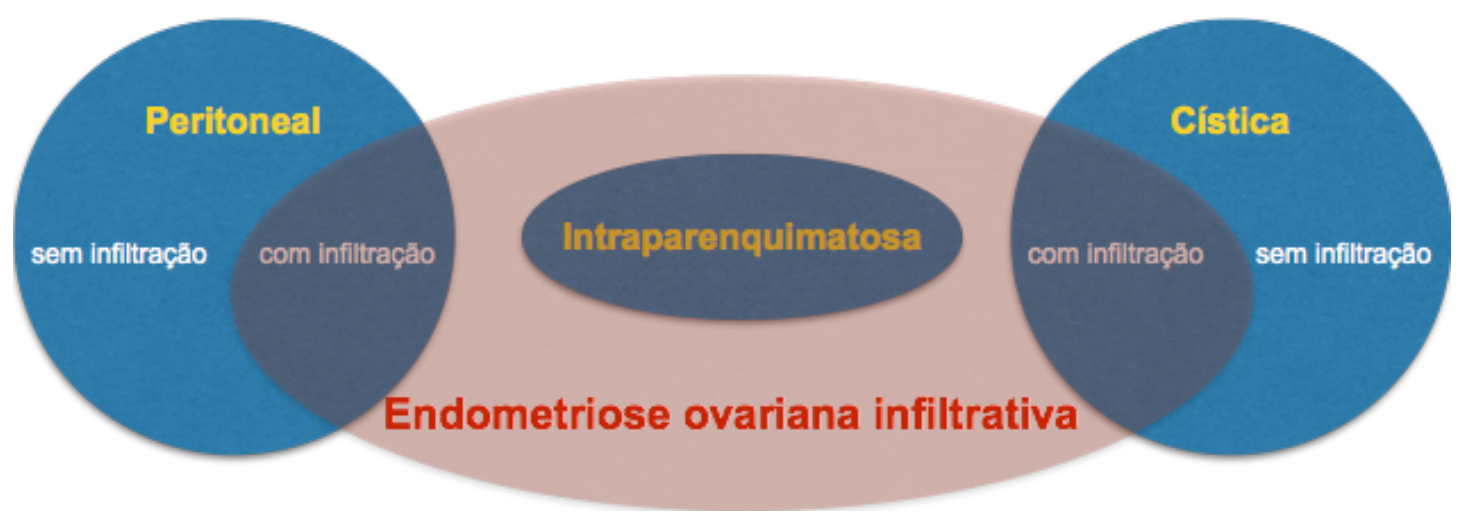

Figura 16 - Esquema ilustrativo da endometriose ovariana infiltrativa

\subsection{MÉTODO DO EXAME IMUNOISTOQUÍMICO PARA RECEPTOR DE ESTROGÊNIO a, Ki-67, Bcl-2 e p53}

As lâminas foram preparadas e fixadas. Os tecidos foram deparafinados e seus antígenos recuperados pelo PTLink (Dako®) (Figura 17) em solução tampão de $\mathrm{pH}$ alto ou baixo, por tempo variável (20 ou 40 minutos), de acordo com a padronização de cada anticorpo (Tabela 1). A seguir, realizou-se o bloqueio da peroxidase endógena (Peroxidase Blocker, Dako®), impedindo a interferência das enzimas endógenas e a ligação inespecífica dos anticorpos com proteínas do tecido. Aplicou-se o anticorpo primário diluído (REa, Ki-67, p53 e Bcl-2) conforme especificação do 
fabricante (Tabela 1). As lâminas foram incubadas durante à noite a temperatura ambiente. Amplificou-se o sinal do Bcl-2 com o linker rabbit. Aplicou-se o sistema de detecção Envision Flex/HRP (Dako®) - polímero de dextran acoplado a moléculas de peroxidase e anticorpo secundário. Em seguida, utilizou-se o sistema substrato-cromogênio - Envision Flex Substrate Working Solution $D A B$ + solução tamponada contendo peróxido de hidrogênio (Dakoß) - e realizou-se a contra-coloração com Hematoxilina de Mayer. A lâmina, por fim, foi montada de forma automática com o Coverslippler (Dako®) (Figura 18).

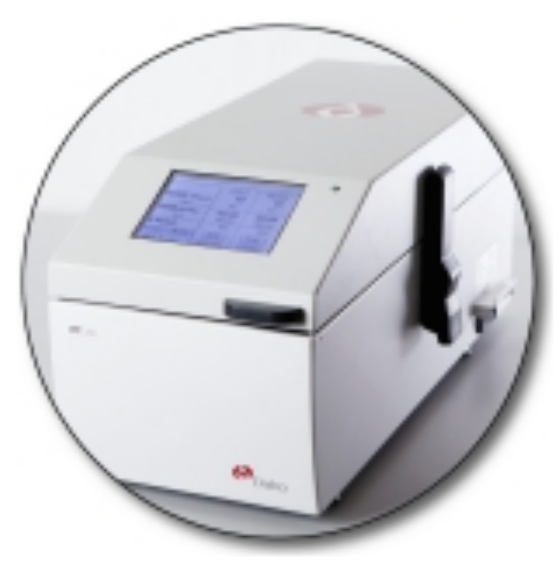

Figura 17 - Fotografia do PTLink (Dako®), sistema usado para deparafinização das lâminas e recuperação antigênica 


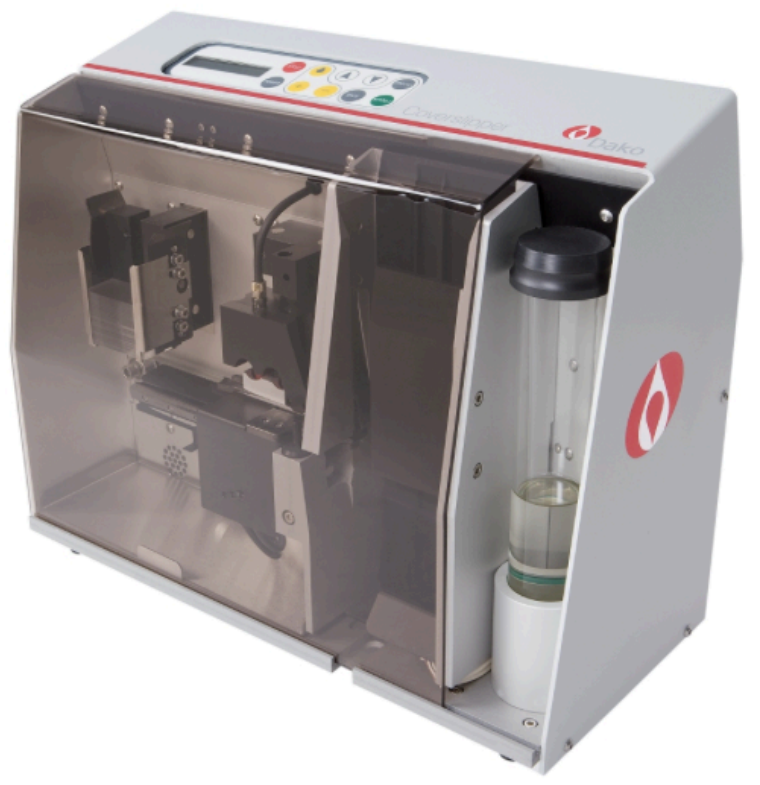

Figura 18 - Fotografia do Coverslippler (Dako®), sistema usado para montagem das lâminas

Tabela 1 - Especificação dos marcadores utilizados

\begin{tabular}{cccccccc}
\hline Marcador & Marca & Clone & Referência & Lote & pH recuperação & Tempo de recuperação (min) & Diluição \\
\hline Bcl-2 & Dako & 124 & M0887 & 42365 & alto & 20 & $1: 2000$ \\
Ki-67 & Dako & MIB-1 & M7240 & 65742 & baixo & 20 & $1: 3000$ \\
553 & Dako & DO-7 & M7001 & 40529 & baixo & 20 & $1: 100$ \\
RE & Cell-Marque & SP - 1 & $249 R-16$ & $1316403 \mathrm{e}$ & alto & 40 & $1: 750$ \\
\hline
\end{tabular}

\section{7 - INTERPRETAÇÃO IMUNOISTOQUÍMICA POR MICROSCOPIA ÓTICA}

As lâminas foram analisadas por uma patologista experiente por microscopia ótica (MO) e interpretadas de acordo com a intensidade e/ou frequência da expressão de cada marcador no epitélio e no estroma do endometrioma ovariano (Figura 19). 
O p53 e os receptores de estrogênio alfa foram analisados de acordo com o percentual de células que os expressavam.

Para a avaliação do Bcl-2 e Ki-67 foi utilizado o escore de imunohistoquímico $(E I H)$, considerando a porcentagem de células positivas e a intensidade de sua coloração. A porcentagem de positividade varia de 0 a $100 \%$ e à intensidade foi conferido a seguinte graduação: 0 - ausência de coloração; 1 - fraca; 2 - moderada; 3 - forte. O EIH foi calculado multiplicando a porcentagem de células positivas pela intensidade de coloração $(0-3)$, podendo variar de 0 a $300^{98,99}$.

\section{$\mathrm{EIH}=\%$ positividade $\mathrm{x}$ intensidade}
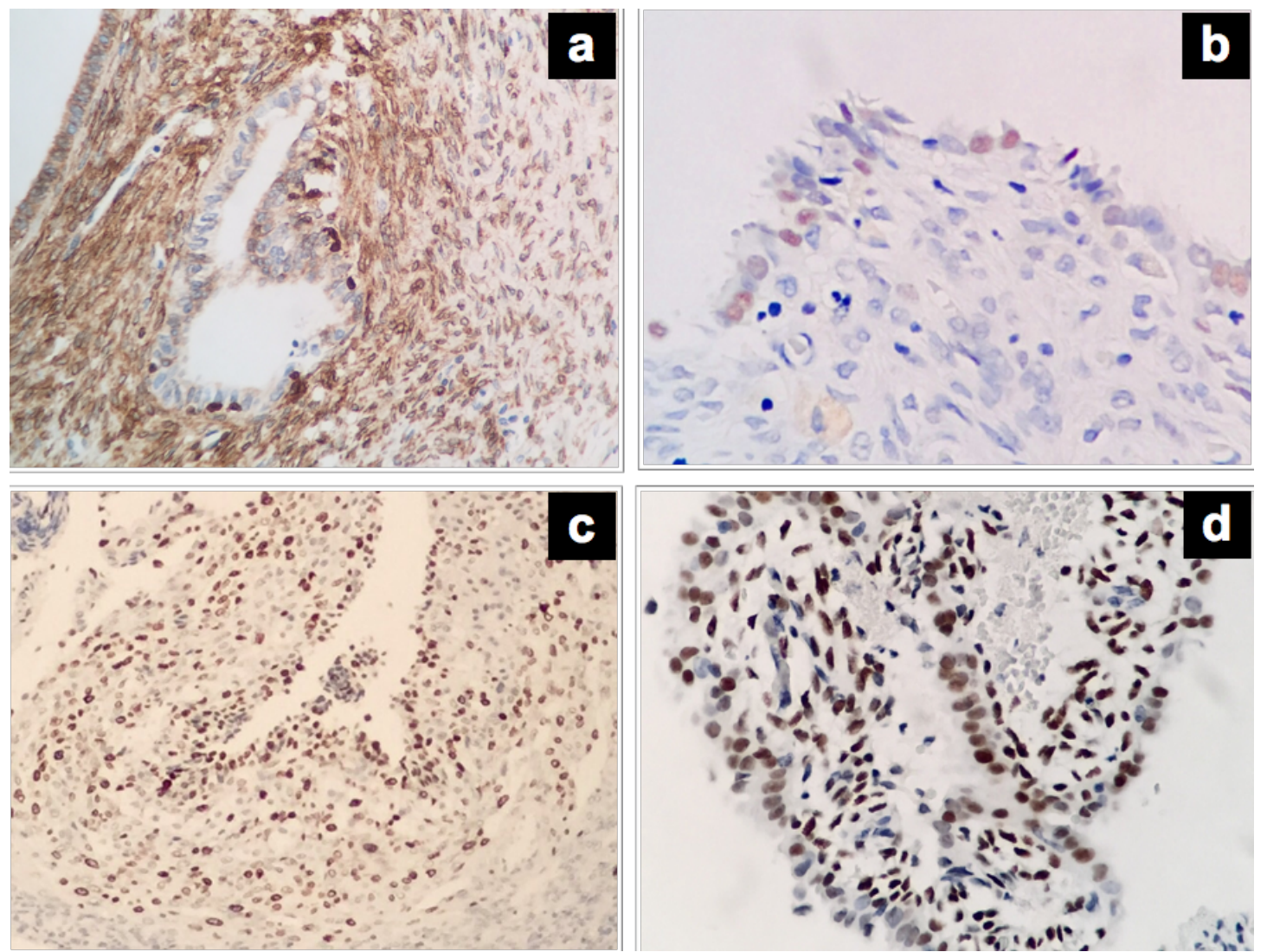

Figura 19 - Fotomicrografias ópticas da imunoistoquímica de espécimes de endometriose ovariana: a) Bcl-2; b) p53; c) Ki-67; d) RE 


\section{8 - ANÁLISE ESTATÍSTICA}

Realizou-se a análise descritiva dos dados, com distribuição de frequências para variáveis discretas, cálculo de média e desvio padrão para variáveis quantitativas. Diagramas box-plot foram empregados na apresentação dos marcadores.

Empregou-se o teste do Qui-quadrado de Pearson para análise de tabelas de contingência. Na observação de células com menos do que 5 observações, empregou-se a razão de máxima verossimilhança. Os testes comparativos das médias foram realizados utilizando a técnica de análise de variância - ANOVA - sempre que as condições de normalidade e homocedasticidade foram respeitadas, caso contrário, utilizou-se o teste não paramétrico de Kruskal-Wallis. Avaliou-se as correlações entre os marcadores através do coeficiente de Spearman.

Modelos de regressão logístical foram ajustados para avaliação do efeito da infiltração do parênquima ovariano, assim como na avaliação dos resultados dos marcadores, no epitélio e estroma. A variável idade foi incorporada aos modelos como covariada. Utilizou-se o teste Wald para avaliação dos parâmetros acima.

Foi considerado o nível de significância de $5 \%$ para todo estudo.

Os cálculos estatísticos foram realizados pelo software $\mathbf{R}(\mathrm{R}$ Core Team, 2012, Vienna, Austria). 
4. RESULTADOS

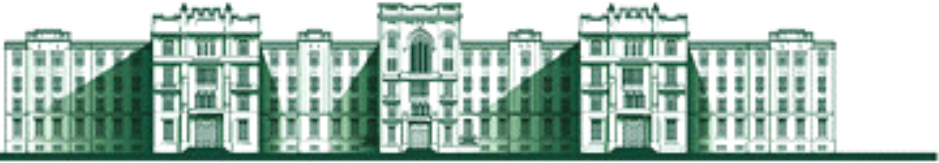


Das 63 pacientes incluídas no estudo, nove apresentaram doença bilateral, totalizando 72 ovários analisados. Cinco pacientes $(7,9 \%)$ foram submetidas a ooforectomia. A média etária foi de $33,1( \pm 6,1)$ anos. Os sintomas mais prevalentes foram infertilidade $(80 \% ; 28 / 35)$, dismenorréia (65\%; 41/63) e dispareunia de profundidade $(64,5 \% ; 40 / 62)$. Vinte e sete mulheres não tinham desejo reprodutivo e uma não apresentava vida sexual ativa. Em um pouco mais do que a metade destas mulheres constatou-se endometriose peritoneal e em $74,6 \%$ endometriose profunda. Nestas, a principal região acometida foi a retrocervical $(55,6 \%)$, seguida pelo envolvimento do retossigmóide em $44,4 \%$ das situações. Quarenta e três $(59,7 \%)$ pacientes apresentaram endometriose ovariana do padrão endometrioide. A forma de apresentação mais comum foi a cística, encontrada em $72,2 \%$ (52/72) dos casos, seguida pela intra-parenquimatosa e peritoneal, com frequências relativas de $22,2 \%(16 / 72)$ e $5,6 \%(4 / 72)$, respectivamente. Quando houve mais de um tipo de forma de apresentação da doença ovariana, conforme descrito nos métodos, os tipos de comprometimento foram categorizados de acordo com a severidade da doença. Dentre todas as apresentações, 30,5\% (22/72) apresentaram infiltração do parênquima adjacente. $\mathrm{Na}$ tabela 2 , pode-se notar as características clínicas, cirúrgicas e histopatológicas da pacientes estudadas. 
Tabela 2 - Características clínicas, cirúrgicas e histopatológicas das pacientes estudadas

\begin{tabular}{|c|c|c|c|}
\hline Idade (Anos) & & & $33,1 \pm 6,1$ \\
\hline \multicolumn{4}{|c|}{ Tipo de cirurgia } \\
\hline & Ooforoplastia & & $92,1 \%(58 / 63)$ \\
\hline & Ooforectomia & & $7,9 \%(5 / 63)$ \\
\hline \multicolumn{4}{|l|}{ Lateralidade } \\
\hline & Direita & & $44,4 \%(28 / 63)$ \\
\hline & Esquerda & & $41,3 \%(26 / 63)$ \\
\hline & Bilateral & & $14,3 \%(9 / 63)$ \\
\hline \multicolumn{4}{|l|}{ Sintomas } \\
\hline & Infertilidade & & $80 \%(28 / 35)$ \\
\hline & Dismenorréia & & $65 \%(41 / 63)$ \\
\hline & Dispareunia de profundidade & & $64,5 \%(40 / 62)$ \\
\hline & Alteração intestinal cíclica & & $27 \%(17 / 63)$ \\
\hline & Dor pélvica acíclica & & $22,2 \%(14 / 63)$ \\
\hline & Alteração urinária cíclica & & $11,1 \%(7 / 63)$ \\
\hline \multicolumn{4}{|c|}{ Outros locais de doença } \\
\hline & Peritônio & & $52,4 \%(33 / 63)$ \\
\hline & Profunda & & $74,6 \%(47 / 63)$ \\
\hline & & Bexiga & $7,9 \%(5 / 63)$ \\
\hline & & Ureter & $11,1 \%(7 / 63)$ \\
\hline & & Apêndice & $4,8 \%(3 / 63)$ \\
\hline & & Íleo & $1,6 \%(1 / 63)$ \\
\hline & & Retossigmóide & $44,4 \%(28 / 63)$ \\
\hline & & Retrocervical & $55,6 \%(35 / 63)$ \\
\hline & & Vagina & $11,1 \%(7 / 63)$ \\
\hline \multicolumn{4}{|c|}{$\begin{array}{l}\text { Tipos histológicos da doença } \\
\text { ovariana }\end{array}$} \\
\hline & Endometrioide & & $59,7 \%(43 / 72)$ \\
\hline & Não endometrioide & & $40,3 \%(29 / 72)$ \\
\hline \multicolumn{4}{|c|}{$\begin{array}{l}\text { Formas de apresentação da } \\
\text { endometriose ovariana }\end{array}$} \\
\hline & Cística & & $72,2 \%(52 / 72)$ \\
\hline & Intra-parenquimatosa & & $22,2 \%(16 / 72)$ \\
\hline & Peritoneal & & $5,6 \%(4 / 72)$ \\
\hline \multicolumn{4}{|c|}{$\begin{array}{l}\text { Formas de infiltração da } \\
\text { endometriose ovariana }\end{array}$} \\
\hline & Infiltrativa & & $30,5 \%(22 / 72)$ \\
\hline & Não infiltrativa & & $69,5 \%(50 / 72)$ \\
\hline \multicolumn{4}{|c|}{ Estadiamento ASRM* (1996) } \\
\hline & 1 & & $0 \%(0 / 63)$ \\
\hline & 2 & & $0 \%(0 / 63)$ \\
\hline & 3 & & $44,4 \%(28 / 63)$ \\
\hline & 4 & & $55,6 \%(35 / 63)$ \\
\hline
\end{tabular}

* ASRM = Classificação da American Society for Reproductive Medicine revisada em 1996 
Não houve associação entre os sintomas referidos com o tipo histológico e forma de apresentação da endometriose ovariana, como mostrado nas tabelas 3 e 4 .

Tabela 3 - Características clínicas das pacientes estudadas de acordo com o tipo histológico da endometriose ovariana

\begin{tabular}{lccc}
\hline & Endometrioide & Não endometrioide & $\boldsymbol{p}$ \\
\hline Dismenorréia & $79,2 \%(19 / 24)$ & $56,4 \%(22 / 39)$ & 0.06 \\
Dor pélvica acíclica & $16,7 \%(4 / 24)$ & $25,6 \%(10 / 39)$ & 0.603 \\
Dispareunia de profundidade & $58,3 \%(14 / 24)$ & $68,4 \%(26 / 38)$ & 0.6 \\
Alteração intestinal cíclica & $33,3 \%(8 / 24)$ & $23 \%(9 / 39)$ & 0.5 \\
Alteração urinária cíclica & $8,3 \%(2 / 24)$ & $12,8 \%(5 / 39)$ & 0.9 \\
Infertilidade & $69,2 \%(9 / 13)$ & $86,4 \%(19 / 22)$ & 0.4 \\
\hline
\end{tabular}

Tabela 4 - Características clínicas das pacientes estudadas de acordo com a forma de apresentação da endometriose ovariana

\begin{tabular}{lcccc}
\hline & Peritoneal & Cística & Intra-parenquimatosa & $\boldsymbol{p}$ \\
\hline Dismenorréia & $66,7 \%(2 / 3)$ & $68 \%(32 / 47)$ & $53,8 \%(7 / 13)$ & 0.6 \\
Dor pélvica acíclica & $0 \%(0 / 3)$ & $23,4 \%(11 / 47)$ & $23 \%(3 / 13)$ & 0.6 \\
Dispareunia de profundidade & $66,7 \%(2 / 3)$ & $58,7 \%(27 / 46)$ & $84,6 \%(11 / 13)$ & 0.2 \\
Alteração intestinal cíclica & $0 \%(0 / 3)$ & $27,7 \%(13 / 47)$ & $30,8 \%(4 / 13)$ & 0.5 \\
Alteração urinária cíclica & $0 \%(0 / 3)$ & $10,6 \%(5 / 47)$ & $15,4 \%(2 / 13)$ & 0.7 \\
Infertilidade & $100 \%(1 / 1)$ & $77,8 \%(21 / 27)$ & $85,7 \%(6 / 7)$ & 0.8 \\
\hline
\end{tabular}

A distribuição anatômica da doença foi considerada semelhante entre os diferentes tipos histológicos, assim como entre as formas de apresentação da endometriose ovariana (Tabelas 5 e 6). 
Tabela 5 - Características cirúrgicas das pacientes estudadas de acordo com o tipo histológico da endometriose ovariana

\begin{tabular}{llccc}
\hline & & Endometrioide & Não endometrioide & $\boldsymbol{p}$ \\
\hline Superficial & & $56,4 \%(22 / 39)$ & $45,8 \%(11 / 24)$ & 0.6 \\
Profunda & & $69,2 \%(27 / 39)$ & $83,3 \%(20 / 24)$ & 0.3 \\
& Bexiga & $10,3 \%(4 / 39)$ & $4,2 \%(1 / 24)$ & 0.7 \\
& Ureter & $5,1 \%(2 / 39)$ & $20,8 \%(5 / 24)$ & 0.1 \\
& Apêndice & $2,6 \%(1 / 39)$ & $8,3 \%(2 / 24)$ & 0.7 \\
& Íleo & $2,6 \%(1 / 39)$ & $0 \%(0 / 24)$ & 1 \\
& Retossigmóide & $41 \%(16 / 39)$ & $50 \%(12 / 24)$ & 0.7 \\
& Retrocervical & $56,4 \%(22 / 39)$ & $54,2 \%(13 / 24)$ & 1 \\
& Vagina & $12,8 \%(5 / 39)$ & $8,3 \%(2 / 24)$ & 0.9 \\
\hline
\end{tabular}

Tabela 6 - Características cirúrgicas das pacientes estudadas de acordo com a forma de apresentação da endometriose ovariana

\begin{tabular}{llcccc}
\hline & & Peritoneal & Cística & Intra-parenquimatosa & $\boldsymbol{p}$ \\
\hline Superficial & & $100 \%(3 / 3)$ & $48,9 \%(23 / 47)$ & $53,8 \%(7 / 13)$ & 0,1 \\
Profunda & & $100 \%(3 / 3)$ & $74,5 \%(35 / 47)$ & $69,2 \%(9 / 13)$ & 0,4 \\
& Bexiga & $0 \%(0 / 3)$ & $8,5 \%(4 / 47)$ & $7,7 \%(1 / 13)$ & 0,8 \\
& Ureter & $33,3 \%(1 / 3)$ & $8,5 \%(4 / 47)$ & $15,4 \%(2 / 13)$ & 0,5 \\
& Apêndice & $33,3 \%(1 / 3)$ & $4,3 \%(2 / 47)$ & $0 \%(0 / 13)$ & 0,2 \\
& Íleo & $0 \%(0 / 3)$ & $2,1 \%(1 / 47)$ & $0 \%(0 / 13)$ & 0,7 \\
& Retossigmóide & $33,3 \%(1 / 3)$ & $42,6 \%(20 / 47)$ & $53,8 \%(7 / 13)$ & 0,7 \\
& Retrocervical & $100 \%(3 / 3)$ & $55,3 \%(26 / 47)$ & $46,2 \%(6 / 13)$ & 0,1 \\
& Vagina & $0 \%(0 / 3)$ & $12,8 \%(6 / 47)$ & $7,7 \%(1 / 13)$ & 0,6 \\
\hline
\end{tabular}

Avaliou-se o efeito da presença de infiltração do parênquima ovariano adjacente (endometriose ovariana infiltrativa) nas repercussões clínicas e nos locais de doença. No entanto, não se evidenciou relação com sintomas, tampouco com a distribuição anatômica da endometriose (Tabelas 7 e 8). 
Tabela 7 - Análise da associação da endometriose ovariana infiltrativa com sintomas

\begin{tabular}{lccc}
\hline & Infiltrativa & Não infiltrativa & $\boldsymbol{p}$ \\
\hline Dismenorréia & $63,2 \%(12 / 19)$ & $65,9 \%(29 / 44)$ & 0,8 \\
Dor pélvica acíclica & $26,3 \%(5 / 19)$ & $20,5 \%(9 / 44)$ & 0,6 \\
Dispareunia de profundidade & $78,9 \%(15 / 19)$ & $58,1 \%(25 / 43)$ & 0,1 \\
Alteração intestinal cíclica & $31,6 \%(6 / 19)$ & $25 \%(11 / 44)$ & 0,6 \\
Alteração urinária cíclica & $10,5 \%(2 / 19)$ & $11,4 \%(5 / 44)$ & 0,9 \\
Infertilidade & $81,8 \%(9 / 11)$ & $79,2 \%(19 / 24)$ & 0,8 \\
\hline
\end{tabular}

Tabela 8 - Análise da associação da endometriose ovariana infiltrativa com a distribuição anatômica das lesões

\begin{tabular}{llccc}
\hline & & Infiltrativa & Não infiltrativa & $\boldsymbol{p}$ \\
\hline Superficial & & $54,5 \%(12 / 22)$ & $52 \%(26 / 50)$ & 0,8 \\
Profunda & & $77,3 \%(17 / 22)$ & $72 \%(36 / 50)$ & 0,8 \\
& Bexiga & $4,5 \%(1 / 22)$ & $8 \%(4 / 50)$ & 0,6 \\
& Ureter & $22,7 \%(5 / 22)$ & $8 \%(4 / 50)$ & 0,1 \\
& Apêndice & $9,10 \%(2 / 22)$ & $6 \%(3 / 50)$ & 0,6 \\
& Íleo & $4,5 \%(1 / 22)$ & $0 \%(0 / 50)$ & 0,1 \\
& Retossigmóide & $50 \%(11 / 22)$ & $42 \%(21 / 50)$ & 0,5 \\
& Retrocervical & $45,5 \%(10 / 22)$ & $56 \%(28 / 50)$ & 0,4 \\
& Vagina & $4,5 \%(1 / 22)$ & $12 \%(6 / 50)$ & 0,3 \\
\hline
\end{tabular}

Não foram observadas diferenças significativas na expressão dos marcadores Bcl-2, Ki-67, p53 e REa no epitélio e estroma da endometriose ovariana nas diferentes formas de apresentação (Gráficos 1 a 8). 
Gráfico 1 - Expressão do Bcl-2 no epitélio da endometriose ovariana de acordo com as formas de apresentação

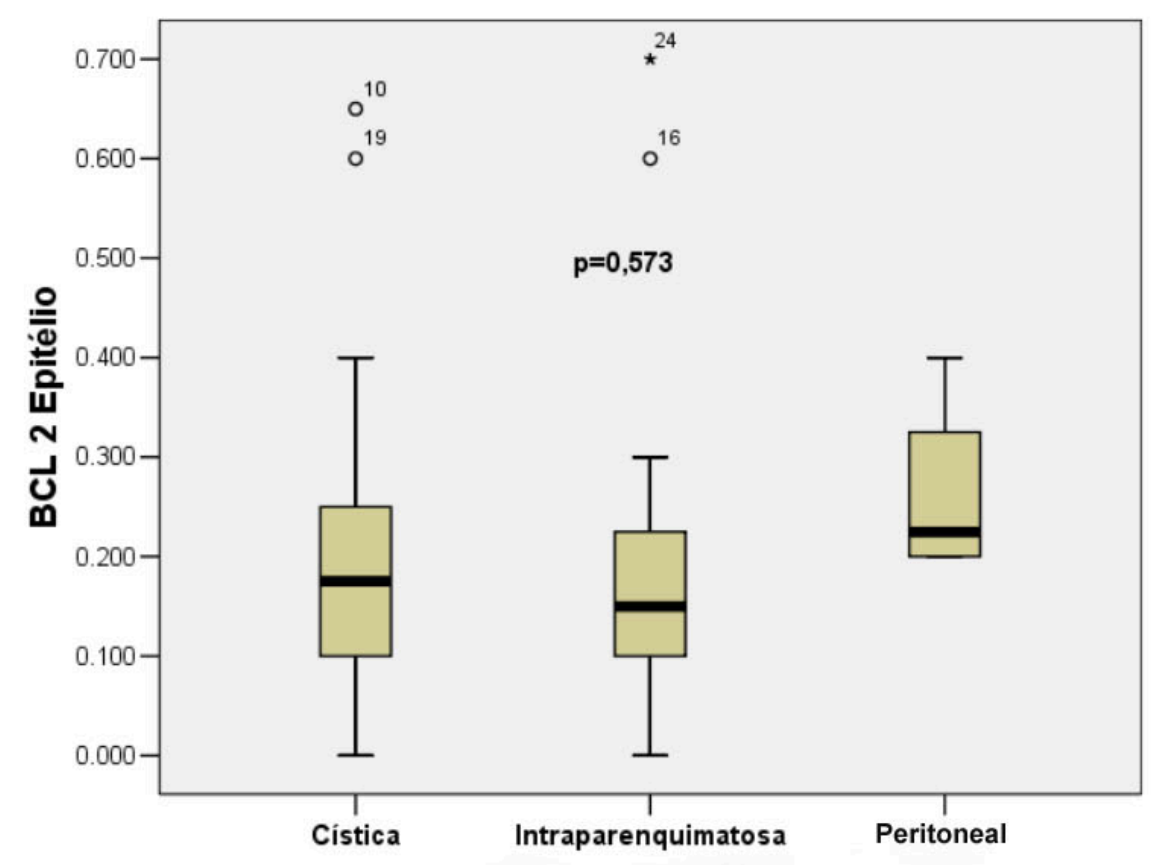

Gráfico 2 - Expressão do Bcl-2 no estroma da endometriose ovariana de acordo com as formas de apresentação

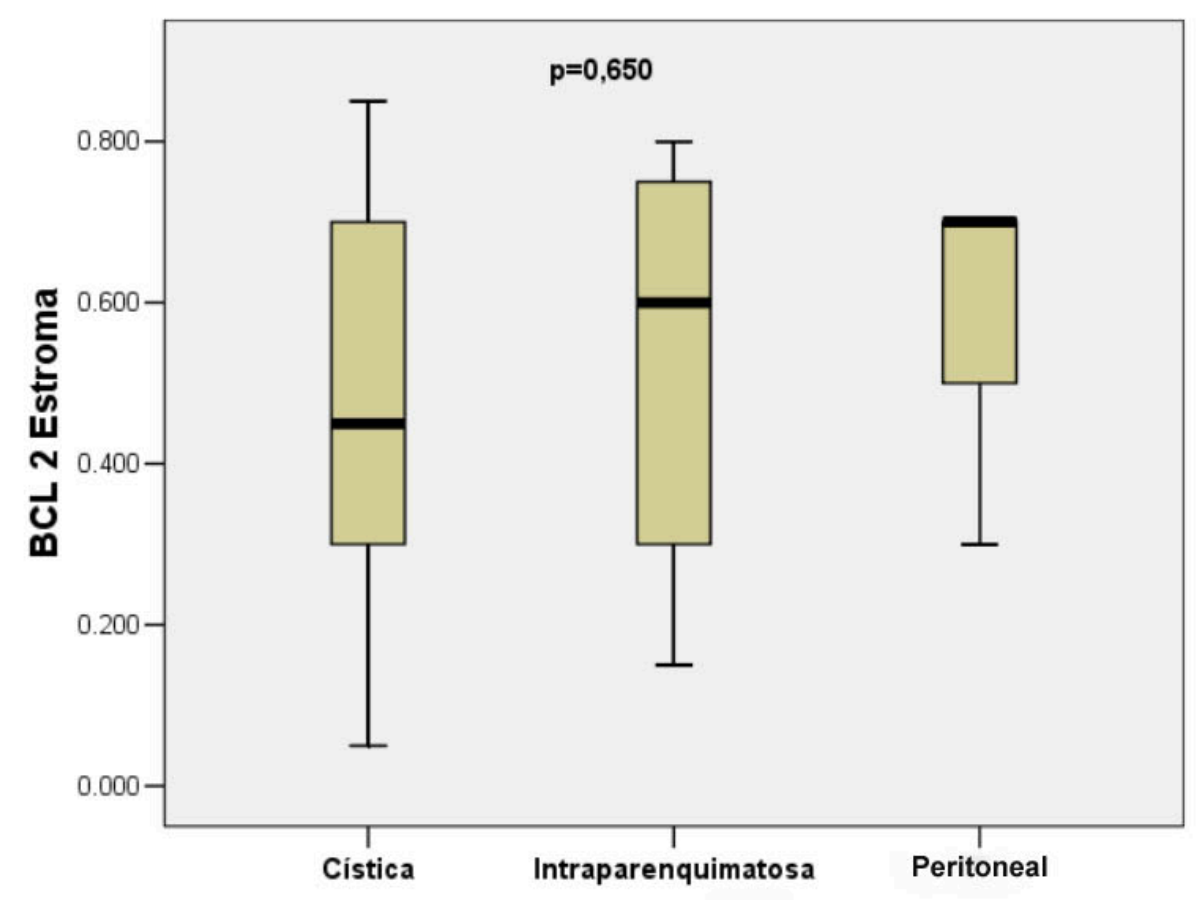


Gráfico 3 - Expressão do Ki-67 no epitélio da endometriose ovariana de acordo com as formas de apresentação

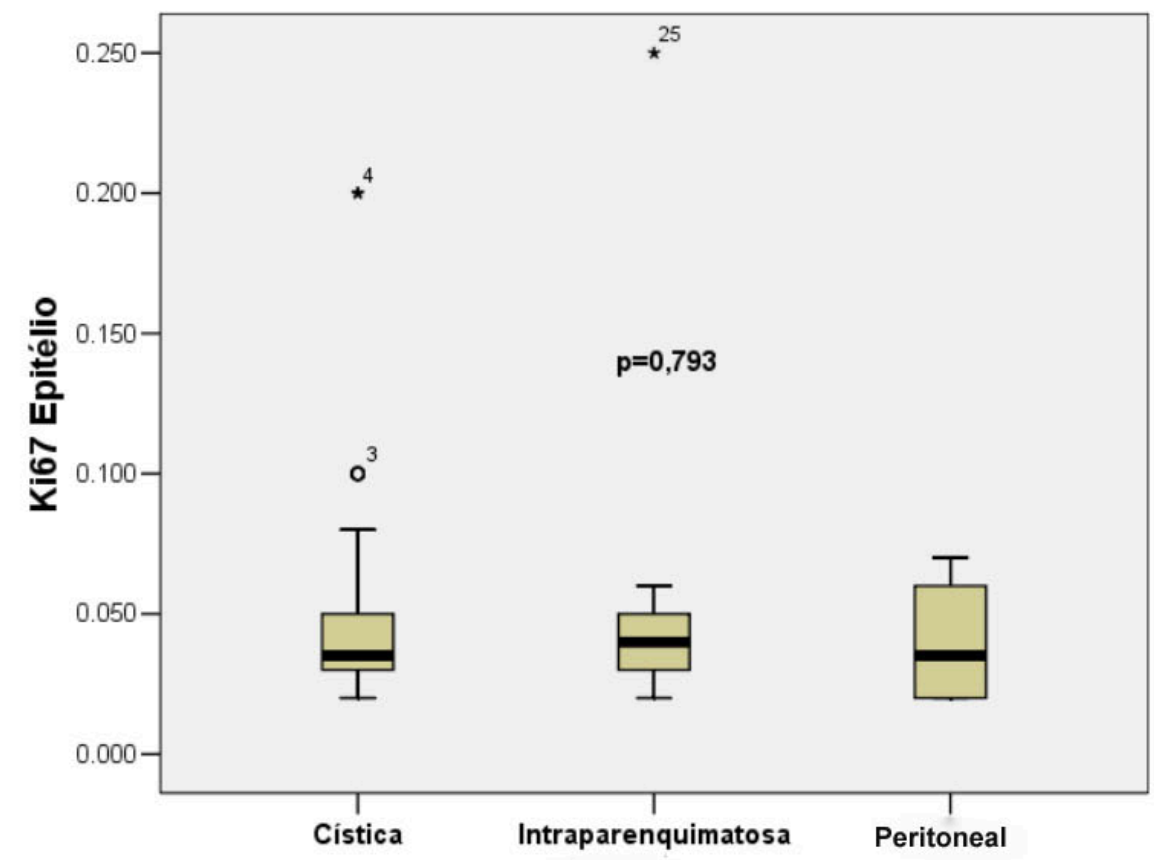

Gráfico 4 - Expressão do Ki-67 no estroma da endometriose ovariana de acordo com as formas de apresentação

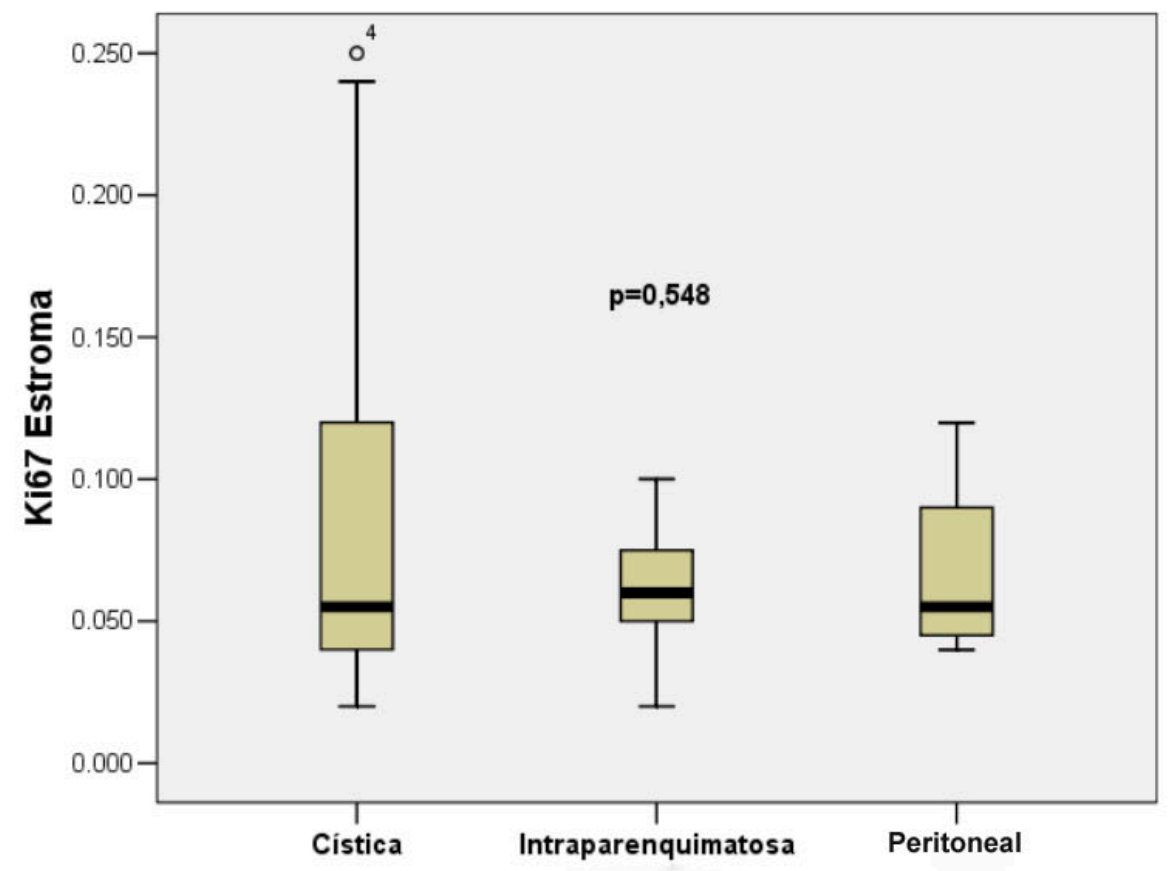


Gráfico 5 - Expressão do REa no epitélio da endometriose ovariana de acordo com as formas de apresentação

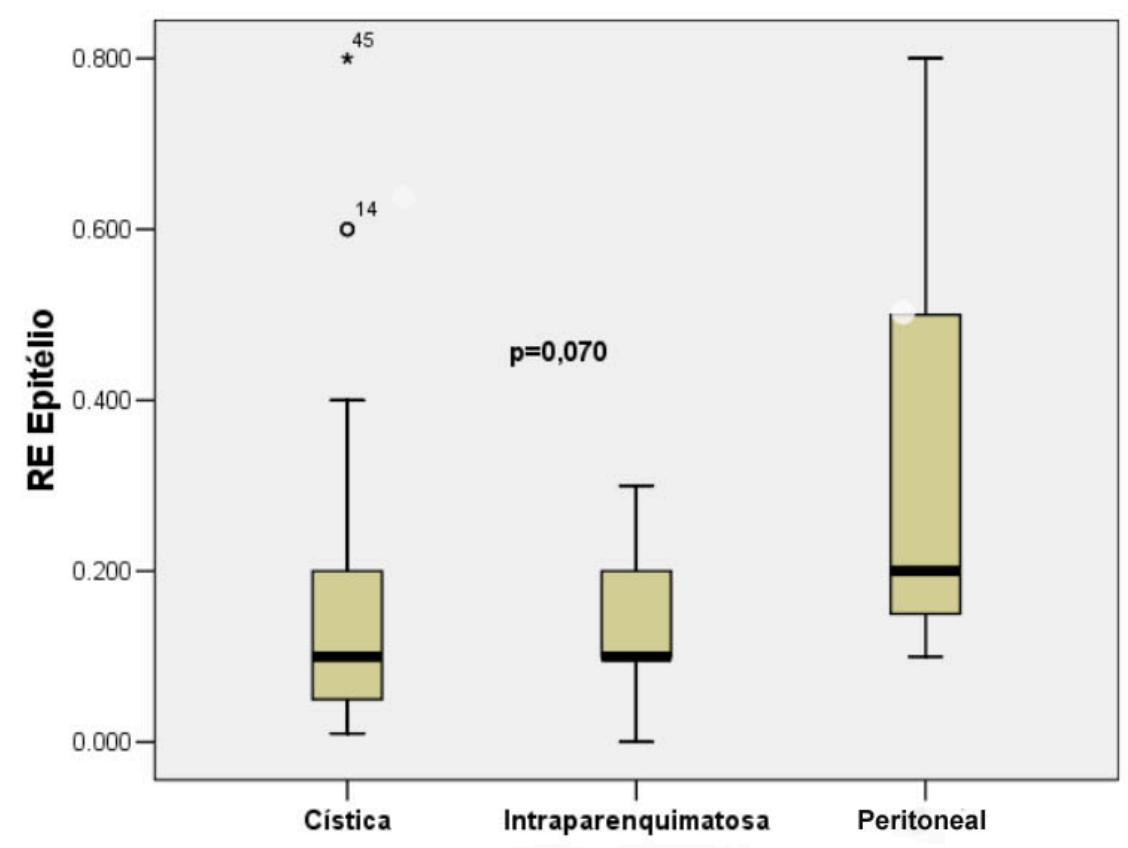

Gráfico 6 - Expressão do REa no estroma da endometriose ovariana de acordo com as formas de apresentação

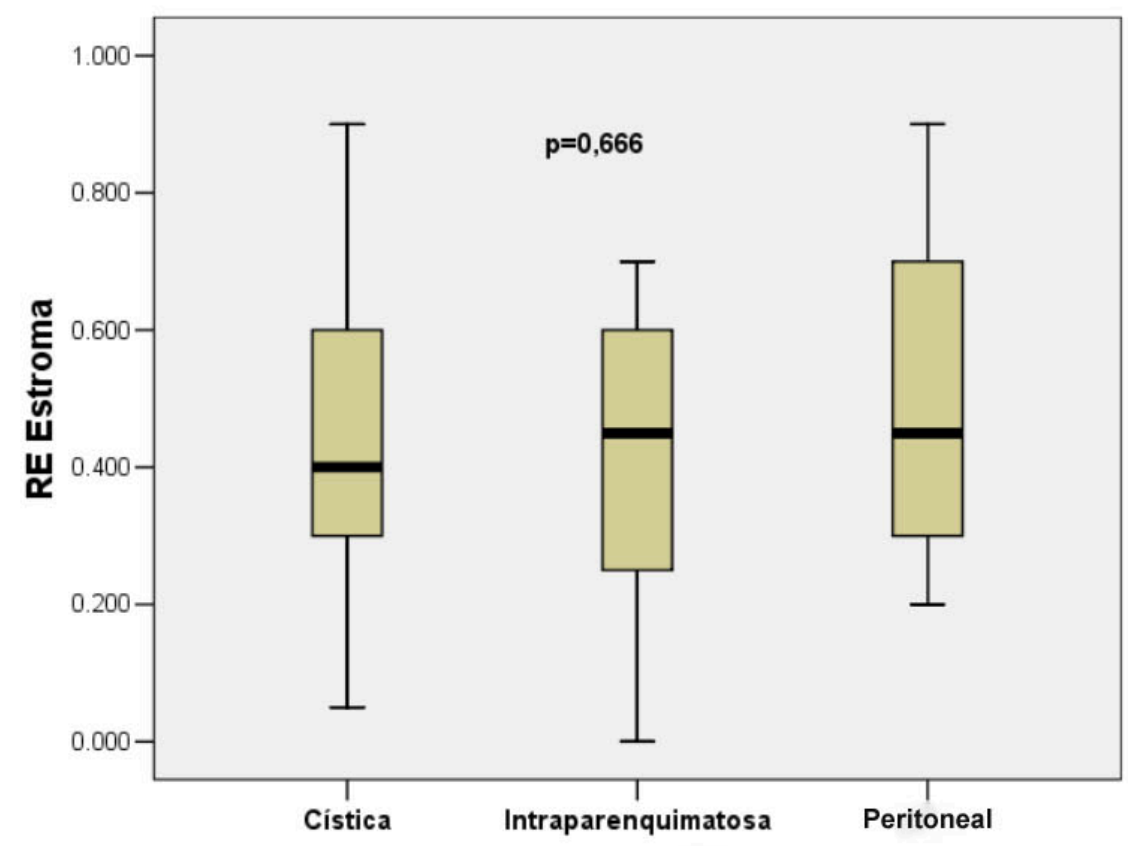


Gráfico 7 - Expressão do p53 no epitélio da endometriose ovariana de acordo com as formas de apresentação

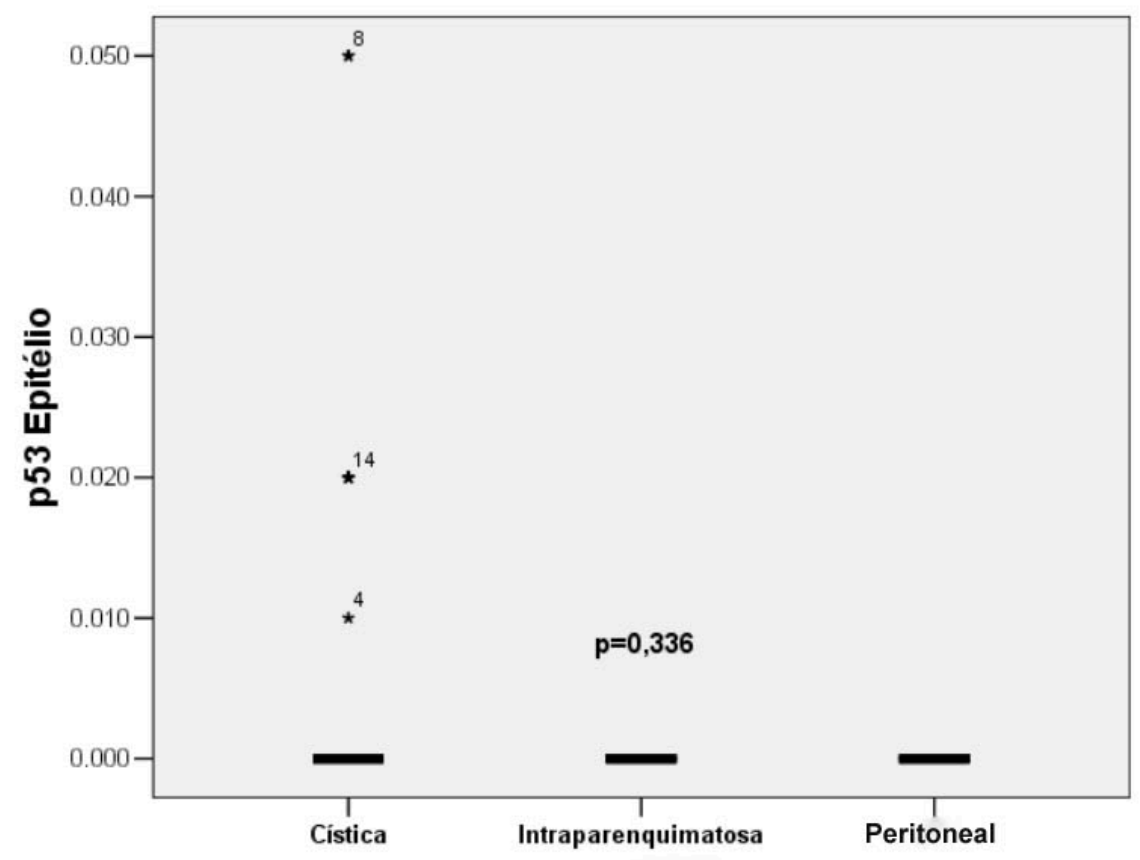

Gráfico 8 - Expressão do p53 no estroma da endometriose ovariana de acordo com as formas de apresentação

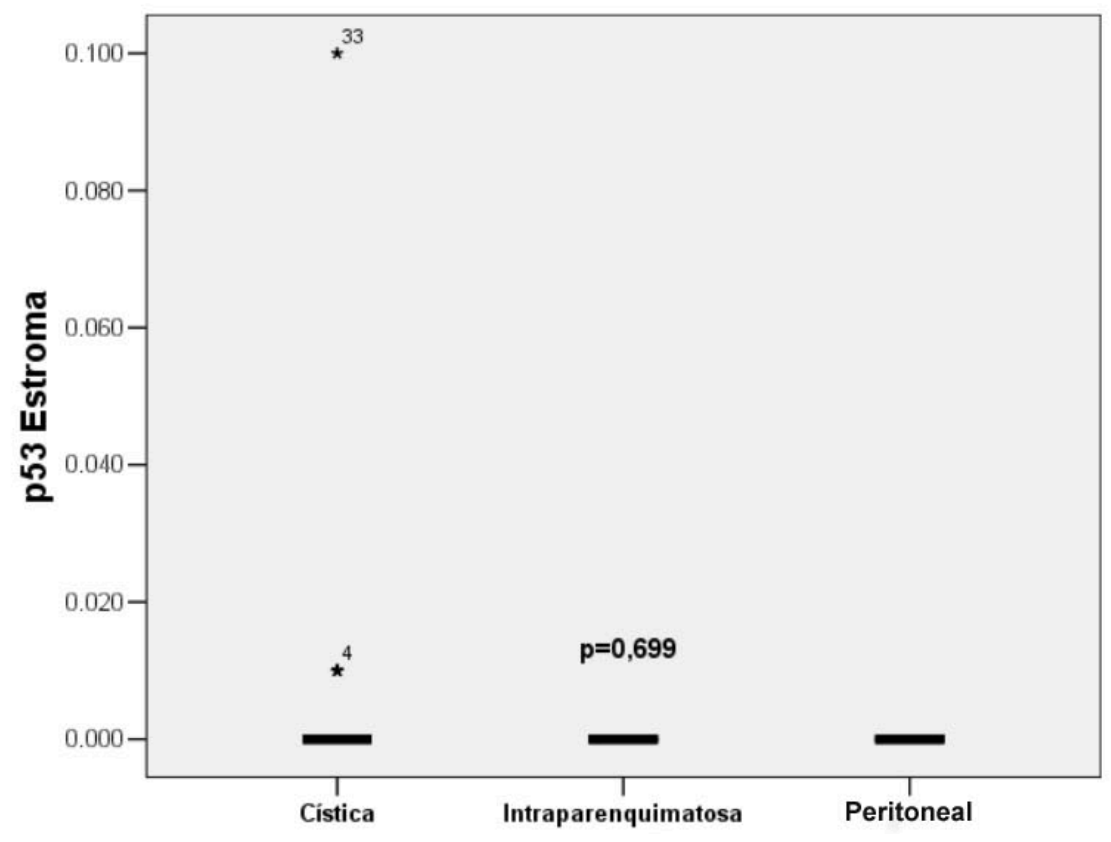


Não foram observadas diferenças significativas na expressão dos marcadores Bcl-2, Ki-67 e p53 no epitélio e no estroma da endometriose ovariana de acordo com a infiltração do parênquima ovariano adjacente (endometriose ovariana infiltrativa) (Gráficos 9 a 14).

Gráfico 9 - Expressão do Bcl-2 no epitélio da endometriose ovariana de acordo com a infiltração do parênquima adjacente

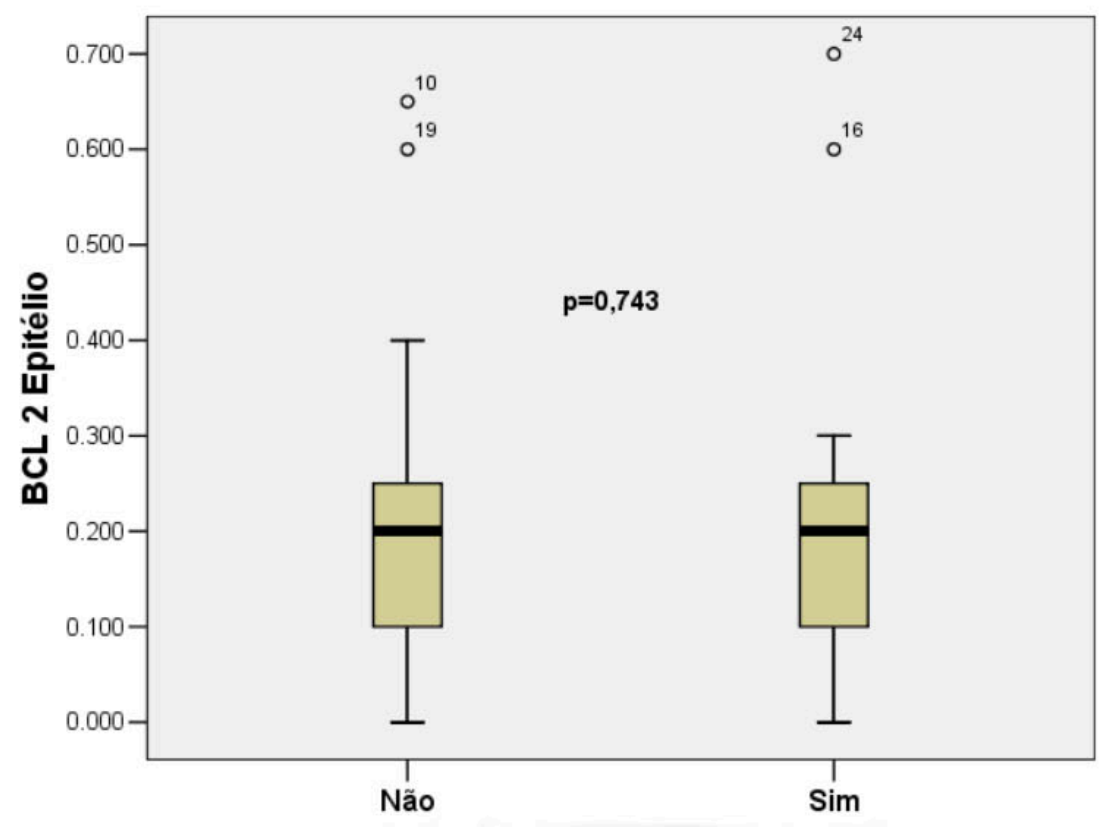


Gráfico 10 - Expressão do Bcl-2 no estroma da endometriose ovariana de acordo com a infiltração do parênquima adjacente

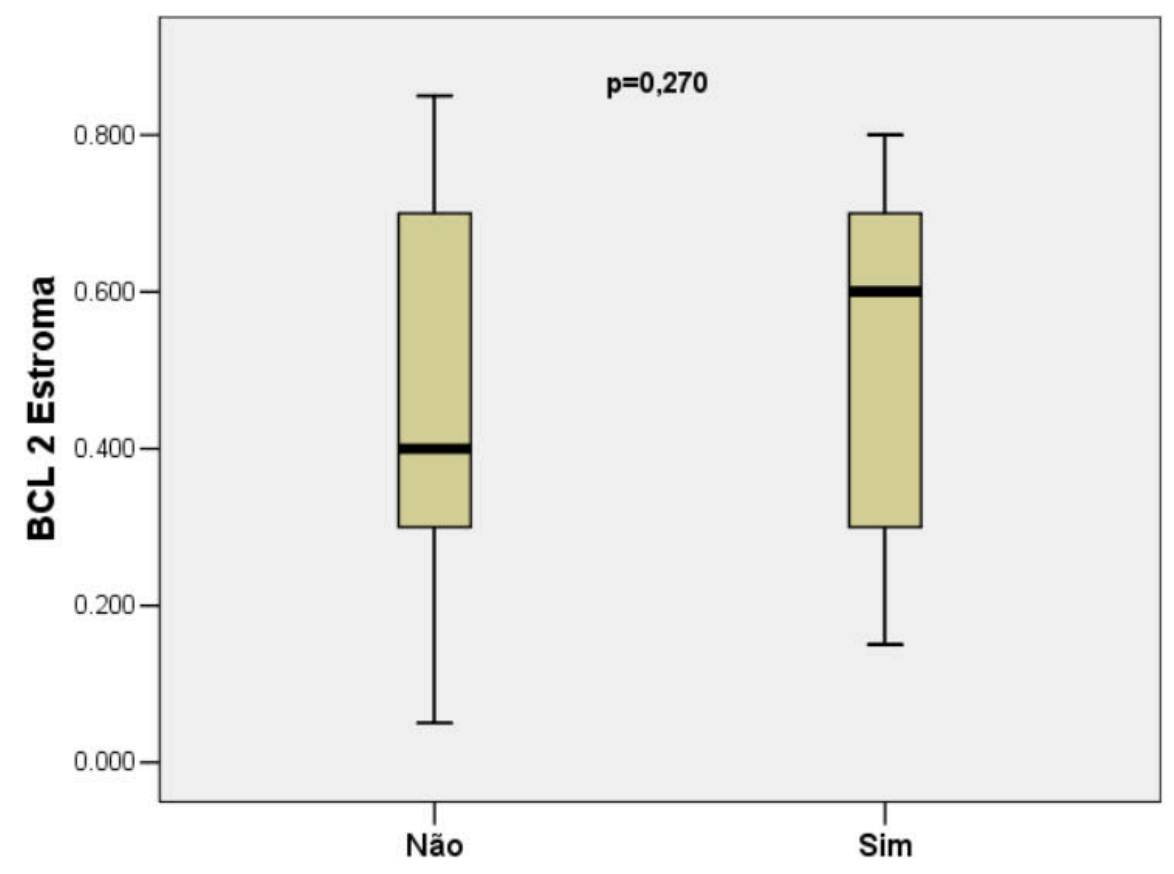

Gráfico 11 - Expressão do Ki-67 no epitélio da endometriose ovariana de acordo com a infiltração do parênquima adjacente

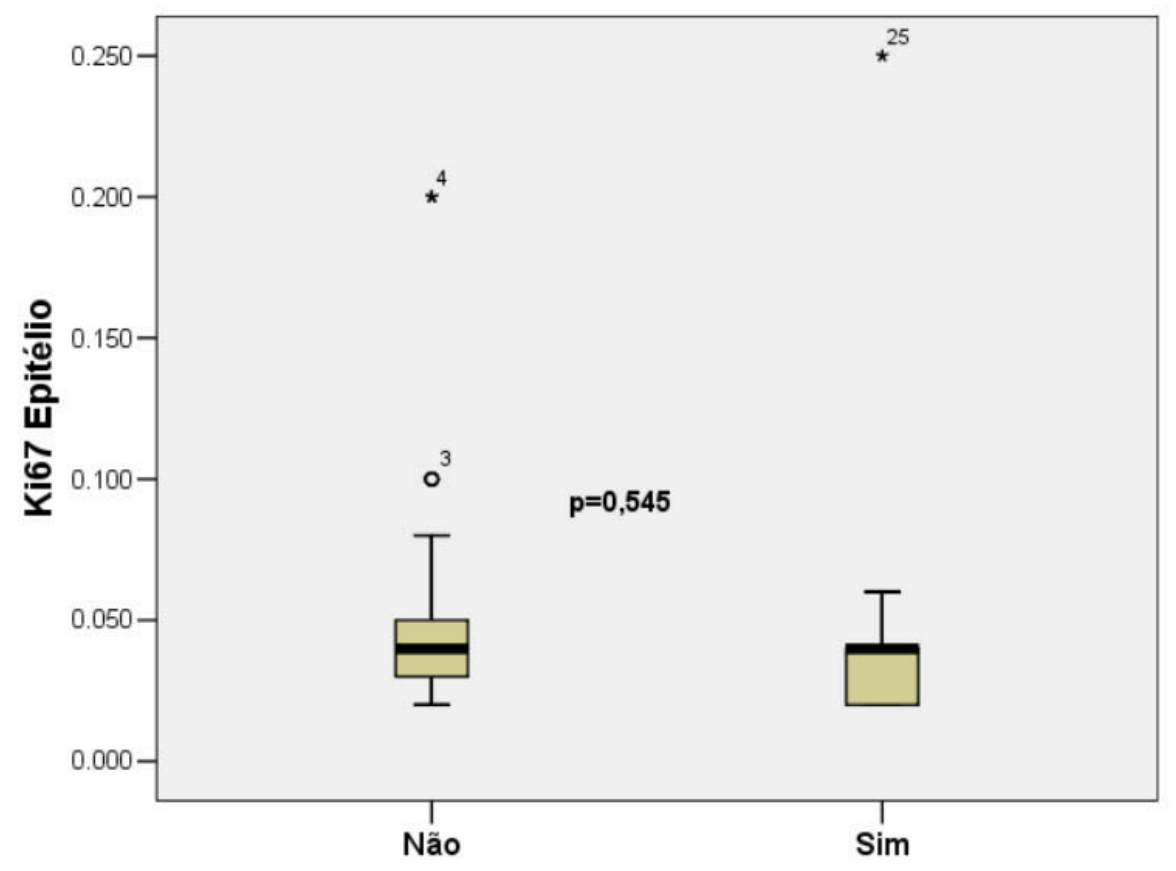


Gráfico 12 - Expressão do Ki-67 no estroma da endometriose ovariana de acordo com a infiltração do parênquima adjacente

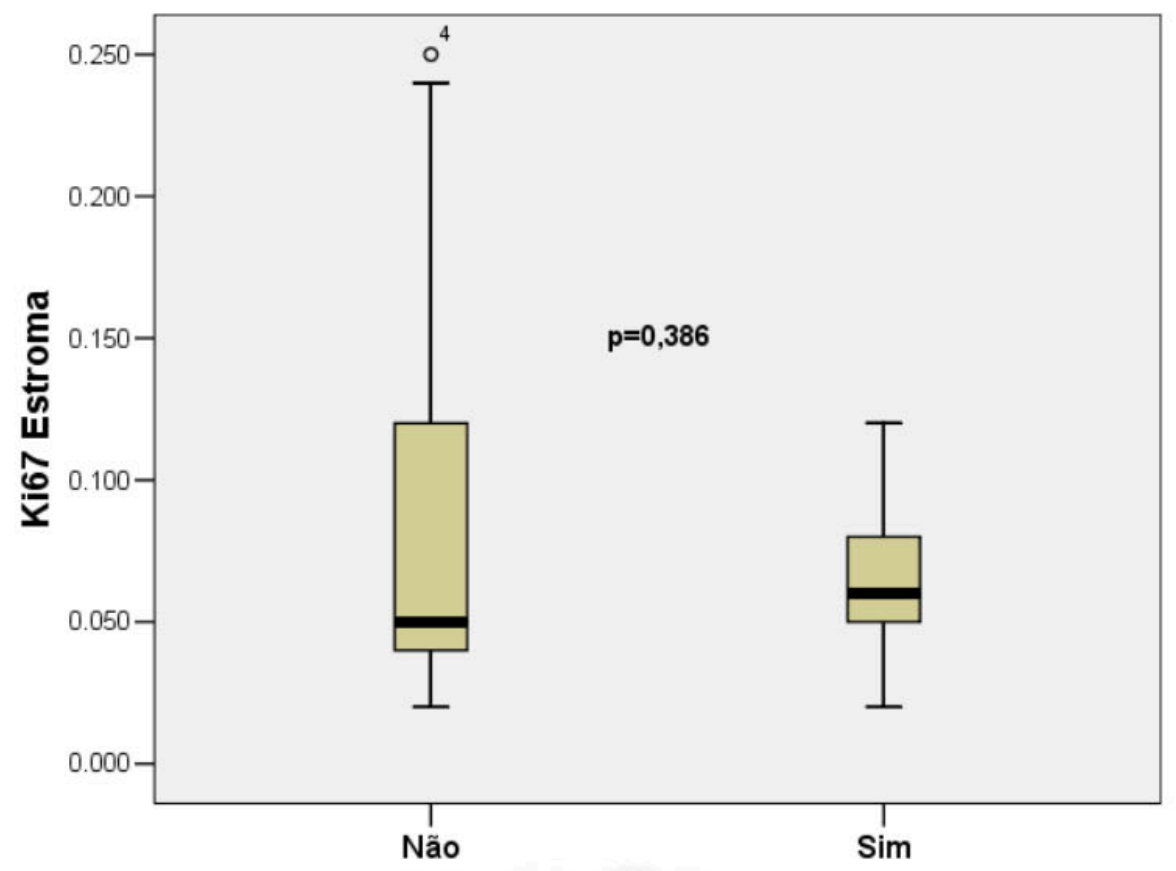

Gráfico 13 - Expressão do p53 no epitélio da endometriose ovariana de acordo com a infiltração do parênquima adjacente

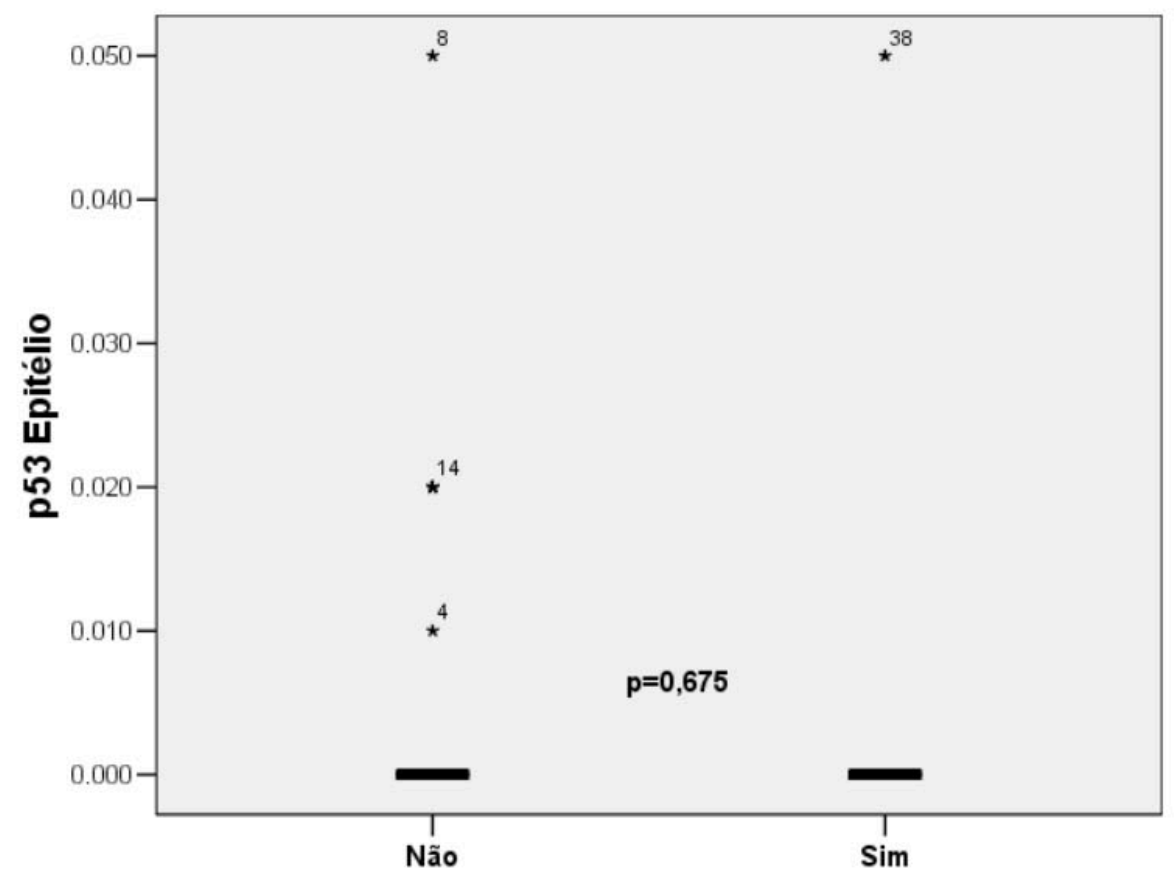


Gráfico 14 - Expressão do p53 no estroma da endometriose ovariana de acordo com a infiltração do parênquima adjacente

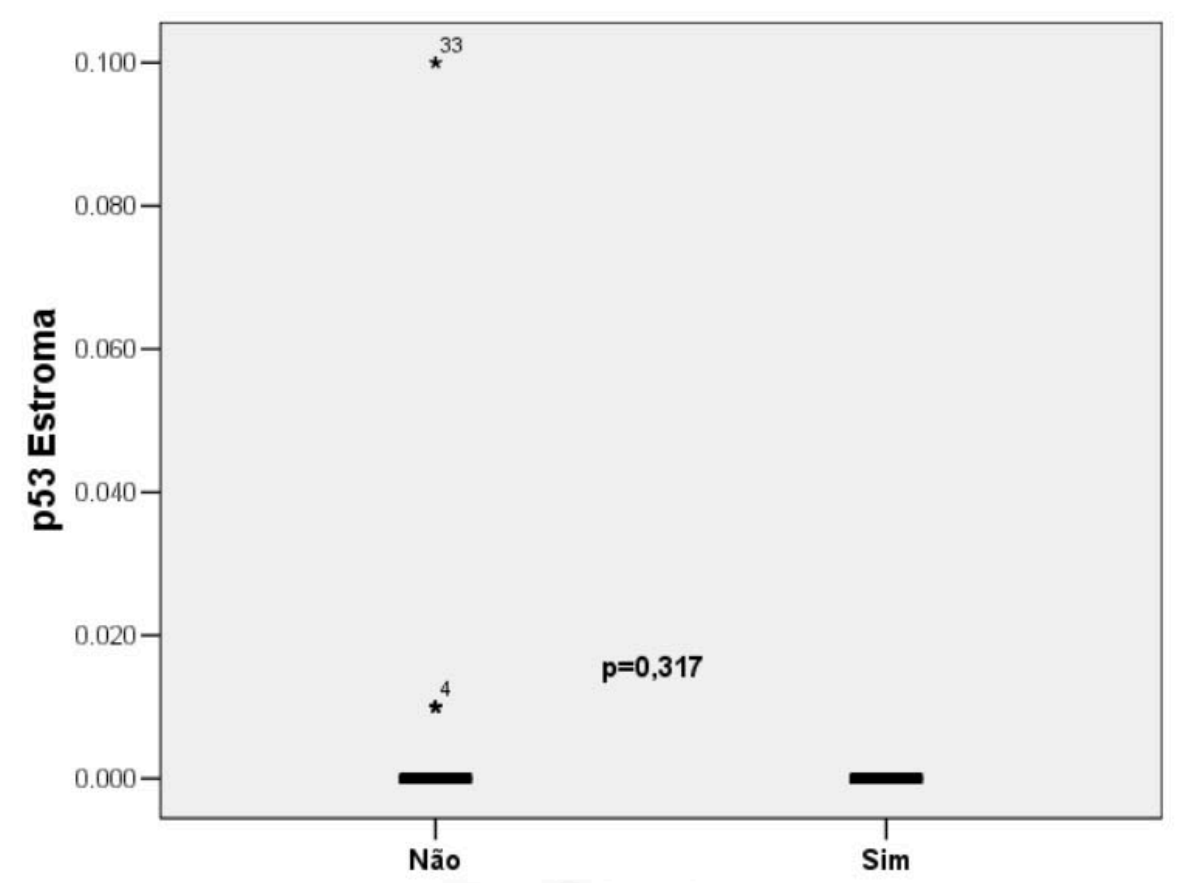

Sugere-se uma menor expressão dos REa no epitélio e no estroma das formas infiltrativas da endometriose ovariana (Gráficos 15 e 16). 
Gráfico 15 - Expressão do REa no epitélio da endometriose ovariana de acordo com a infiltração do parênquima adjacente

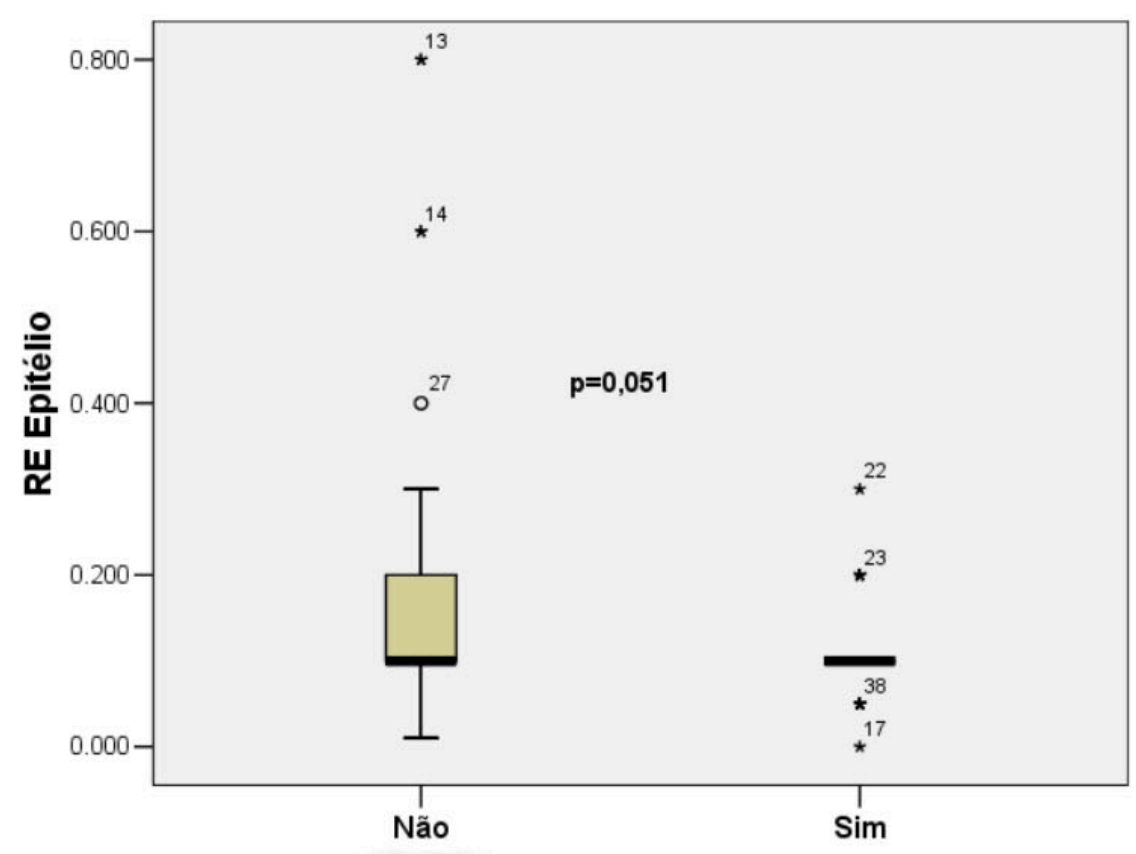

Gráfico 16 - Expressão do REa no estroma da endometriose ovariana de acordo com a infiltração do parênquima adjacente

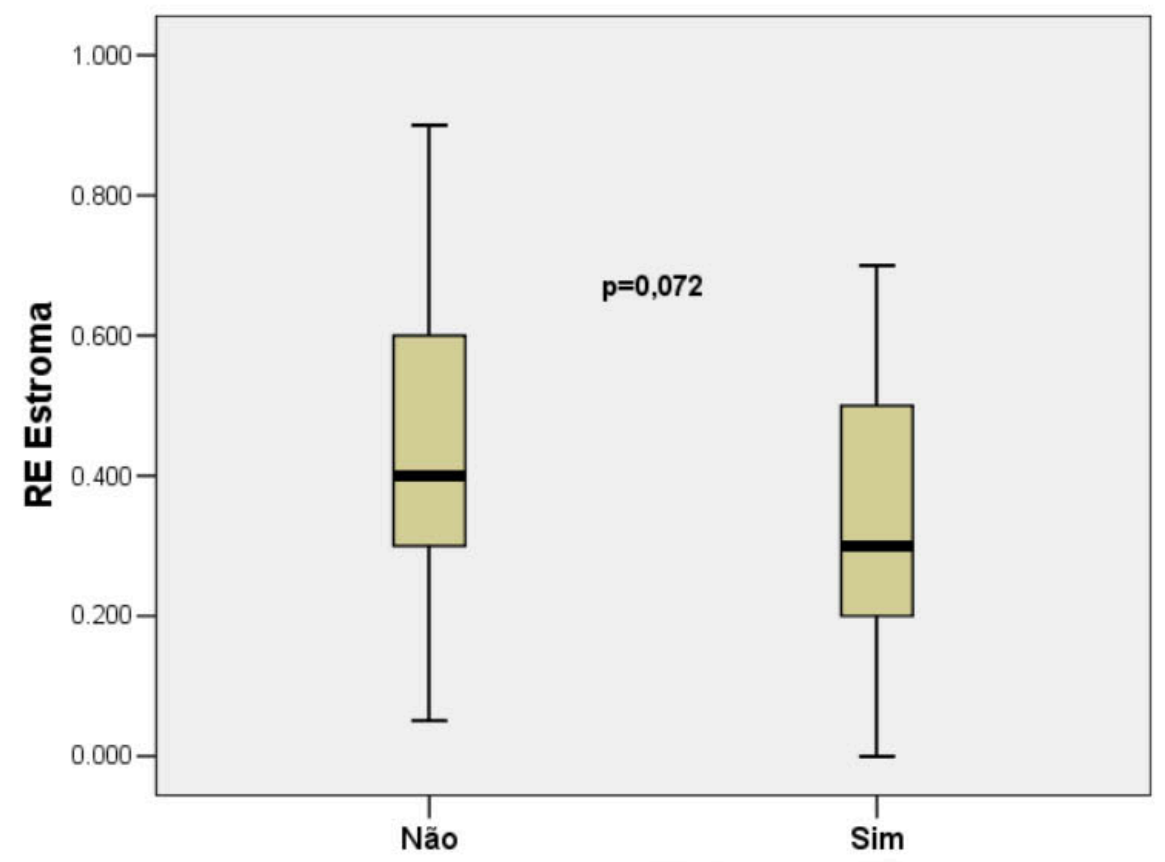


Avaliando a correlação entre os marcadores, verificou-se, no epitélio, uma baixa correlação negativa entre a expressão do Bcl-2 e do p53 ( $r_{\mathrm{s}}=$ $0,257 ; p<0,05)$ e uma baixa correlação positiva entra a expressão do Ki-67 e do p53 $\left(r_{s}=0,284 ; p<0,05\right)$ (Tabela 9). No estroma, verificou-se uma baixa correlação negativa entre as expressões do Bcl-2 e do Ki-67 ( $r_{\mathrm{s}}=-$ 0,259; $p<0,05)$ e do Bcl-2 e do p53 $\left(r_{s}=-0,349 ; p<0,01\right)$ e uma média correlação positiva entre a expressão do Ki-67 e do p53 $\left(r_{\mathrm{s}}=0,422 ; p<0,01\right)$ (Tabela 10).

Tabela 9 - Correlação entre os marcadores no epitélio do endometrioma ovariano

\begin{tabular}{ccccc}
\hline \multicolumn{5}{c}{ Correlação de Spearman (Epitélio) } \\
\hline Bcl -2 & Bcl-2 & Ki-67 & RE & p53 \\
Ki-67 & 1 & $-0,142$ & $-0,008$ & $-0,257^{*}$ \\
RE & $-0,142$ & 1 & 0,212 & $0,284^{*}$ \\
p53 & $-0,008$ & 0,212 & 1 & $-0,023$ \\
${ }^{*} p<0,05$ & $-0,257^{*}$ & $0,284^{*}$ & $-0,023$ & 1 \\
\hline
\end{tabular}

Tabela 10 - Correlação entre os marcadores no estroma do endometrioma ovariano

\begin{tabular}{ccccc}
\hline \multicolumn{5}{c}{ Correlação de Spearman (Estroma) } \\
\hline Bcl -2 & Bcl-2 & Ki-67 & RE & p53 \\
Ki-67 & 1 & $-0,259^{*}$ & 0,139 & $-0,349^{* *}$ \\
RE & $-0,259^{*}$ & 1 & 0,101 & $0,422^{* *}$ \\
p53 & 0,139 & & 1 & $-0,171$ \\
\hline & $-0,349 * *$ & $0,422^{* *}$ & $-0,171$ & 1 \\
\hline$<0,05 ;{ }^{* *} p<0,01$ & & &
\end{tabular}


Por fim, tentou-se identificar se as formas de apresentação, a presença de endometriose ovariana infiltrativa e a expressão dos marcadores (Bcl-2, Ki-67, p53 e REa) eram fatores associados aos sintomas e à distribuição anatômica da endometriose através de modelos de regressão logística. Não se identificou nenhum fator associado estatisticamente significante. 
5. DISCUSSÃO

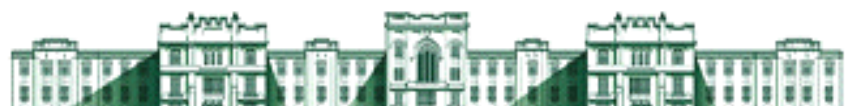

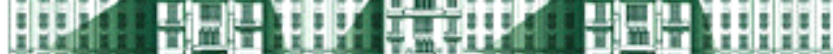


A endometriose ovariana representa agravo endócrino ginecológico controverso e desafiante. Cursa com variadas repercussões clínicas e seu tratamento envolve fármacos de pouca eficácia e cirurgias imprevisíveis.

Assume grande importância na pratica clinica, pois além de comprometer a função de um expressivo órgão endócrino-reprodutivo ovário - associa-se também a um maior risco de endometriose profunda tanto que é considerada seu marcador ${ }^{28}$; ademais, pode estar envolvida numa maior probabilidade de transformação maligna, quando comparada com o acometimento em outros sítios ${ }^{42}$.

Por ser de origem incerta, inúmeras teorias tentam explicá-la e, duas delas recentemente tem sido reativadas, como a da metaplasia celômica que justifica o conceito atual de endometriose intra-ovariana profunda e a da menstruação retrógrada, que explica a origem tubárea dos endometriomas ${ }^{29}$, 33,34 .

O nosso estudo reveste-se de originalidade, pois foi o pioneiro na identificação de três formas histológicas distintas da endometriose ovariana: a cística, a intra-parenquimatosa e a peritoneal.

A forma cística, a mais frequentemente por nós observada $(72,2 \%)$ se caracteriza pela presença macroscópica de um cisto com parede fibrosa cicatricial, comumente aderida ao folheto posterior do ligamento largo ou mesmo à superfície externa do útero; seu revestimento interno é preenchido, focal ou difusamente por tecido endometrioide, e áreas de infiltração da cápsula podem ser notadas no parênquima ovariano adjacente, resultado de uma extensão extracística, o que a caracteriza como uma das formas 
infiltrativas de endometriose ovariana. $\mathrm{Na}$ forma intra-parenquimatosa (22,2\% dos casos) constatamos a presença de tecido endometrióide na intimidade do estroma ovariano, com comportamento típico da forma infiltrativa. Essa frequência observada, difere dos 12\% obtidos por Donnez (1996), que admite sua origem a partir do processo de metaplasia de cistos de inclusão, uma vez que muitos endometriomas cursam sem aderências ao ligamento largo, ou seja, estão livres. Inclusões epiteliais são relatadas em $30 \%$ dos ovários e seu achado reforça a importância do papel do epitélio tubário na gênese da forma intraparenquimatosa, processo conhecido por endossalpingiose ${ }^{32,34}$. Entretanto, o reduzido número de ooforectomias realizadas $(7,9 \%$ dos casos) é um fator limitante no nosso estudo. Tal redução se deve ao fato de as participantes incluídas serem muito jovens, o que dificulta a correta análise histológica (o corte das peças pode falsear sua apresentação).

A forma de apresentação menos frequente que constatamos foi a peritoneal (5,6\% dos casos). Esse resultado pode estar subestimado, uma vez que o tratamento dessa forma habitualmente se faz por cauterização de seus focos, o que implica na não obtenção do material anátomo-patológico. Tal como a cística, a peritoneal pode apresentar extensão estromal, sendo por isso considerada a terceira forma infiltrativa da endometriose ovariana.

Ao contrário do observado na endometriose profunda, onde se nota nítida associação positiva entre gravidade de sintomas e o número de locais afetados pela doença, o presente estudo não caracterizou qualquer relação das três formas de endometriose ovariana com a clínica nem com a 
distribuição anatômica da doença ${ }^{23,}{ }^{100}$. Entretanto, comprovou histologicamente de maneira muito clara que as três formas podem ser infiltrativas, até mesmo para a peritoneal com extensão estromal. Na análise da influência da infiltração estromal dos endometriomas, em analogia à endometriose profunda, não constatamos qualquer relação sobre o comportamento clínico, nem sobre a distribuição da doença.

Para Chapron et al. a queixa de sintomas clínicos associados à endometriose ovariana sinaliza a presença de outros focos concomitantes da doença e que eles são os responsáveis diretos pelos sintomas ${ }^{26}$. Assim, apesar da clara diferenciação histológica das formas infiltrativas, o ovário, per se, não é a razão dos sintomas álgicos das pacientes.

No tocante a transformação maligna da endometriose ovariana já se sabe que seu risco varia entre 0,3 a $2,5 \%$ dos casos, sendo os carcinomas de células claras e o endometrioide os mais prevalentes ${ }^{40,101}$. Sua patogênese se fundamenta no conceito de que as células da maioria dos tumores epiteliais de ovário derivem das tubas ${ }^{45}$. Há uma evidente consistência para essa possibilidade, tanto pelo fenótipo mulleriano destes tumores, como pela relação anatômica entre tuba uterina e ovários; de fato, as fímbrias quando englobam a superfície ovariana na ovulação favorece o contato das células epiteliais tubáreas e ao se destacarem, facilitam a formação de cistos de inclusão na superfície gonadal (endosalpingiose). Nesses casos, o tipo do carcinoma a ser desenvolvido depende da expressão gênica das células tubáreas, sendo os serosos de alto grau aqueles que apresentam mais prevalentemente a mutação no gene TP53 ${ }^{45}$. 
Os carcinomas de células claras e endometrioide, comumente associados à endometriose derivam do tecido endometrial, que atinge a superfície ovariana, via menstruação retrógrada ${ }^{101}$. Assim, frente ao conhecimento do papel das tubas uterinas na gênese de alguns fenótipos da endometriose ovariana é possível que haja uma interssecção entre os subtipos apresentados ${ }^{102}$.

Ogawa et al. (2000) ao estudarem a atividade proliferativa nas portadoras de endometriose, por meio do Ki-67, com o intuito de avaliar a transição da endometriose típica para atípica e da forma atípica para carcinoma notaram que ocorre uma evolução crescente da atividade proliferativa, sugerindo um processo contínuo e evolutivo da transformação maligna ${ }^{103}$. Os resultados de Castiblanco et al. (2006) foram idênticos, pois constataram maior expressão do Ki-67 na endometriose atípica quando comparado com a típica confirmando assim uma correlação direta entre atipia e alto índice de proliferação celular ${ }^{104}$.

Visando identificar a forma histológica de endometriose ovariana que expressasse um padrão mais proliferativo, e assim sugerir um maior potencial de malignização, estudamos, e não constatamos, qualquer relação entre formas histológicas e comportamento molecular, nem dependência hormonal, proliferação celular e perturbação dos mecanismos pró e antiapoptóticos. Não encontramos nenhuma amostra de endometriose atípica em nossa coorte, apesar de uma frequência descrita de $1,7 \%$ na literatura ${ }^{48}$. Kurman (2010) descreveu a presença de mutação no gene TP53 em mais de $80 \%$ dos casos de carcinomas epiteliais avançados ${ }^{45}$. A expressão 
aumentada da p53 é considerada a alteração genética mais comum no câncer de ovário, principalmente nos serosos, mas também está presente em $30 \%$ e $10 \%$ dos carcinomas endometrioides e de células claras, respectivamente ${ }^{105,106}$. Dufournet et al. (2006) na avaliação da expressão das proteínas relacionadas à apoptose na endometriose peritoneal, ovariana e intestinal identificaram aumento da p53 na endometriose ovariana quando comparada com a peritoneal e intestinal, bem como menor expressão do Bcl-2 na endometriose ovariana quando comparada com a peritoneal e intestinal ${ }^{90}$. Este achado ovariano é contrário aos demonstrados por outros autores, que relataram completa ausência de expressão da p53 nos endometriomas, com ou sem atipia 107, 108. Vigano et al. (2006) sustentam que a imunorreatividade para p53 é indetectável na endometriose não associada a carcinomas. Sugere-se, portanto que a expressão alterada da p53 ocorra em uma fase mais tardia da doença e reflita uma maior agressividade $^{106}$.

Na nossa amostra, a expressão do p53 foi nula na maioria dos casos, sendo que, quando presente, nunca ultrapassou $10 \%$ das células, provavelmente refletindo o baixo potencial maligno destas lesões e a baixa associação com carcinomas serosos de alto grau.

Na avaliação e comparação que fizemos em relação à expressão dos RE, Ki-67, Bcl-2 e p53 no epitélio, não constatamos diferenças entre as formas de apresentação; tal achado, possivelmente possa ter decorrido de algumas razões, como o painel de marcadores estudados não terem sido o mais adequado para identificação das formas específicas de endometriose 
ovariana; a muito baixa prevalência de câncer de ovário em pacientes com endometriose, o que pode ter dificultado a avaliação; a dificuldade de identificar, as alterações que ocorrem tardiamente na transição entre tecido benigno e maligno, pela raridade da condição estudada.

$\mathrm{Na}$ endometriose há um desequilíbrio no mecanismo apoptótico. As células endometriais que refluem para a cavidade peritoneal através das tubas uterinas são desprovidas de mecanismos adequados de apoptose, o que Ihes permitem escapar da vigilância imunológica e, assim, invadir a superfície peritoneal, processo que, associado à neovascularização, favorece o estabelecimento da doença ${ }^{109}$. Este desequilíbrio associa-se à superexpressão de fatores anti-apoptóticos e subexpressão de fatores próapoptóticos ${ }^{110}$. E, vários genes relacionados à apoptose estão expressos diferenciadamente na endometriose, variando com a localização e o tipo de lesão ${ }^{78,90}$.

A análise da expressão dos marcadores entre si, tanto no epitélio quanto no estroma, mostrou que ocorre uma correlação negativa entre a expressão do Bcl-2 e do p53 em ambos sítios, ou seja, há um aumento da expressão de proteínas com fatores pró-apoptóticos, que redunda na redução dos fatores anti-apoptóticos, visando o encontro do equilíbrio. Correlação positiva foi notada entre a expressão do Ki-67 e do p53 no epitélio e estroma, sinalizando que o aumento da atividade proliferativa é acompanhado de maior atividade de fatores pró-apoptóticos. Por fim, identificamos uma correlação negativa entre a expressão do Bcl-2 e do Ki-67 
no estroma ovariano sugerindo que o aumento da proliferação celular se acompanha na diminuição da atividade de fatores anti-apoptóticos.

Quanto à expressão dos receptores de estrogênio, não evidenciamos qualquer correlação, fato que sinaliza uma independência hormonal das diferentes formas de apresentação, diferenciação e infiltração da endometriose ovariana.

Do exposto, baseado em nossos resultados, pode-se concluir que a endometriose ovariana apresenta claramente formas de apresentação histológicas distintas, com potencial infiltrativo. Entretanto, não demonstramos diferenciação clínica entre elas. São necessários mais estudos para melhor compreender o significado de tais individualizações.

Assim, a endometriose - agravo endócrino, imuno-genético e comportamental - ainda continua sendo uma condição enigmática, misteriosa e desafiante! 
6. CONCLUSÕES ing 
O presente estudo permitiu-nos concluir que:

1. Três são as formas de apresentação da endometriose ovariana: cística, intraparenquimatosa e peritoneal;

2. A forma de apresentação mais freqüente foi a cística $(72,2 \%)$, seguida pela intraparenquimatosa $(22,2 \%)$ e peritoneal (5,6\%). A endometriose ovariana foi caracterizada como infiltrativa em $30,5 \%$ dos casos e não infiltrativa em 69,5\%;

3. Não há associação entre as formas de apresentação da afecção com sintomas clínicos, nem com o comprometimento extra-ovariano;

4. Não há associação entre as formas de apresentação com a expressão imunoistoquímica dos receptores de estrogênios do tipo alfa, nem com a expressão das proteínas Ki-67, Bcl2 e p53. 


\section{ANEXOS}

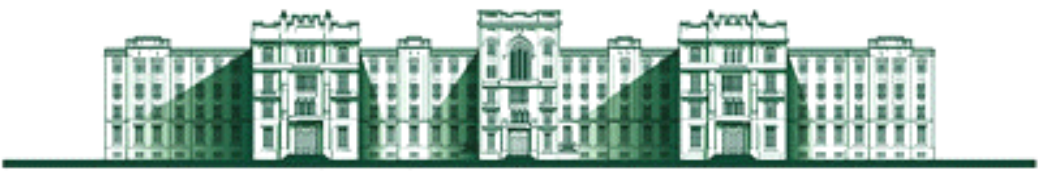




\title{
Anexo A - Aprovação do comitê de ética e pesquisa da FMUSP
}

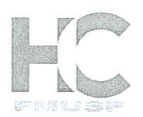

\author{
Hospital das Clínicas da FMUSP \\ Comissão de Ética para Análise de Projetos de Pesquisa \\ CAPPesq
}

No Protocolo: 0525/11

Título: CARACTERIZAÇÃO MORFOLÓGICA DA ENDOMETRIOSE OVARIANA E POSSIVVEIS REPERCUSSÕES CLIINICAS

Pesquisador Responsável: Maurício Simões Abrão

Pesquisador Execułante: Luiz Flávio Cordeiro Fernandes

Finalidade Acadêmica: Doutorado

Departamento: OBSTETRÍCIA E GINECOLOGIA

A Comissão de Ética para Análise de Projetos de Pesquisa CAPPesq da Diretoria Clínica do Hospital das Clínicas da Faculdade de Medicina da Universidade de São Paulo, APRovou na sessão datada de 17/08/2011 ○ protocolo acima.

A CAPPesq em obediência à Resolução CNS 196/96, solicita ao pesquisador (a) s elaboração de relatório parcial e final.

No caso de relatório parcial é necessário informar o tempo previsto para a conclusão do protocolo e breve resumo dos resultados obtidos.

CAPPesq, 22 de Agosto de 2011.

PROF. DR. EUCLIDES AYRES DE CASTILHO Coordenador

Comissão de Ética para Análise de Projetos de Pesquisa - CAPPesq 
Anexo B - Dados referentes à análise histológica da endometriose ovariana, sintomas clínicos e outros locais concomitantes de doença

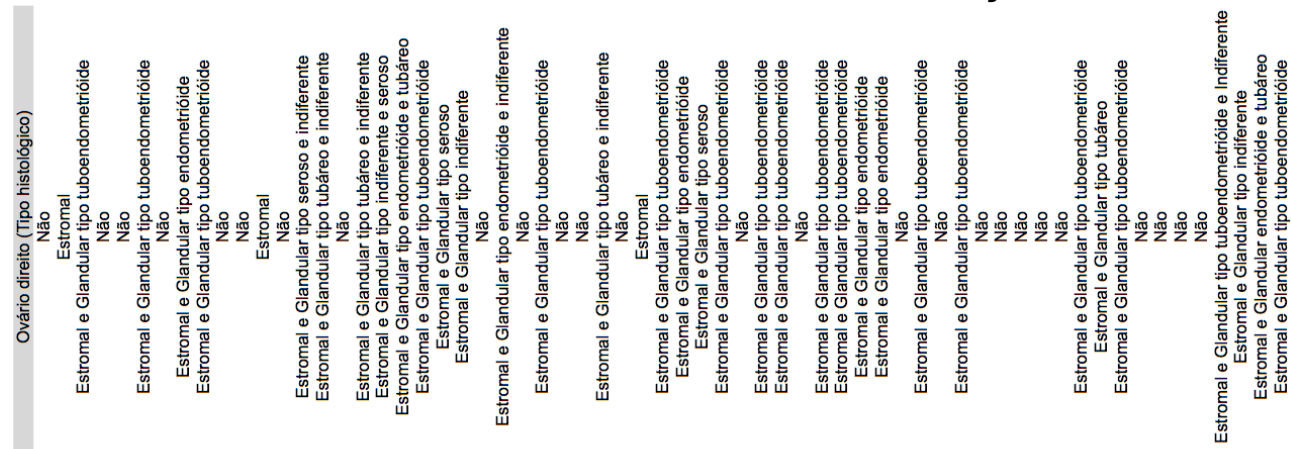

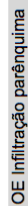

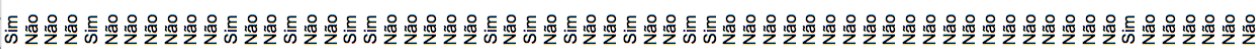

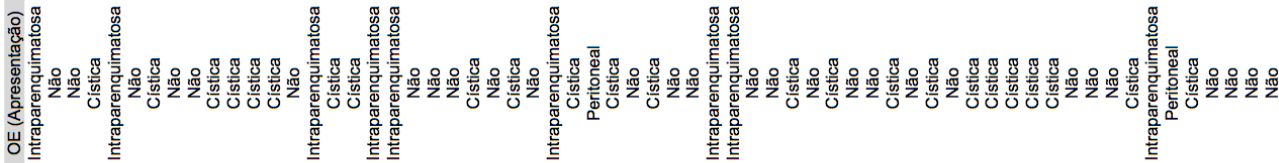

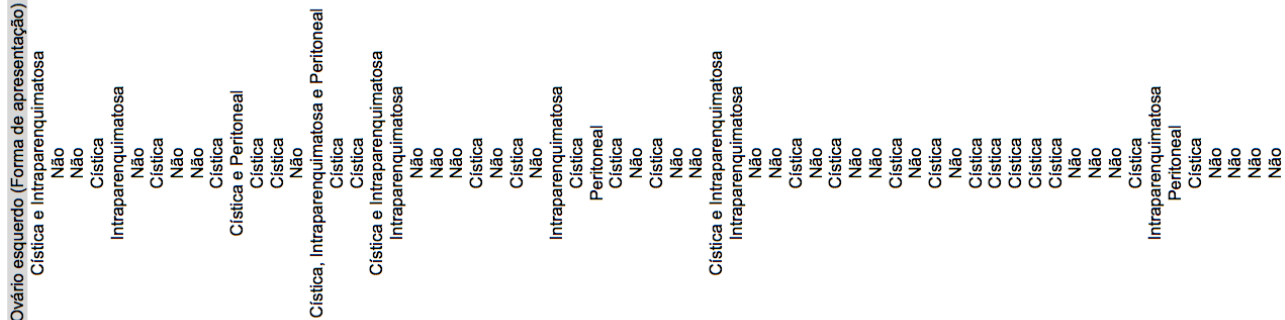

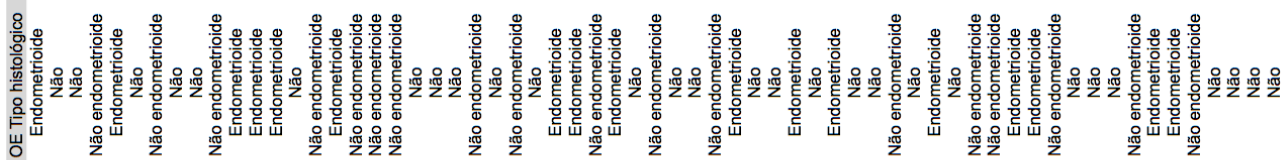

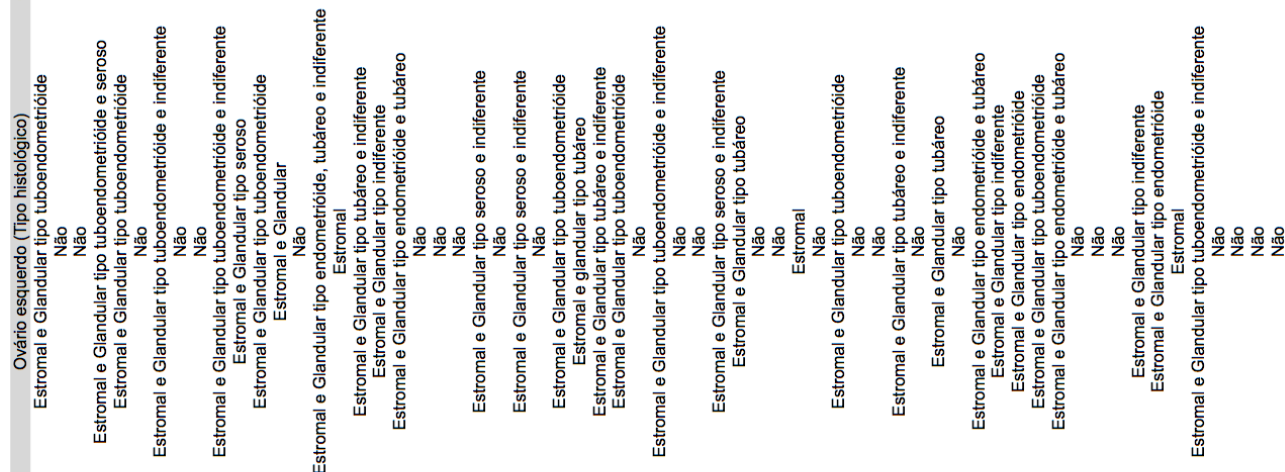

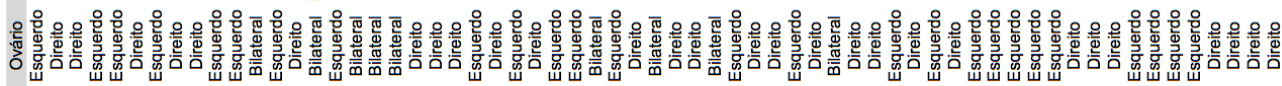

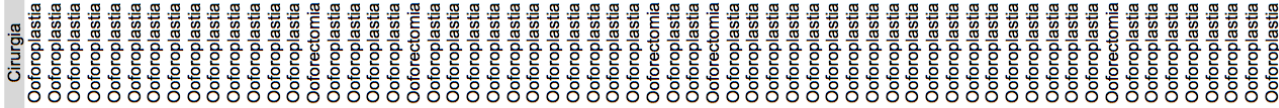

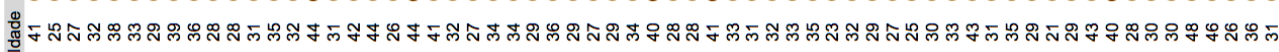

总 


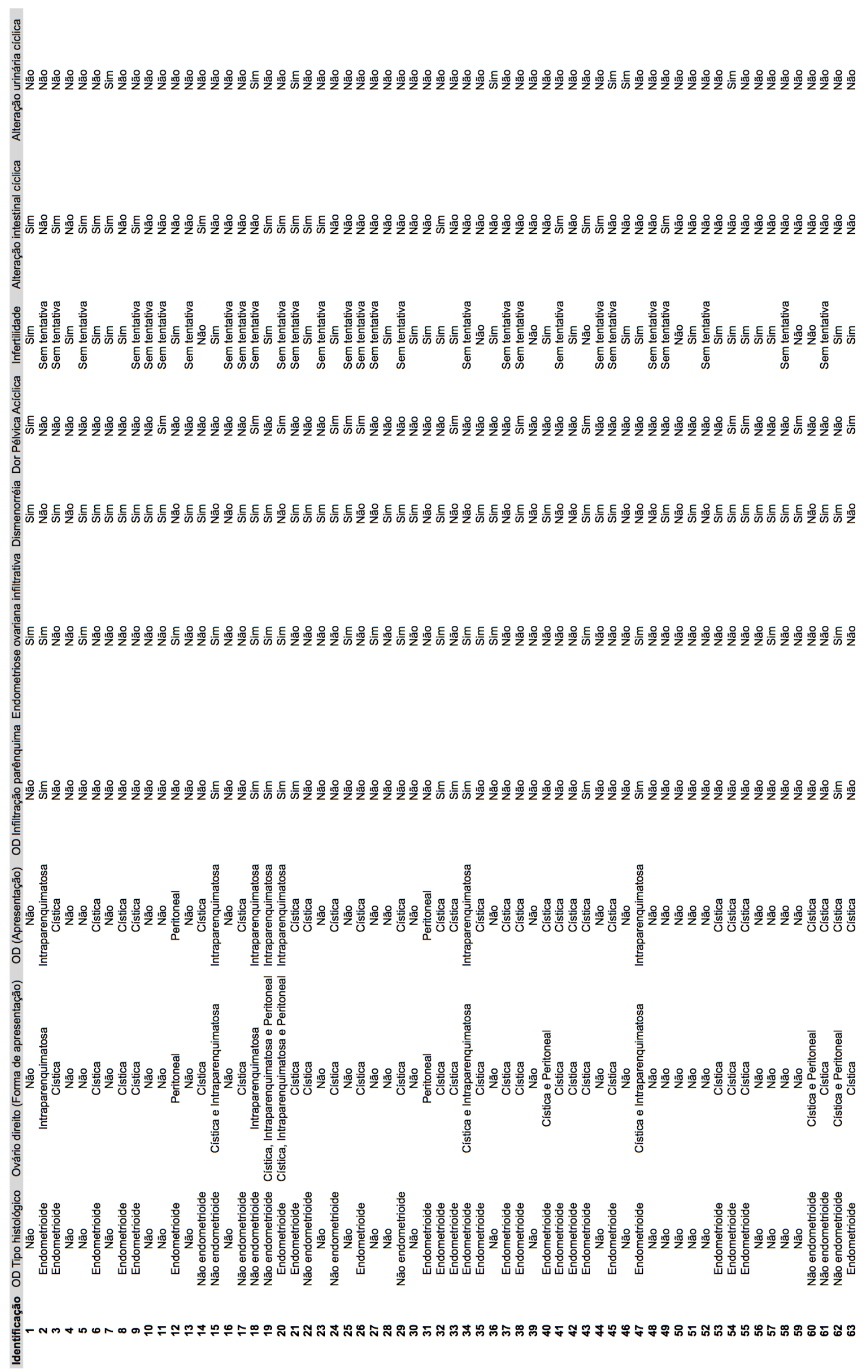




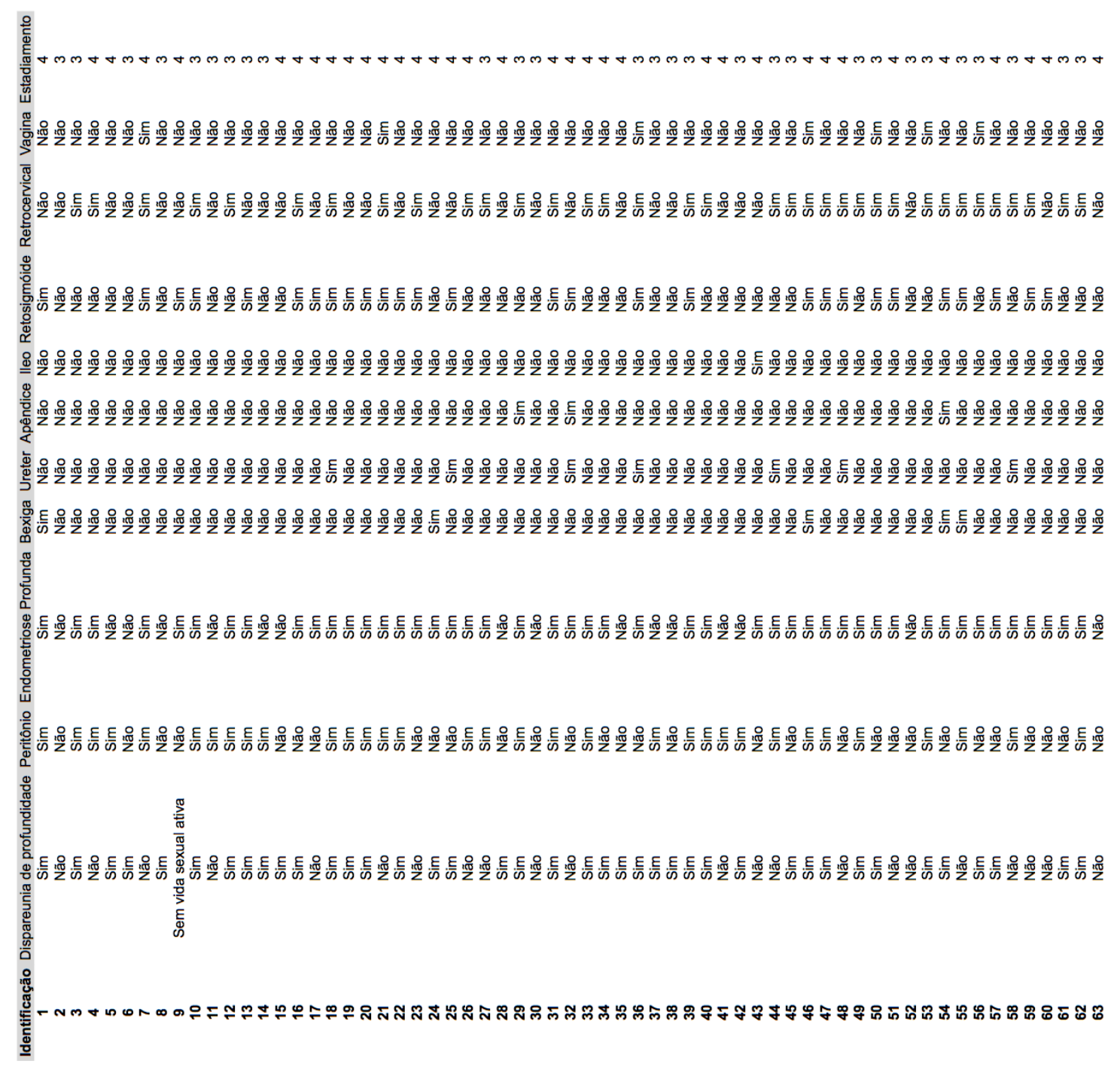


Anexo C - Dados referentes à análise histológica e imuno-histoquímica da endometriose ovariana

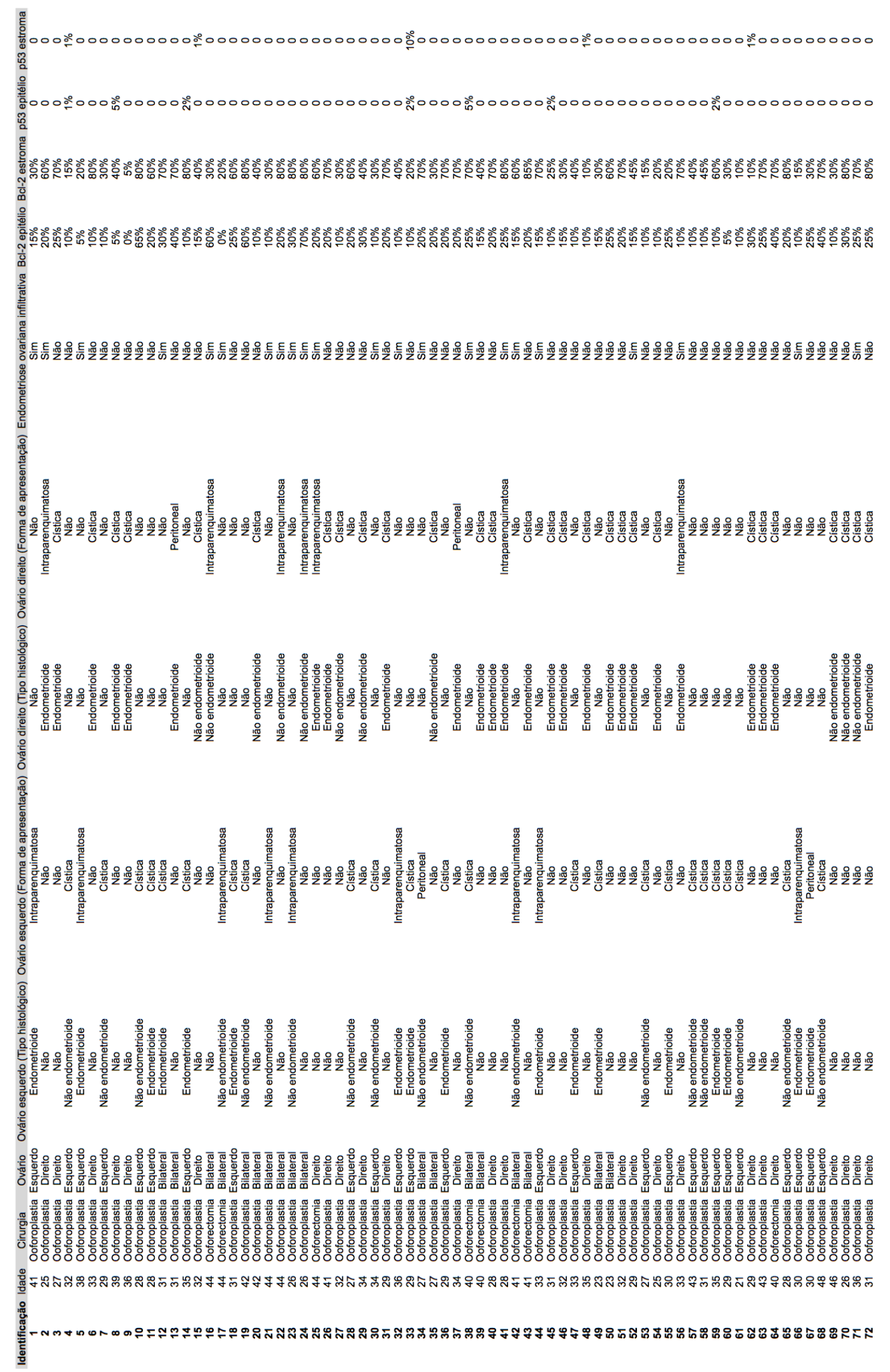




\begin{tabular}{|c|c|c|c|c|}
\hline $\begin{array}{c}\text { Identificação } \\
1\end{array}$ & $\begin{array}{c}\text { Ki-67 epitélio } \\
5 \%\end{array}$ & $\begin{array}{c}\text { Ki-67 estroma } \\
5 \%\end{array}$ & $\begin{array}{c}\text { RE epitélio } \\
10 \%\end{array}$ & $\begin{array}{c}\text { RE estroma } \\
50 \%\end{array}$ \\
\hline 2 & $4 \%$ & $7 \%$ & $10 \%$ & $50 \%$ \\
\hline 3 & $10 \%$ & $6 \%$ & $20 \%$ & $60 \%$ \\
\hline 4 & $20 \%$ & $25 \%$ & $5 \%$ & $20 \%$ \\
\hline 5 & $6 \%$ & $8 \%$ & $20 \%$ & $40 \%$ \\
\hline 6 & $5 \%$ & $4 \%$ & $20 \%$ & $60 \%$ \\
\hline 7 & $7 \%$ & $2 \%$ & $10 \%$ & $50 \%$ \\
\hline 8 & $5 \%$ & $14 \%$ & $5 \%$ & $90 \%$ \\
\hline 9 & $4 \%$ & $11 \%$ & $20 \%$ & $70 \%$ \\
\hline 10 & $5 \%$ & $10 \%$ & $20 \%$ & $40 \%$ \\
\hline 11 & $3 \%$ & $12 \%$ & $10 \%$ & $40 \%$ \\
\hline 12 & $2 \%$ & $8 \%$ & $10 \%$ & $30 \%$ \\
\hline 13 & $7 \%$ & $4 \%$ & $80 \%$ & $90 \%$ \\
\hline 14 & $10 \%$ & $14 \%$ & $60 \%$ & $90 \%$ \\
\hline 15 & $20 \%$ & $24 \%$ & $30 \%$ & $70 \%$ \\
\hline 16 & $3 \%$ & $7 \%$ & $10 \%$ & $30 \%$ \\
\hline 17 & $4 \%$ & $8 \%$ & $0 \%$ & $0 \%$ \\
\hline 18 & $5 \%$ & $7 \%$ & $10 \%$ & $60 \%$ \\
\hline 19 & $8 \%$ & $3 \%$ & $5 \%$ & $5 \%$ \\
\hline 20 & $5 \%$ & $7 \%$ & $20 \%$ & $60 \%$ \\
\hline 21 & $6 \%$ & $5 \%$ & $5 \%$ & $5 \%$ \\
\hline 22 & $4 \%$ & $5 \%$ & $30 \%$ & $60 \%$ \\
\hline 23 & $2 \%$ & $5 \%$ & $20 \%$ & $70 \%$ \\
\hline 24 & $3 \%$ & $5 \%$ & $20 \%$ & $60 \%$ \\
\hline 25 & 25 & $5 \%$ & $10 \%$ & $50 \%$ \\
\hline 26 & $3 \%$ & $10 \%$ & $10 \%$ & $20 \%$ \\
\hline 27 & $4 \%$ & $12 \%$ & $40 \%$ & $80 \%$ \\
\hline 28 & $5 \%$ & $12 \%$ & $10 \%$ & $40 \%$ \\
\hline 29 & $3 \%$ & $2 \%$ & $10 \%$ & $50 \%$ \\
\hline 30 & $2 \%$ & $11 \%$ & $20 \%$ & $40 \%$ \\
\hline 31 & $3 \%$ & $5 \%$ & $20 \%$ & $60 \%$ \\
\hline 32 & $5 \%$ & $7 \%$ & $20 \%$ & $60 \%$ \\
\hline 33 & $3 \%$ & $13 \%$ & $5 \%$ & $20 \%$ \\
\hline 34 & $2 \%$ & $5 \%$ & $10 \%$ & $20 \%$ \\
\hline 35 & $4 \%$ & $6 \%$ & $60 \%$ & $80 \%$ \\
\hline 36 & $5 \%$ & $5 \%$ & $10 \%$ & $40 \%$ \\
\hline 37 & $2 \%$ & $6 \%$ & $20 \%$ & $50 \%$ \\
\hline 38 & $4 \%$ & $5 \%$ & $5 \%$ & $60 \%$ \\
\hline 39 & $2 \%$ & $4 \%$ & $5 \%$ & $30 \%$ \\
\hline 40 & $2 \%$ & $12 \%$ & $10 \%$ & $30 \%$ \\
\hline 41 & $5 \%$ & $7 \%$ & $10 \%$ & $60 \%$ \\
\hline 42 & $4 \%$ & $8 \%$ & $10 \%$ & $20 \%$ \\
\hline 43 & $3 \%$ & $5 \%$ & $20 \%$ & $30 \%$ \\
\hline 44 & $2 \%$ & $2 \%$ & $10 \%$ & $30 \%$ \\
\hline 45 & $5 \%$ & $4 \%$ & $80 \%$ & $90 \%$ \\
\hline 46 & $3 \%$ & $12 \%$ & $30 \%$ & $90 \%$ \\
\hline 47 & $2 \%$ & $4 \%$ & $20 \%$ & $40 \%$ \\
\hline 48 & $5 \%$ & $13 \%$ & $10 \%$ & $20 \%$ \\
\hline 49 & $3 \%$ & $5 \%$ & $30 \%$ & $50 \%$ \\
\hline 50 & $5 \%$ & $15 \%$ & $5 \%$ & $30 \%$ \\
\hline 51 & $2 \%$ & $2 \%$ & $20 \%$ & $70 \%$ \\
\hline 52 & $4 \%$ & $6 \%$ & $10 \%$ & $30 \%$ \\
\hline 53 & $2 \%$ & $5 \%$ & $2 \%$ & $30 \%$ \\
\hline 54 & $3 \%$ & $6 \%$ & $1 \%$ & $40 \%$ \\
\hline 55 & $3 \%$ & $5 \%$ & $5 \%$ & $10 \%$ \\
\hline 56 & $2 \%$ & $5 \%$ & $5 \%$ & $15 \%$ \\
\hline 57 & $3 \%$ & $3 \%$ & $10 \%$ & $20 \%$ \\
\hline 58 & $2 \%$ & $4 \%$ & $10 \%$ & $30 \%$ \\
\hline 59 & $10 \%$ & $12 \%$ & $30 \%$ & $40 \%$ \\
\hline 60 & $4 \%$ & $3 \%$ & $10 \%$ & $30 \%$ \\
\hline 61 & $2 \%$ & $3 \%$ & $5 \%$ & $20 \%$ \\
\hline 62 & $4 \%$ & $14 \%$ & $10 \%$ & $30 \%$ \\
\hline 63 & $3 \%$ & $4 \%$ & $20 \%$ & $40 \%$ \\
\hline 64 & $2 \%$ & $3 \%$ & $5 \%$ & $20 \%$ \\
\hline 65 & $4 \%$ & $2 \%$ & $10 \%$ & $30 \%$ \\
\hline 66 & $4 \%$ & $10 \%$ & $10 \%$ & $30 \%$ \\
\hline 67 & $5 \%$ & $12 \%$ & $20 \%$ & $40 \%$ \\
\hline 68 & $3 \%$ & $5 \%$ & $10 \%$ & $60 \%$ \\
\hline 69 & $4 \%$ & $3 \%$ & $20 \%$ & $30 \%$ \\
\hline 70 & $2 \%$ & $3 \%$ & $10 \%$ & $30 \%$ \\
\hline 71 & $2 \%$ & $5 \%$ & $5 \%$ & $20 \%$ \\
\hline 72 & $3 \%$ & $6 \%$ & $5 \%$ & $30 \%$ \\
\hline
\end{tabular}




\section{REFERÊNCIAS}


1. Cullen TS. Adenomyoma of the uterus. Philadelphia: W.B. Saunders, 1908.

2. Giudice LC and Kao LC. Endometriosis. Lancet. 2004; 364: 1789-99.

3. Attar E, Tokunaga H, Imir G, et al. Prostaglandin E2 via steroidogenic factor-1 coordinately regulates transcription of steroidogenic genes necessary for estrogen synthesis in endometriosis. The Journal of clinical endocrinology and metabolism. 2009; 94: 623-31.

4. Vigano P, Parazzini F, Somigliana E and Vercellini P. Endometriosis: epidemiology and aetiological factors. Best practice \& research Clinical obstetrics \& gynaecology. 2004; 18: 177-200.

5. Stratton $\mathrm{P}$ and Berkley $\mathrm{KJ}$. Chronic pelvic pain and endometriosis: translational evidence of the relationship and implications. Human reproduction update. $2011 ; 17: 327-46$.

6. Bellelis P, Dias JA, Jr., Podgaec S, Gonzales M, Baracat EC and Abrao MS. Epidemiological and clinical aspects of pelvic endometriosis-a case series. Revista da Associacao Medica Brasileira. 2010; 56: 467-71.

7. Sinaii N, Cleary SD, Younes N, Ballweg ML and Stratton P. Treatment utilization for endometriosis symptoms: a cross-sectional survey study of lifetime experience. Fertility and sterility. 2007; 87: 1277-86.

8. Gao X, Outley J, Botteman M, Spalding J, Simon JA and Pashos CL. Economic burden of endometriosis. Fertility and sterility. 2006; 86: 1561-72.

9. Sampson JA. Peritoneal endometriosis due to the menstrual dissemination of endometrial tissue into the peritoneal cavity. Am J Obstet Gynecol. 1927; 14: 422-5. 
10. Sampson JA. Metastatic or Embolic Endometriosis, due to the Menstrual Dissemination of Endometrial Tissue into the Venous Circulation. Am J Pathol. 1927; 3: 93-110 43.

11. Podgaec S, Abrao MS, Dias JA, Jr., Rizzo LV, de Oliveira RM and Baracat EC. Endometriosis: an inflammatory disease with a Th2 immune response component. Human reproduction. 2007; 22: 1373-9.

12. Meyer R. Uber den staude der frage der adenomyosites adenomyoma in allgemeinen und adenomyonetitis sarcomatosa. Zentralbl Gynakol. 1919; 36: $745-59$.

13. Eyster KM, Klinkova O, Kennedy $\mathrm{V}$ and Hansen KA. Whole genome deoxyribonucleic acid microarray analysis of gene expression in ectopic versus eutopic endometrium. Fertility and sterility. 2007; 88: 1505-33.

14. Podgaec S, Dias Junior JA, Chapron C, Oliveira RM, Baracat EC and Abrao MS. Th1 and Th2 ummune responses related to pelvic endometriosis. Revista da Associacao Medica Brasileira. 2010; 56: 92-8.

15. Nisolle M and Donnez J. Peritoneal endometriosis, ovarian endometriosis, and adenomyotic nodules of the rectovaginal septum are three different entities. Fertility and sterility. 1997; 68: 585-96.

16. Yuan Z, Wang L, Wang $Y$, et al. Tubal origin of ovarian endometriosis. Modern pathology : an official journal of the United States and Canadian Academy of Pathology, Inc. 2014; 27: 1154-62.

17. Halban J. Histeroadenosis metastatica. Die linphogene genese der adenofibromatosis heterotopica. Arch Gynäk. 1925; 124: 457-82. 
18. Javert CT. Pathogenesis of endometriosis based on endometrial homeoplasia, direct extension, exfoliation and implantation, lymphatic and hematogenous metastasis, including five case reports of endometrial tissue in pelvic lymph nodes. Cancer. 1949; 2: 399-410.

19. Weed JC and Arquembourg PC. Endometriosis: can it produce an autoimmune response resulting in infertility? Clin Obstet Gynecol. 1980; 23: 885-93.

20. Klagsbrun M and D'Amore PA. Regulators of angiogenesis. Annu Rev Physiol. 1991; 53: 217-39.

21. Yamamoto $\mathrm{K}$, Mitsuhashi $\mathrm{Y}$, Takaike $\mathrm{T}$, Takase $\mathrm{K}$, Hoshiai $\mathrm{H}$ and Noda K. Tubal endometriosis diagnosed within one month after menarche: a case report. The Tohoku journal of experimental medicine. 1997; 181: 385-7. 22. Schenken RS and Guzick DS. Revised endometriosis classification: 1996. Fertil Steril. 1997; 67: 815-6.

23. Cornillie FJ, Oosterlynck D, Lauweryns JM and Koninckx PR. Deeply infiltrating pelvic endometriosis: histology and clinical significance. Fertility and sterility. 1990; 53: 978-83.

24. Abrao MS, Neme RM, Carvalho FM, Aldrighi JM and Pinotti JA. Histological classification of endometriosis as a predictor of response to treatment. International journal of gynaecology and obstetrics: the official organ of the International Federation of Gynaecology and Obstetrics. 2003; 82: 31-40. 
25. Chapron $\mathrm{C}$, Vercellini $\mathrm{P}$, Barakat $\mathrm{H}$, Vieira $\mathrm{M}$ and Dubuisson JB. Management of ovarian endometriomas. Hum Reprod Update. 2002; 8: 5917.

26. Chapron C, Santulli P, de Ziegler D, et al. Ovarian endometrioma: severe pelvic pain is associated with deeply infiltrating endometriosis. Human reproduction. 2012; 27: 702-11.

27. Redwine DB. Ovarian endometriosis: a marker for more extensive pelvic and intestinal disease. Fertility and sterility. 1999; 72: 310-5.

28. Chapron C, Pietin-Vialle C, Borghese B, Davy C, Foulot H and Chopin N. Associated ovarian endometrioma is a marker for greater severity of deeply infiltrating endometriosis. Fertility and sterility. 2009; 92: 453-7.

29. Brosens IA, Puttemans PJ and Deprest J. The endoscopic localization of endometrial implants in the ovarian chocolate cyst. Fertility and sterility. 1994; 61: 1034-8.

30. Koninckx PR, Kennedy SH and Barlow DH. Pathogenesis of endometriosis: the role of peritoneal fluid. Gynecologic and obstetric investigation. 1999; 47 Suppl 1: 23-33.

31. Scurry J, Whitehead $\mathrm{J}$ and Healey $\mathrm{M}$. Classification of ovarian endometriotic cysts. International journal of gynecological pathology : official journal of the International Society of Gynecological Pathologists. 2001; 20 : 147-54.

32. Zheng W, Li N, Wang J, et al. Initial endometriosis showing direct morphologic evidence of metaplasia in the pathogenesis of ovarian endometriosis. International journal of gynecological pathology : official 
journal of the International Society of Gynecological Pathologists. 2005; 24: 164-72.

33. Hughesdon PE. The structure of endometrial cysts of the ovary. $J$ Obstet Gynaecol Br Emp. 1957; 64: 481-7.

34. Donnez J, Nisolle M, Gillet N, Smets M, Bassil S and Casanas-Roux F. Large ovarian endometriomas. Human reproduction. 1996; 11: 641-6.

35. Muzii L, Bianchi A, Bellati F, et al. Histologic analysis of endometriomas: what the surgeon needs to know. Fertility and sterility. 2007; 87: $362-6$

36. Li J, Abushahin N, Pang S, et al. Tubal origin of 'ovarian' low-grade serous carcinoma. Modern pathology : an official journal of the United States and Canadian Academy of Pathology, Inc. 2011; 24: 1488-99.

37. Sampson JA. Endometrial carcinoma of the ovary, arising in endometrial tissue in that organ. Arch Surg. 1925; 10.

38. Scott RB. Malignant changes in endometriosis. Obstetrics and gynecology. 1953; 2: 283-9.

39. Ness RB. Endometriosis and ovarian cancer: thoughts on shared pathophysiology. Am J Obstet Gynecol. 2003; 189: 280-94.

40. Gadducci A, Lanfredini N and Tana R. Novel insights on the malignant transformation of endometriosis into ovarian carcinoma. Gynecol Endocrinol. 2014; 30: 612-7.

41. Kobayashi H. Ovarian cancer in endometriosis: epidemiology, natural history, and clinical diagnosis. Int J Clin Oncol. 2009; 14: 378-82. 
42. Anglesio MS, Bashashati A, Wang YK, et al. Multifocal endometriotic lesions associated with cancer are clonal and carry a high mutation burden. $J$ Pathol. 2015; 236: 201-9.

43. Pearce CL, Templeman C, Rossing MA, et al. Association between endometriosis and risk of histological subtypes of ovarian cancer: a pooled analysis of case-control studies. Lancet Oncol. 2012; 13: 385-94.

44. Wiegand KC, Shah SP, Al-Agha OM, et al. ARID1A mutations in endometriosis-associated ovarian carcinomas. The New England journal of medicine. 2010; 363: 1532-43.

45. Kurman RJ and Shih le M. The origin and pathogenesis of epithelial ovarian cancer: a proposed unifying theory. Am J Surg Pathol. 2010; 34: 433-43.

46. Sainz de la Cuesta R, Eichhorn JH, Rice LW, Fuller AF, Jr., Nikrui N and Goff BA. Histologic transformation of benign endometriosis to early epithelial ovarian cancer. Gynecologic oncology. 1996; 60: 238-44.

47. LaGrenade A and Silverberg SG. Ovarian tumors associated with atypical endometriosis. Human pathology. 1988; 19: 1080-4.

48. Fukunaga M, Nomura K, Ishikawa E and Ushigome S. Ovarian atypical endometriosis: its close association with malignant epithelial tumours. Histopathology. 1997; 30: 249-55.

49. Nezhat F, Apostol R, Mahmoud M and el Daouk M. Malignant transformation of endometriosis and its clinical significance. Fertility and sterility. $2014 ; 102:$ 342-4. 
50. Nezhat FR, Pejovic T, Reis FM and Guo SW. The link between endometriosis and ovarian cancer: clinical implications. Int J Gynecol Cancer. $2014 ; 24: 623-8$.

51. Munksgaard PS and Blaakaer J. The association between endometriosis and ovarian cancer: a review of histological, genetic and molecular alterations. Gynecologic oncology. 2012; 124: 164-9.

52. Ye S, Yang J, You Y, et al. Comparative study of ovarian clear cell carcinoma with and without endometriosis in People's Republic of China. Fertility and sterility. 2014; 102: 1656-62.

53. Pavlidou A and Vlahos NF. Endometriosis and ovarian cancer: clinical and molecular aspects. Minerva Endocrinol. 2014; 39: 155-65.

54. Garrett LA, Growdon WB, Goodman A, Boruta DM, Schorge JO and del Carmen MG. Endometriosis-associated ovarian malignancy: a retrospective analysis of presentation, treatment, and outcome. J Reprod Med. 2013; 58: 469-76.

55. Kim HS, Kim TH, Chung $\mathrm{HH}$ and Song YS. Risk and prognosis of ovarian cancer in women with endometriosis: a meta-analysis. $\mathrm{Br} J$ Cancer. 2014; 110: 1878-90.

56. Mandai M, Yamaguchi K, Matsumura N, Baba T and Konishi I. Ovarian cancer in endometriosis: molecular biology, pathology, and clinical management. International journal of clinical oncology. 2009; 14: 383-91.

57. Jiang X, Hitchcock A, Bryan EJ, et al. Microsatellite analysis of endometriosis reveals loss of heterozygosity at candidate ovarian tumor suppressor gene loci. Cancer research. 1996; 56: 3534-9. 
58. Shin JC, Ross HL, Elias S, et al. Detection of chromosomal aneuploidy in endometriosis by multi-color fluorescence in situ hybridization (FISH). Human genetics. 1997; 100: 401-6.

59. Gogusev J, Bouquet de Joliniere J, Telvi L, et al. Genetic abnormalities detected by comparative genomic hybridization in a human endometriosis-derived cell line. Molecular human reproduction. 2000; 6: 8217.

60. Bischoff FZ, Heard M and Simpson JL. Somatic DNA alterations in endometriosis: high frequency of chromosome 17 and p53 loss in late-stage endometriosis. Journal of reproductive immunology. 2002; 55: 49-64.

61. Juhasz-Boss I, Fischer C, Lattrich C, et al. Endometrial expression of estrogen receptor beta and its splice variants in patients with and without endometriosis. Archives of gynecology and obstetrics. 2011; 284: 885-91.

62. Akahane T, Sekizawa A, Okuda T, Kushima M, Saito H and Okai T. Disappearance of steroid hormone dependency during malignant transformation of ovarian clear cell cancer. International journal of gynecological pathology : official journal of the International Society of Gynecological Pathologists. 2005; 24: 369-76.

63. Del Carmen MG, Smith Sehdev AE, Fader AN, et al. Endometriosisassociated ovarian carcinoma: differential expression of vascular endothelial growth factor and estrogen/progesterone receptors. Cancer. 2003; 98: 165863.

64. Fujimura M, Hidaka T, Kataoka K, et al. Absence of estrogen receptoralpha expression in human ovarian clear cell adenocarcinoma compared with 
ovarian serous, endometrioid, and mucinous adenocarcinoma. The American journal of surgical pathology. 2001; 25: 667-72.

65. Gerdes J, Lemke H, Baisch H, Wacker HH, Schwab U and Stein H. Cell cycle analysis of a cell proliferation-associated human nuclear antigen defined by the monoclonal antibody Ki-67. Journal of immunology. 1984; 133: $1710-5$.

66. Pathmanathan $\mathrm{N}$ and Balleine $\mathrm{RL}$. Ki67 and proliferation in breast cancer. J Clin Pathol. 2013; 66: 512-6.

67. Patsouris E, Stocker U, Kallmeyer V, Keiditsch E, Mehraein P and Stavrou D. Relationship between Ki-67 positive cells, growth rate and histological type of human intracranial tumors. Anticancer research. 1988; 8: $537-44$

68. Brown DC and Gatter KC. Monoclonal antibody Ki-67: its use in histopathology. Histopathology. 1990; 17: 489-503.

69. Park JS, Lee JH, Kim M, Chang HJ, Hwang $\mathrm{KJ}$ and Chang $\mathrm{KH}$. Endometrium from women with endometriosis shows increased proliferation activity. Fertility and sterility. 2009; 92: 1246-9.

70. Lian F, Liu HP, Wang YX, et al. Expressions of VEGF and Ki-67 in eutopic endometrium of patients with endometriosis and effect of Quyu Jiedu Recipe on VEGF expression. Chinese journal of integrative medicine. 2007; 13: 109-14.

71. Calcagno A, Grassi T, Mariuzzi L, et al. Expression patterns of Aurora $\mathrm{A}$ and $\mathrm{B}$ kinases, $\mathrm{Ki}-67$ and the estrogen and progesterone receptors 
determined using an endometriosis tissue microarray model. Human reproduction. $2011 ; 26$ : 2731-41.

72. Kim HO, Yang KM, Kang IS, et al. Expression of CD44s, vascular endothelial growth factor, matrix metalloproteinase-2 and Ki-67 in peritoneal, rectovaginal and ovarian endometriosis. The Journal of reproductive medicine. 2007; 52: 207-13.

73. Kahyaoglu I, Kahyaoglu S, Moraloglu O, Zergeroglu S, Sut N and Batioglu S. Comparison of Ki-67 proliferative index between eutopic and ectopic endometrium: a case control study. Taiwanese journal of obstetrics \& gynecology. 2012; 51: 393-6.

74. Khan MS, Dodson AR and Heatley MK. Ki-67, oestrogen receptor, and progesterone receptor proteins in the human rete ovarii and in endometriosis. Journal of clinical pathology. 1999; 52: 517-20.

75. Osborne BA and Schwartz LM. Essential genes that regulate apoptosis. Trends in cell biology. 1994; 4: 394-9.

76. Reis FM, Petraglia F and Taylor RN. Endometriosis: hormone regulation and clinical consequences of chemotaxis and apoptosis. Human reproduction update. 2013; 19: 406-18.

77. Kerr JF, Wyllie $\mathrm{AH}$ and Currie AR. Apoptosis: a basic biological phenomenon with wide-ranging implications in tissue kinetics. British journal of cancer. 1972; 26: 239-57.

78. Harada T, Kaponis A, Iwabe T, et al. Apoptosis in human endometrium and endometriosis. Human reproduction update. 2004; 10: 2938. 
79. Pollacco J, Sacco K, Portelli M, Schembri-Wismayer P and CallejaAgius J. Molecular links between endometriosis and cancer. Gynecological endocrinology : the official journal of the International Society of Gynecological Endocrinology. 2012; 28: 577-81.

80. Reed JC. Double identity for proteins of the Bcl-2 family. Nature. 1997; 387: 773-6.

81. Szymanowski K. Apoptosis pattern in human endometrium in women with pelvic endometriosis. European journal of obstetrics, gynecology, and reproductive biology. 2007; 132: 107-10.

82. Dmowski WP, Ding J, Shen J, Rana N, Fernandez BB and Braun DP. Apoptosis in endometrial glandular and stromal cells in women with and without endometriosis. Human reproduction. 2001; 16: 1802-8.

83. Abdalla Ribeiro HS, Galvao MA, Aoki T, Aldrighi JM and Ribeiro PA. Anti-apoptotic activity in deep pelvic endometriosis. Histol Histopathol. 2014; 29: $1129-33$.

84. Wang C, Jin A, Huang W, et al. Up-regulation of Bcl-2 by CD147 Through ERK Activation Results in Abnormal Cell Survival in Human Endometriosis. The Journal of clinical endocrinology and metabolism. 2015; 100: E955-63.

85. Nezhat F, Cohen C, Rahaman J, Gretz H, Cole P and Kalir T. Comparative immunohistochemical studies of bcl-2 and p53 proteins in benign and malignant ovarian endometriotic cysts. Cancer. 2002; 94: 293540. 
86. Korkmaz D, Bastu E, Dural O, Yasa C, Yavuz E and Buyru F. Apoptosis through regulation of $\mathrm{Bcl}-2$, Bax and $\mathrm{Mcl}-1$ expressions in endometriotic cyst lesions and the endometrium of women with moderate to severe endometriosis. Journal of obstetrics and gynaecology : the journal of the Institute of Obstetrics and Gynaecology. 2013; 33: 725-8.

87. Watanabe $\mathrm{H}$, Kanzaki $\mathrm{H}$, Narukawa $\mathrm{S}$, et al. Bcl-2 and Fas expression in eutopic and ectopic human endometrium during the menstrual cycle in relation to endometrial cell apoptosis. Am J Obstet Gynecol. 1997; 176: 3608.

88. Goumenou AG, Matalliotakis IM, Tzardi M, Fragouli YG, Mahutte NG and Arici A. Apoptosis and differential expression of apoptosis-related proteins in endometriotic glandular and stromal cells. Journal of the Society for Gynecologic Investigation. 2004; 11: 318-22.

89. Zubor P, Hatok J, Galo S, et al. Anti-apoptotic and pro-apoptotic gene expression evaluated from eutopic endometrium in the proliferative phase of the menstrual cycle among women with endometriosis and healthy controls. European journal of obstetrics, gynecology, and reproductive biology. 2009; 145: $172-6$.

90. Dufournet C, Uzan C, Fauvet R, Cortez A, Siffroi JP and Darai E. Expression of apoptosis-related proteins in peritoneal, ovarian and colorectal endometriosis. Journal of reproductive immunology. 2006; 70: 151-62.

91. Beliard A, Noel A and Foidart JM. Reduction of apoptosis and proliferation in endometriosis. Fertility and sterility. 2004; 82: 80-5. 
92. Allavena G, Carrarelli P, Del Bello B, Luisi S, Petraglia F and Maellaro E. Autophagy is upregulated in ovarian endometriosis: a possible interplay with p53 and heme oxygenase-1. Fertility and sterility. 2015; 103: 1244-51 e1. 93. Fauvet R, Poncelet C, Hugol D, Lavaur A, Feldmann G and Darai E. Expression of apoptosis-related proteins in endometriomas and benign and malignant ovarian tumours. Virchows Archiv : an international journal of pathology. 2003; 443: 38-43.

94. Sainz de la Cuesta R, Izquierdo M, Canamero M, Granizo JJ and Manzarbeitia F. Increased prevalence of p53 overexpression from typical endometriosis to atypical endometriosis and ovarian cancer associated with endometriosis. European journal of obstetrics, gynecology, and reproductive biology. 2004; 113: 87-93.

95. Mhawech P, Kinkel K, Vlastos $\mathrm{G}$ and Pelte MF. Ovarian carcinomas in endometriosis: an immunohistochemical and comparative genomic hybridization study. International journal of gynecological pathology : official journal of the International Society of Gynecological Pathologists. 2002; 21: 401-6.

96. Akahane T, Sekizawa A, Purwosunu Y, Nagatsuka M and Okai T. The role of p53 mutation in the carcinomas arising from endometriosis. International journal of gynecological pathology : official journal of the International Society of Gynecological Pathologists. 2007; 26: 345-51.

97. Prefumo F, Venturini PL and Fulcheri E. Analysis of p53 and c-erbB-2 expression in ovarian endometrioid carcinomas arising in endometriosis. 
International journal of gynecological pathology : official journal of the International Society of Gynecological Pathologists. 2003; 22: 83-8.

98. Chaudhry P, Srinivasan R and Patel FD. Differential expression of Fas family members and $\mathrm{Bcl}-2$ family members in benign versus malignant epithelial ovarian cancer (EOC) in North Indian population. Mol Cell Biochem. 2012; 368: 119-26.

99. Miyamoto $\mathrm{Y}$, Hosotani R, Wada $\mathrm{M}$, et al. Immunohistochemical analysis of $\mathrm{Bcl}-2$, Bax, Bcl-X, and $\mathrm{Mcl}-1$ expression in pancreatic cancers. Oncology. 1999; 56: 73-82.

100. Koninckx PR, Ussia A, Adamyan L, Wattiez A and Donnez J. Deep endometriosis: definition, diagnosis, and treatment. Fertility and sterility. 2012; 98: 564-71.

101. Machado-Linde F, Sanchez-Ferrer ML, Cascales P, et al. Prevalence of endometriosis in epithelial ovarian cancer. Analysis of the associated clinical features and study on molecular mechanisms involved in the possible causality. Eur J Gynaecol Oncol. 2015; 36: 21-4.

102. Wang $\mathrm{Y}$, Mang $\mathrm{M}$, Wang $\mathrm{Y}$, et al. Tubal origin of ovarian endometriosis and clear cell and endometrioid carcinoma. Am J Cancer Res. 2015; 5: 869-79.

103. Ogawa S, Kaku T, Amada S, et al. Ovarian endometriosis associated with ovarian carcinoma: a clinicopathological and immunohistochemical study. Gynecol Oncol. 2000; 77: 298-304. 
104. Castiblanco GA, Pires NY, Wistuba OI, Riquelme SE, Andrade ML and Corvalan RA. [Pathogenic role of PTEN tumor suppressor gene in ovarian cancer associated to endometriosis]. Rev Med Chil. 2006; 134: 271-8. 105. Schuijer M and Berns EM. TP53 and ovarian cancer. Human mutation. 2003; 21: 285-91.

106. Vigano $\mathrm{P}$, Somigliana E, Chiodo I, Abbiati $A$ and Vercellini $P$. Molecular mechanisms and biological plausibility underlying the malignant transformation of endometriosis: a critical analysis. Hum Reprod Update. 2006; 12: 77-89.

107. Bayramoglu H and Duzcan E. Atypical epithelial changes and mutant p53 gene expression in ovarian endometriosis. Pathol Oncol Res. 2001; 7: 33-8.

108. Schneider J, Jimenez E, Rodriguez F and del Tanago JG. c-myc, cerb-B2, nm23 and p53 expression in human endometriosis. Oncol Rep. 1998; 5: 49-52.

109. Agic A, Djalali S, Diedrich $K$ and Hornung D. Apoptosis in endometriosis. Gynecologic and obstetric investigation. 2009; 68: 217-23.

110. Nasu K, Nishida M, Kawano $Y$, et al. Aberrant expression of apoptosis-related molecules in endometriosis: a possible mechanism underlying the pathogenesis of endometriosis. Reprod Sci. 2011; 18: 206-18. 